\title{
Vital Traditions: \\ Assessing the status of skilled trades work in \\ Toronto's heritage policy
}

by

Luke McElcheran

A thesis submitted to the Faculty of Graduate and Postdoctoral Affairs in partial fulfillment of the requirements for the degree of

Master of Architecture
in
$\begin{aligned} & \text { M. Architecture 3-Year } \\ & \text { Stream }\end{aligned}$

Carleton University

Ottawa, Ontario

(C) 2021

Luke McElcheran 
Part I: Research and Analysis

Vital Traditions: Heritage Trades in Toronto's Conservation Sector Luke McElcheran

Supervisor: Prof. Mario Santana

Master of Architecture, 2021 


\begin{abstract}
New priorities in the heritage conservation field that argue for widespread rehabilitation and maintenance of existing buildings are hampered in Canadian jurisdictions by difficulties contracting appropriately skilled workers to carry out that maintenance. This phenomenon is general, but it is produced by local market conditions and demands locally directed study. In Toronto, the regulatory organization of the heritage sector creates an environment where heritage professionals can flourish while trades skills associated with maintenance decline. This study considers this policy framework in terms of its capacity to support viable careers for heritage tradespeople. Looking at new theories in heritage conservation, emerging concerns in the Canadian heritage conservation sector, and Toronto's culture industries outside of architecture conservation, it argues for a re-evaluation of Toronto's heritage policy to support a robust skilled workforce and ensure that the city can continue to sustainably rehabilitate and maintain its existing building stock.
\end{abstract}




\section{Acknowledgements}

This research was possible through the generous support of the NSERC CREATE Heritage Engineering Program. My research was informed and enriched by participating in their heritage forums and events, and through their commitment to facilitating opportunities with industry partners. I am grateful to ERA Architects and Taylor Hazell Architects for introducing me to the realities of work in Toronto's Heritage Conservation sector and supporting my research interest in skilled trades in the city. I am indebted to the tradespeople and educators who took time to speak with me in the early stages of my research, to the faculty members at Carleton who supported the project with feedback and criticism, and to Laurie Smith for making this project possible through the NSERC CREATE program and for her unfailing insights as a critic of the work. 


\section{Contents}

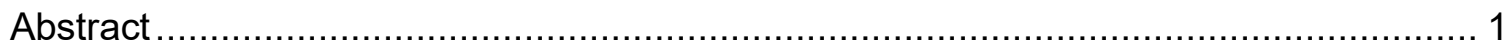

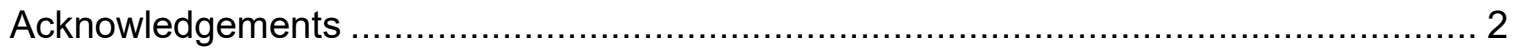

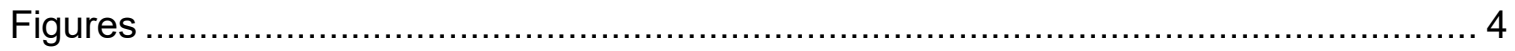

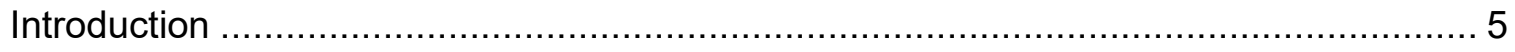

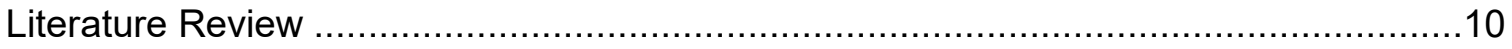

Policy Context for Trades Work in Toronto's Heritage Sector ....................................21

Setting the Standard: Federal Heritage Guidelines …….................................21

Funding Heritage Values: Ontario's Provincial Heritage Framework ........................28

Conservation Theory at Work: How Toronto's Heritage Policy Shapes a Market with Asymmetrical Opportunities for Professionals and Tradespeople.

Comparing the Status of Skilled Trades in Heritage to Trades in other Culture Industries

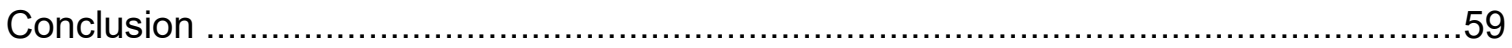

Recommendations

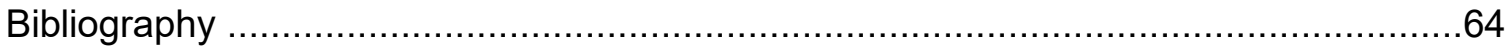




\section{Figures}

Figure 1: Documents Governing Work in Toronto's Heritage Conservation Market........21

Figure 2: Official Plan Policies Impacting Professional and Trades Opportunities in

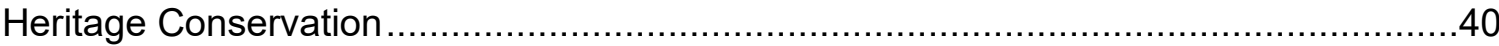

Figure 3: Heritage Adjacency as per Toronto Official Plan Section $23 \ldots \ldots \ldots \ldots \ldots \ldots \ldots \ldots \ldots . .43$

Figure 4: Donations to Heritage Toronto by Industry Group ..........................................54 


\section{Introduction}

This project is overshadowed by the COVID-19 pandemic and the ways that it has disrupted conventional models to calculate the value of heritage conservation programs. Before the pandemic, the shift towards sustainable practice and the economic and environmental logic of reuse, rehabilitation and maintenance were already challenging dominant models that treat heritage narratives and visual character as resources that can be leveraged to generate return on investment for heritage programs by attracting tourists and stimulating urban growth by attracting desirable businesses and workers. Now, travel restrictions have disrupted the tourist industry and the future of policies aimed at attracting highly mobile upper middle class knowledge workers is uncertain after the normalization of distributed models for office work, particularly in the innovative sectors these policies target. For heritage to remain relevant in a post-pandemic world, advocates need to shift their focus to the economic benefits of investing in heritage work. The scramble to resuscitate tourism-based models in digital formats ignores the problem. It doesn't generate the spillover economic effect for communities that were supposed to make those models viable, and it diverts resources away from projects that support the physical sustainability of heritage properties. To make the transition from a pre-pandemic growth economy, to a post-pandemic stimulus economy, advocates need to rediscover the benefits that come from investing in the skilled trades work involved in heritage conservation. Heritage can play a meaningful role in post-pandemic stimulus if heritage advocates are ready to abandon the idea that doing heritage means selling stories to tourists, businesses, and well-paid office workers. Advocating for heritage work that engages skilled trades can give the sector new life as a key component of sustainable investment in the built environment. It can jump start a healthy, growing 
trades sector and help create more equitable access to opportunity. Above all it will create career opportunities for the skilled tradespeople we need to repair and maintain our building stock and meet sustainability goals, to preserve our cultural resources, and to build excellent new buildings that will stand the test of time in their turn.

This project considers policy documents and advocacy in Toronto's heritage conservation sector in terms of their ability to support a market for the skilled trades the sector needs to sustainably maintain and rehabilitate existing buildings. Heritage conservation is well suited to this top-down approach because it is structured around policy that mandates forms of work that, while they can generate long-term economic benefits to communities and preserve non-monetary forms of value, may not otherwise be competitive in terms of short-term profit. However, there are challenges associated with this approach. It doesn't give a clear sense of how much work exists, and it doesn't engage directly with the people doing that work. The main advantage is that it frames the issue of skilled trades shortages in heritage conservation in terms of the tools that architects, planners, and heritage activists already use.

There is a tendency to shift the responsibility for these shortages to individual tradespeople, particularly to a young generation that, as the assumption goes, just isn't interested in pursuing the kinds of specialised, skilled work that the heritage conservation sector needs, or to an education and apprenticeship system that isn't preparing graduates to pursue this kind of work. What this research shows is that these positions ignore the tools available to policy makers and planners who shape heritage regulation, and heritage specializing architects who interpret that policy to determine appropriate interventions. It finds that Toronto's heritage framework doesn't reliably 
direct funds raised for conservation to the kinds of work that skilled tradespeople do. While heritage specializing professionals enjoy access to forms of work that are mandated in heritage regulations, heritage specializing tradespeople are asked to take a leap of faith, accepting significant personal risk in the hope that the work they do will be prioritized in a market shaped by unpredictable fashions among academic theorists and professional designers, a complicated web of regulations and guidelines from three levels of government, and industry advocacy preoccupied with tourism revenues and real estate values.

Chapter One reviews the literature on skilled trades in heritage conservation in Canada and relates it to international trends. It shows that the issue of skills shortages is a common concern in heritage conservation circles and that it is particularly pressing for advocates of preventive maintenance and long-term management approaches. It establishes the well researched connection between heritage trades work and positive economic effects for communities and sets it in contrast to the discipline's overwhelming focus on tourist revenue and spillover effects related to quality of life and interurban competition to attract mobile international corporations and upper middle class knowledge workers. It validates the top-down, policy focused approach taken in this research by showing how heritage work, the legislative financial tools to fund that work, and the policy governed value systems that determine what work should be done are fundamentally interrelated.

Chapter Two is divided into three sections that assess how each level of government policy acting on Toronto's heritage conservation sector helps or hinders skilled trades workers in the market. It finds that Canada's Standards and Guidelines are generally 
supportive of the kinds of work that skilled tradespeople do but have a limited role in shaping the economic conditions that govern the market for that work. They encourage work that would typically engage skilled tradespeople, but they stop short of any measures that would directly support traditional building trades. Ontario's heritage framework leaves most important decisions about heritage programs to municipal governments, but it defines the financial tools that those governments have available to fund heritage work. Toronto's heritage policy is integrated with contemporary urban planning goals and financial tools. It mandates certain professional services through the heritage permitting process, but it leaves heritage trades scopes of work to be determined on a case-by-case basis. In combination with economic pressure and shifting theoretical priorities for heritage among professionals and academics, this leaves heritage building trades in a precarious position where decisions about appropriate intervention are subject to economic pressure, client preference, and academic fashions.

Chapter Three steps back from heritage conservation to establish a precedent for policy that does support work for specialised skilled tradespeople. It shows that, compared to similar culture economy industries, heritage advocates' reluctance to engage with issues facing skilled trades workers is the exception and not the norm. Advocacy and policy documents from the culture sector and fashion, film, and music subsectors show that there are precedents for municipal level industry advocacy concerned with typical heritage issues like the quality of urban space, interurban competition, and cultural cohesion that also actively promotes skilled trades workers' access to quality education and industry opportunity. 
This approach highlights issues related to skilled trades that are internal to Toronto's heritage system. It has the advantage of addressing issues that are under heritage advocates' control, but it leaves out other important factors. The most glaring gap is the voice of skilled tradespeople themselves. Toronto does have a robust market for heritage specialising trades work compared to most other Canadian jurisdictions. There is a need for research that engages with these workers to understand the challenges they face and the opportunities that they see working in Toronto's heritage sector. Heritage work is also subject to external pressures like procurement processes, material supply chains, work scheduling practices, insurance, and liability that impact the viability of traditional building trades and rehabilitation work. Despite these unanswered questions, this research shows that heritage policy makers, activists, and professionals have an important role to play in promoting the success of skilled tradespeople in the sector.

The straightforward narrative that the heritage sector is the victim of external economic, technological, and social pressures that limit access to appropriately skilled tradespeople doesn't tell the whole story. Heritage policy in Toronto creates its own market conditions where heritage specializing professionals can thrive while heritage specializing tradespeople struggle. While external factors contribute to this situation, focusing on them ignores the real opportunities heritage policymakers, professionals, and advocates have to actively address skilled trades shortages. This research identifies the tools that heritage advocates, policy makers and professionals can use to promote viable, stable careers for skilled tradespeople in the heritage sector, building the capacity we need to sustainably maintain our built environment and to build excellent new buildings that will stand the test of time in their turn.

Luke McElcheran | 9 


\section{Literature Review}

Heritage conservation work is shaped by theoretical frameworks that define heritage value, and economic models that determine how conservation is funded. This review explores the interrelationships between work, money, and value that influence the market for conservation work in Toronto. Because of the limited literature addressing local conditions, it refers to research on the heritage sector in Ontario where no municipal information is available and in Canada where no provincial information is available. It relates this local, regional, and national research to sources that exemplify international heritage trends and best practices.

Carr and Gibson conclude in their research in human geography that in the face of imminent environmental crisis driven by societies experiencing increasing financialization, automation, and shifting economic structures, we need more focus on the actual physical work involved in producing the material things that surround us, not less. They argue "that rather than becoming increasingly marginalized and redundant, the ability to work with materials, and to make, repair or repurpose physical things, are vital skills, for a future where such resources become increasingly limited and extreme events related to a shifting climate are more common." ${ }^{1}$ This is particularly important to heritage conservation in Canada where new federal priorities emphasize the benefits of building rehabilitation for overall built environment sustainability. ${ }^{2,3}$ However, Carr and

\footnotetext{
${ }^{1}$ Chantel Carr and Chris Gibson, "Geographies of Making: Rethinking materials and skills for volatile futures," Progress in Human Geography, 40.3 (2016) 299.

2 House of Commons Committee on Environment and Sustainable Development, Preserving Canada's Heritage: The Foundation for Tomorrow, 2017

${ }^{3}$ Federal Provincial Territorial Historic Places Collaboration, Building Resilience: Practical Guidelines for the sustainable rehabilitation of buildings in Canada, 2016.
} 
Gibson's perspective is somewhat at odds with some current trends in conservation that see material intervention as a threat to heritage authenticity or assume that embodied and intellectual trades knowledge can be effectively translated into digital 3D models and textual metadata by professionals and academic researchers. ${ }^{4}$

The focus on labour in the context of sustainability is gaining ground in international literature on heritage conservation. It is representative of a more general shift where new conservation approaches are less concerned with cultural value than with the material efficiency of reuse and the sustainable building technologies employed in traditional construction ${ }^{5,6,7}$ Larsen and Marstein's work on international best practices for the conservation of timber structures explicitly argues that the vitality of traditional trades skills is central to the implementation of new heritage value theory focused on sustainability. They advocate for an approach where replaced parts have heritage authenticity because of the work they represent and its role in maintaining the continuity of the whole. They argue that the way that new and old parts are worked by trades practitioners engaging in a common tradition of skilled work gives the structure enduring heritage value, not the protection of specific individual components. Larsen and Marstein make the connection between tradespeople's ability to access well-paying careers and

\footnotetext{
${ }^{4}$ S. Fai, M. Filippi, and S. Paliaga, "Parametric Modelling (BIM) for the Documentation of Vernacular Construction Methods: A BIM model for the Commissariat Building, Ottawa, Canada," ISPRS Annals of the Photogrammetry, Remote Sensing and Spatial Information Sceinces,25/W1, 2013.

5 Jean Carroon, Sustainable Preservation: Greening Existing Buildings, Hoboken, N.J: Wiley, 2010.

6 Susan Ross, Victoria Angel, et al, "Heritage and Waste" Journal of Cultural Heritage Management and Sustainable Development 10.1, 2020.

7 Susan Ross, "Re-evaluating Heritage Waste: Sustaiing Material Values through Deconstruction and Reuse," The Historic Environment: Policy and Practice 11.2-3 (2020) 382-408.
} 
social recognition, and the general availability of skilled labour in the market, and they warn that continued economic opportunity for traditional skills is a critical component of long-term built environment sustainability. ${ }^{8}$

Larsen and Marstein establish the historical relevance of this approach in heritage theory in the context of wood structures, but other perspectives from skilled heritage workers suggest it is applicable to other trades where materials are less perishable. In a manual on English heritage masonry written twenty years earlier, Peter Hill and David John make essentially the same argument, engaging in the debate between preserve-asfound and replace-in-kind approaches. "The present authors have both worked and fixed everything from ashlar to mouldings and tracery which were replacements for mediaeval work, and are prepared and content for these stones to be cut out and replaced in their turn when they have reached the end of their useful life in 200,300 or 500 years. There is nothing sacrosanct about a piece of worked stone, merely on the grounds that it once had a face or some detail on it which has long disappeared or become unsound. It is very clear to the authors, who have examined and measured historic masonry in far greater detail than the average architectural historian, that the mediaeval mason was very like his present-day counterpart." ${ }^{9}$ Like Larsen and Marstein, they argue that modern tradespeople practicing traditional skills can and do participate in the same tradition of work that imbues heritage structures with craft value and authenticity. This idea that heritage programs should be concerned with managing

\footnotetext{
${ }^{8}$ Larsen \& Marstein, III, 4, 6.

9 P.R.Hill and J.C.E. David, Practical Stone Masonry, Wimbledon: Donhead Publishing, 1995. 213-14
} 
appropriate changes within criteria that protect overall systemic continuity is more and more widespread. ${ }^{10,11,12}$

New heritage standards in nations that, like Canada, have no tools to designate and protect craft skills reflect this shift in thinking. They increasingly emphasize preventive maintenance strategies and highlight heritage skills shortages. Australia's 2013 Burra Charter, for instance, specifically mandates maintenance and formally supports education and career opportunities for skilled tradespeople. ${ }^{13}$ Australia and the United Kingdom both recognize the importance of specific trades skills in their heritage legislation and have programs to address shortages in those trades. ${ }^{14}$ In Ontario, the Ministry of Culture and Communications' 1990 publication, A Strategy for Conserving Ontario's Heritage proposed the integration of skilled trades apprenticeships into the province's heritage program, but this was never implemented and subsequent government publications do not share the same interest in the need for appropriately skilled tradespeople. ${ }^{15}$

There is growing research interest in education programs involving these skilled trades and, to a lesser degree, in the challenges and opportunities qualified students will face

\footnotetext{
${ }^{10}$ Francesco Bandarin and Ron van Oers, The Historic Urban Landscape: Managing Heritage in an Urban Century, John Wiley \& Sons, inc., 2012.

11 Stewart Brand, How Buildings Learn: what happens after they're built, New York: Viking, 1994

12 S. Huuhka and I. Vestergaard, "Building Conservation and the Circular Economy: A Theoretical Consideration" Journal of Cultural Heritage Management and Sustainability, 10.1, 29-40, 2019.

${ }^{13}$ The Burra Charter: The Australian ICOMOS Charter for Places of Cultural Significance, Australia ICOMOS, 2013.

${ }^{14}$ Cultural Human Resources Council, Human Resources in Canada's Built Heritage Sector: Mapping the Work Force and Setting Strategic Priorities, 2004. 31-32, 38-40

${ }^{15}$ Ministry of Culture and Communications, A Strategy for Conserving Ontario's Heritage, Government of Ontario, 1990. 25
} 
entering the job market and the nature of their relationships with heritage professionals. ${ }^{16,17}$ Some exciting new research In the Canadian context explores how digitally enabled fabrication tools can be adapted to facilitate traditional craftwork. ${ }^{18}$ However, the focus in Canada is overwhelmingly on education. ${ }^{19,20,21,22}$ In Toronto, this interest in education hasn't translated into opportunities. Toronto is home to four colleges but no trades programs in heritage specific skills. The Willowbank School, a private college in Queenston near Niagara Falls, offers specialized curriculum in traditional building trades but, interestingly, much of their programming is targeted to a professional audience. The closest public program is offered at Algonquin College in Perth Ontario, some six hours drive away. As of the time of this writing, this program is being redeveloped, with the heritage masonry program currently on hold to focus on equipping practicing masons with restoration skills and with plans to introduce a hybrid four year degree program offering a university credential, a Bachelor of Applied Science

\footnotetext{
16 Jonathan Djabarouti and Christopher O'Flaherty, "Experiential learning with building craft in the architectural design studio: A pilot study exploring its implications for built heritage in the UK," Thinking Skills and Creativity 32, Elsevier, 2019. 102-113.

17 Trevor Marchand, "The Pursuit of Pleasurable Work: craftwork in $21^{\text {st }}$ century England" RAI Research Webinar: Trevor Marchand, 4 February 2021.

$18 \mathrm{~J}$. Hayes, et al, "Digitally-Assisted Stone Carving of a Relief Sculpture for the Parliament Buildings National Historic Site of Canada," ISPRS Annals of the photogrammetry remote sensing and spatial information sciences, II-5/W3. 5, 2015, 97-103.

${ }^{19}$ Robert Pajot, "Building strength - Heritage Trades in Canada," National Trust for Canada, 1 May 2020.

${ }^{20} \mathrm{CBC}$ News, "New program teaches restoration of heritage buildings in Quebec," CBC News Montreal, 2021.

21 Cynthia Gunn et al., Human Resource Issues in the Preservation of Heritage Buildings, Research Report, Ottawa: Heritage Canada Foundation, 2003.

22 Human Resources Canada. Human Resources in Canada's Built Heritage Sector: Mapping the Work Force and Setting Strategic Priorities, Ottawa: Cultural Human Resources Council, 2004.
} 
in Building Conservation. ${ }^{23}$ There is a need for research to understand where graduates of these programs end up working, and to what extent specialized training in heritage trades skills is translating into careers working in heritage conservation.

The opportunity for skilled tradespeople to pursue careers in the heritage sector has been the subject of study at the federal level, and growing skills shortages are a cause for concern in the conservation sector. However, no significant programs exist to address these shortages or even to measure them accurately. ${ }^{24,25}$ Data published by Toronto Workforce Innovation Group attempts to measure projected skilled labour shortages in the city's construction industry as a whole ${ }^{26}$ There is no metric to determine what proportion of these shortages will fall to the heritage sector, but it is possible that heritage conservation work, which tends to be more labour intensive and require more highly skilled workers than new construction, could be an important tool to stimulate growth in some of the skilled trades that will be critical to the broader construction industry. While conservation policy at various levels recognizes the value of intangible trades heritage, the subject of how to identify and support significant trades work is underdeveloped.

The economic case for investing in skilled trades work, has been a major component of economic arguments for heritage conservation programs since they were introduced in

\footnotetext{
${ }^{23}$ Algonquin College, New Degree Program Proposal: Bachelor of Applied Science (Building Conservation) (Honours), April 6, 2021.

${ }^{24}$ Cynthia Gunn et al., Human Resource Issues in the Preservation of Heritage Buildings, Research Report, Ottawa: Heritage Canada Foundation, 2003.

25 Human Resources Canada, Human Resources in Canada's Built Heritage Sector: Mapping the Work Force and Setting Strategic Priorities, Ottawa: Cultural Human Resources Council, 2004.

26 Toronto Workforce Innovation Group, Constructing Toronto, 2015. 25
} 
Donovan Rypkema's ground-breaking work in the '90s ${ }^{27}$ In practice, these economic values are often overlooked in favour of real estate values that are convincing to owners and municipal managers, or the value of public realm investments that compete for tourist dollars and attract highly mobile international businesses. ${ }^{28}$ In Ontario, this school of economic analysis as a form of heritage advocacy is represented by the work of Robert Shipley, whose studies of heritage designation programs and heritage conservation districts in Ontario tackle questions about property values, urban revitalization, and development return on investment. ${ }^{29,30,31}$ This work has opened doors for heritage in the province with important data to argue for conservation as a best practice for urban planning. Ken Greenberg, Toronto's former Director of Urban Design and Architecture, promotes this type of heritage led revitalization in Toronto Rebom emphasizing the rezoning and adaptive reuse of post-industrial neighbourhoods south of King Street on either side of the downtown core as a critical early step in the City's downtown revitalization and celebrating the recent adaptive reuse of urban space created by ageing infrastructure under the Gardiner Expressway. ${ }^{32}$

\footnotetext{
27 Rypkema, 1994.

${ }^{28}$ Randall Mason, "Be Interested and Beware: Joining Economic Valuation and Heritage Conservation," The International Journal of Heritage Studies, 14.4 (2008): 303-318.

${ }^{29}$ Robert Shipley, "Heritage Designation and Property Values: Is there an Effect?" The International Journal of Heritage Studies 6.1, 2000.

${ }^{30}$ Robert Shipley and M. Snyder, "The role of heritage conservation districts in achieving community economic development goals," The International Journal of Heritage Studies 19.3, 2013.

${ }^{31}$ Robert Shipley, Steve Utz, \& Michael Parsons, "Does Adaptive Reuse Pay? A Study of the Business of Building Renovation in Ontario, Canada" The International Journal of Heritage Studies, 12.9. 2006.
}

32 Ken Greenberg, Toronto Reborn, Toronto: Dundurn Press, 2019. 
However, over the past decade the urban decline that stimulated this need for revitalization has given way to forms of urban success that are creating new challenges for cities related to housing unaffordability and income inequality. ${ }^{33}$ In Toronto, research in urban geography links major placemaking heritage conservation projects in the Distillery District and Liberty Village to new urban issues of economic homogeneity, displacement, gentrification, and, ironically, the erosion of a sense of place. ${ }^{34,35,36}$ Activist architects, planners, and community organizers argue that municipal zoning practices informed by 70's era conservationist principles meant to protect vibrant inner city communities are now contributing to an increasingly unaffordable, inequitable housing market. ${ }^{37} \mathrm{~A}$ renewed focus on the benefits associated with creating jobs in the skilled trades as an economic argument for conservation programs would give conservation advocacy new relevance in this shifting urban landscape.

Heritage advocates in Ontario are already promoting the economic benefits of job creation in the skilled trades, but they ignore the challenges those tradespeople face entering the market for heritage work. The Architectural Conservancy of Ontario's 2020 Heritage Week advocacy strategy prominently featured these jobs as a benefit of

\footnotetext{
${ }^{33}$ City of Toronto, Housing Market Analysis: From insight to action, Toronto: 2019.

34 John Paul Catungal, Deborah Leslie \& Yvonne Hii, "Geographies of Displacement in the Creative City: The Case of Liberty Village Toronto," Urban Studies, 46.5/6 Sage Publications, 2009. 1095-1114.

35 Vanessa Matthews, Place Differentiation: Redeveloping the Distillery District, Toronto, Proquest Dissertations Publishing, 2010.

36 Vanessa Matthews, "Incoherence and Tension in Culture-Led Redevelopment," International Journal of Urban and Regional Research, 38.3 2014. 1019-1036

${ }^{37}$ Bozikovic et al, House Divided: How the missing middle can solve Toronto's affordability crisis, Toronto: Coach House Books, 2019.
} 
investment in conservation programs. ${ }^{38}$ This assumes that the labour market will respond with increased supply to meet increased demand for these skills. Research in Canada and internationally challenges this assumption. In their introduction to Innovative Built Heritage Models, a compilation of work from 10 years experience in preventive conservation at Monumentwacht in the Netherlands. Van Balen and Vandesande call attention to the challenge that market failure poses for heritage maintenance, "built heritage maintenance entails a service which in itself cannot be effectively traded in terms of strategic market management, i.e. the service is not an identical interchangeable and standardised commodity; it is not yet accepted in the market and the demand and supply side do not have sufficient price information and assurance."39 Human Resource Canada's 2004 report on issues in the built heritage sector observes that in Canada this market failure has practical consequences for heritage priorities: "The relationship between preservation goals and the availability of skills is not necessarily straight forward. In the private sector, preservation goals can be influenced by the availability of skills. In other words, if architects or owners generally believe that high quality traditional skills cannot be hired, they may alter their preservation goal to take account of this perceived shortage of skills." ${ }^{40}$ Without proactive support for skilled trades work, demand side uncertainty responding to perceived skills shortages drives a vicious cycle that can suppress the availability of heritage trades skills in the market even while investment in heritage programs increases.

\footnotetext{
${ }^{38}$ Architectural Conservancy of Ontario, Make Save and Reuse the Norm: Aligning heritage preservation with Provincial priorities, 2020. 7

39 Vandesande and van Balen, 4.

${ }^{40}$ Canada Human Resource Council, 2004.
} 
Considering trends in heritage best practice alongside this literature documenting economic pressures on heritage work shows that theoretical decisions that are presented as abstract interpretations of heritage value systems are, in practice, intimately tied to the market availability of skilled labour. The perceived market availability of skilled trades has a more compelling effect on heritage practice than any heritage theory. Academics, activists, and policy makers engaged with heritage always have a stake in the success of heritage specializing tradespeople because without them informed choices about appropriate intervention are not possible. Without access to appropriately skilled workers, heritage theory can only make a virtue of necessity.

This review demonstrates that, despite a growing body of literature on the importance of skilled tradespeople to meet new sustainability goals for heritage conservation, literature in Canada and Ontario is still more likely to focus on real estate and placemaking as economic drivers. While initial efforts to study and address skilled trades shortages have been made at a national level, there is no coherent position on the value of work either nationally or in local markets and no strategy to address existing or imminent skills shortages. New research in Toronto suggests that heritage programs based on the economic logic of placemaking developed in response to urban failure are amplifying the problems associated with urban success. While advocates sometimes also leverage projected job creation in the skilled trades in arguments for increased investment in heritage, they ignore the need to develop opportunities for those skilled tradespeople to pursue stable, viable careers before those benefits can be realized. This review demonstrates that, beyond being necessary to implement new heritage priorities related to sustainability and reuse, maintaining a healthy market for the work that heritage specializing trades people do is necessary to support meaningful decisions about 
appropriate heritage intervention. It reveals the need for research that engages with specific local market conditions for heritage conservation work to understand the challenges and opportunities that exist for the skilled tradespeople who do it. 


\section{Policy Context for Trades Work in Toronto's Heritage Sector}

\begin{tabular}{|c|c|c|}
\hline \multicolumn{3}{|c|}{ Docurnents Governing Wark in Toranto's Heritage Conservation Market } \\
\hline Level & Document & Defines: \\
\hline Federal & Standards and Guidelines & Best Practices \\
\hline Provincial & $\begin{array}{l}\text { Ontario Regulation 9M06: } \\
\text { The Ontario Heritage Act }\end{array}$ & $\begin{array}{l}\text { Criteria for Designation and the legal framework for murnicipalities } \\
\text { to administer heritage programs }\end{array}$ \\
\hline \multirow[t]{3}{*}{ Municipal } & Toronto Official Plan & Heritage Goals and the Municipal Heritage Permitting Process \\
\hline & $\begin{array}{l}\text { Heritage Conservation District } \\
\text { Policy. }\end{array}$ & $\begin{array}{l}\text { Procedures to Implement Heritage Conservation District } \\
\text { Designation }\end{array}$ \\
\hline & Section 37 Benefits & Criteria to secure funding from new development \\
\hline \multirow[t]{4}{*}{ Property } & $\begin{array}{l}\text { Heritage Conservation } \\
\text { District Plan }\end{array}$ & $\begin{array}{l}\text { Criteria for heritage value of a heritage conservation district } \\
\text { and procedures to protect that value in the long term }\end{array}$ \\
\hline & Property Designation By-Law & Heritage value of a property in terms of Provincial Criteria \\
\hline & Heritage Impact Assessment & The impacts of proposed alterations to a property's values \\
\hline & $\begin{array}{l}\text { Heritage Property } \\
\text { Conservation Plan }\end{array}$ & Scopes of work and appropriate skils to contract for that work \\
\hline
\end{tabular}

Figure 1: Documents Governing Work in Toronto's Heritage Conservation Market

\section{Setting the Standard: Federal Heritage Guidelines}

Canada's Federal Heritage Guidelines are the result of collaborative development with the provinces and territories. Heritage Conservation is a provincial and territorial jurisdiction so the federal guidelines are a cooperative agreement rather than a true national standard. They represent an approach to heritage that is fundamentally conservative, but favourable in many ways to the kinds of work that create job opportunities for heritage trades skills. Ontario has not adopted the current version of the Standards and Guidelines but Toronto's municipal heritage policy refers to them. ${ }^{41}$ The Standards and Guidelines tend to avoid mentioning either specific professional roles or specific trades but do specifically recommend that building owners and caretakers work

${ }^{41}$ City of Toronto, Toronto Official Plan, Toronto, ON: 2019, 3-12. 
with certain professional consultants. These consultants typically have expertise outside of the standard skillset in the conservation sector. ${ }^{42}$ The document does explicitly acknowledge the importance of both skilled tradespeople and competent professionals to the success of conservation programs, insisting in its introduction of the principles for intervention that, "It is equally important to have well-supervised people with the right skills undertake the work as it is to determine the right work to undertake.. ${ }^{43}$ However, there is little federal guidance to determine what the right skills are. The Directory of National Heritage Designations supports intangible heritage criteria by maintaining lists of nationally significant historic events and persons, but has no comparable designation for trades or craft expressions. ${ }^{44}$ The Standards and Guidelines relegate the work typically done by tradespeople to the final step of a three stage decision making process involving "understanding," "planning," and "intervening,"45 They provide no explicit support for heritage trades, but adopt philosophical positions on appropriate forms of intervention that create opportunity for forms of work typically done by heritage tradespeople.

Section 4.1.2 on Evidence of Traditional Practices is illustrative of the way that the Standards and Guidelines encourage and value heritage trades without providing direct support. This section is clear about the value of intangible heritage to significant sites stating that, "Traditional practices may be the strongest influence in determining heritage

\footnotetext{
42 Canada's Historic Places, Standards and Guidelines for the Conservation of Historic Places in Canada, $2^{\text {nd }}$ ed. Ottawa, ON: 2010, 132, 133, 137, 143-144, 150-151, 157-158, 164-165, $171-$ 172, 179, 186, 201, 202, 207, 208.

43 Standards and Guidelines for the Conservation of Historic Places in Canada, 5.

${ }^{44}$ Parks Canada, "Directory of Federal Heritage Designations," Government of Canada website.

45 Standards and Guidelines for the Conservation of Historic Places in Canada, 3.
} 
value, even if evidence of any type of construction or human-generated change appears insignificant." ${ }^{46}$ It also explicitly recognizes heritage trades skills as a kind of intangible heritage having value, "Any historic place may have been influenced by historic practices that evolve over time; for example, stone masonry traditions were transferred and adapted through apprenticeship systems form the Middle Ages to the present day." ${ }^{47}$ However, the guidelines have nothing to say about a conservation approach to these intangible cultural properties themselves. Instead, they provide recommendations for the conservation of physical aspects of a site that support traditional activity. ${ }^{48}$ The guidelines follow a theory of heritage that has no tools to directly address intangible heritage assets.

The resulting approach supports intangible trades heritage indirectly through recommendations for the treatment of material heritage. For instance, standard 8 lays out a hierarchy for priority of interventions. Maintenance is preferred, followed by repair if possible, but in cases where replacement of a part is necessary, it calls for replacement in kind, defined as, "with the same form, material and detailing as seen in the existing elements." 49 This rejects the philosophical position current in some academic heritage discourses that any non-obvious contemporary material intervention is damaging to heritage value. The Standards and Guidelines value the design integrity of the heritage property as a whole over the absolute material authenticity of each individual member. This position creates opportunities for skilled heritage tradespeople who can repair

\footnotetext{
${ }^{46}$ Standards and Guidelines for the Conservation of Historic Places in Canada, 55.

47 Standards and Guidelines for the Conservation of Historic Places in Canada, 55.

48 Standards and Guidelines for the Conservation of Historic Places in Canada, 56.

49 Standards and Guidelines for the Conservation of Historic Places in Canada, 31.
} 
existing components and reproduce appropriate form and detailing in appropriate materials to produce in-kind replacements.

A second element of conservation theory addressed in The Standards and Guidelines in a way that is favourable to heritage trades is the question of reusing heritage materials and components. Standard 4.b. prohibits "creat[ing] a false sense of historical development by adding elements from other historic places or other properties or by combining features of the same property that never coexisted." ${ }^{50}$ However, it adds a clarification that permits and encourages some kinds of salvage and reuse. "For example, using a salvaged lamppost from an historic landscape with identifiable characteristics at another site does not conform to the standard. On the other hand, using recycled bricks of the same age and appearance, or reusing identical windows within a building are appropriate from both conservation and sustainability standpoints." ${ }^{11}$ Permitting the salvage and reuse of heritage materials in conservation practice (albeit within limited parameters) indirectly supports tradespeople practicing the skills to work those materials. Unfortunately, this principle has limited application in Toronto's conservation program because it is undercut by municipal policy. Toronto's Heritage Conservation District Guidelines for instance, take a much stricter line on restoration and the reconstruction of lost historical detail than the Standards and Guidelines. $^{52}$

\footnotetext{
50 Standards and Guidelines for the Conservation of Historic Places in Canada,, 27.

51 Standards and Guidelines for the Conservation of Historic Places in Canada, 27.

52 Heritage Conservation Districts in Toronto: Procedures, Policies and Terms of Reference, by Barrett Scott et al. Toronto: City of Toronto, 2012, 37.
} 
One of the most discussed passages in the Standards and Guidelines is its requirement for compatible contemporary design for heritage additions in Standard 11. This phrasing has become a battleground of interpretation between advocates of complementary additions and those favouring radical contrast. It is beyond the scope of this argument to address the proper definition of 'compatible and subordinate' design but it is pertinent to consider what the Standards and Guidelines do have to say about compatibility. Different interpretations of compatibility have implications for the kind of work that is specified in new additions and where interventions are made to existing structures. Standard 11 stipulates that new construction that affects heritage properties should be "physically and visually compatible with, subordinate to, and distinguishable from the historic place." 53 The current tendency interpreting this standard is toward contrasting, contemporary design with features that testify to some influence from the heritage structure. The Standards and Guidelines break down compatibility into two categories, physical and visual. Section 11 goes on to define physical compatibility, "using materials, assemblies and construction methods that are well suited to the existing materials."54 There are very pragmatic reasons for this. It ensures that the addition of new materials will not conflict with existing cycles of maintenance and potentially result in loss of historic fabric because it is efficient to replace it at the same time as more perishable modern additions. ${ }^{55}$

This is a compelling practical argument to employ heritage trades skills in new construction that affects heritage structures. However, most discussions of compatibility

\footnotetext{
53 Standards and Guidelines for the Conservation of Historic Places in Canada, 34.

${ }^{54}$ Standards and Guidelines for the Conservation of Historic Places in Canada, 34.

55 Standards and Guidelines for the Conservation of Historic Places in Canada, 34.
} 
in design circles focus on visual compatibility in the sense employed in Standard 10 dealing with the replacement of features where there is insufficient evidence to produce an accurate replacement. ${ }^{56}$ Compatibility, in this sense, addresses the 'character' of the new component. It lays out two options, one using traditional materials and detailing, and the other using designed abstractions of existing qualities. "The new element could be discreet and compatible in form, material and detailing, or contemporary in design, achieving compatibility through proportion, scale, or massing." ${ }^{57}$ Contemporary projects show that the second option has become the preference of designers for new additions as well as missing parts. This interpretation of compatibility in terms of either visual similarity or contrast seems more concerned with contemporary discourses of heritage value than it is with the physical longevity and sustainability of heritage structures.

While an approach based on the principle of physical compatibility laid out in Standard 11 is favourable to the work of heritage tradespeople and the long-term resilience of heritage structures, Standard 10 frames this specialized trades work in terms of the visual expression of heritage value. It presents it as one of two equal options alongside contemporary design solutions. Section 10 frames the debate in terms that permit only one approach or the other. It is worth noting that additions that are physically compatible following the definition in Standard 11 need not be visually complementary. A radical interpretation of physical compatibility could engage both traditional building trades and a contrasting contemporary aesthetic. It is not clear why this language from Standard 10 has become so influential in the interpretation of Standard 11 and the debate around

\footnotetext{
${ }^{56}$ Standards and Guidelines for the Conservation of Historic Places in Canada, 33.

${ }^{57}$ Standards and Guidelines for the Conservation of Historic Places in Canada, 33.
} 
appropriate design for new additions to heritage properties. It is clear however, that this quirk of interpretation shifts the focus of debate away from interest in physical qualities and material assemblies that would engage the expertise of skilled tradespeople. It prioritizes visual characteristics and design abstractions that create interesting interpretive questions for heritage professionals.

At best, the Standards and Guidelines support a theoretical rationale for conservation work that is favourable to the practice of heritage trades but lacks the tools to directly support them. They are overwhelmingly concerned with the lasting physical integrity of heritage structures. Their theoretical viewpoint sometimes puts up barriers to trades work or makes it interchangeable with compatibility by design only. They have no tools to directly support skilled trades as heritage assets in themselves, but despite this, they value the work of skilled heritage tradespeople, encourage forms of intervention that engage that work, and reject philosophical positions that fetishize heritage material to the point of stifling the livelihoods of the workers who can maintain it. They carry legal weight in Toronto's conservation sector, but their influence is limited because they deal only with best practices and theory. They have no direct impact on the economics of the heritage sector, or the capacity of heritage programs to secure funds for conservation work. Unfortunately, some of their qualities that are favourable to trades work are undercut by municipal level policy and conventional interpretations. Without a direct influence on the financial environment of the heritage conservation sector, their influence on economic opportunity for trades is limited.

There are still ways that federal programs working within the philosophical constraints of a system that has no tools to directly address intangible heritage could better support 
skilled trades in local markets though. Maintaining a register of significant craft expressions in the same way that the federal government already does for nationally significant events and persons could provide much needed support for designation and interpretation schemes to prioritize skilled trades work. The Standards and Guidelines could support trades work with more explicit, permissive guidance for the reuse of salvaged heritage materials. They could explicitly acknowledge that the contemporary practice of traditional trades skills need not threaten heritage values and can even reinforce them, particularly when defining standards that impact that work. For instance, they could articulate the value of repair and replacement-in-kind in terms of the traditions of intangible trades heritage that they celebrate elsewhere. Finally, they could be clearer about the standard of physical compatibility in response to common interpretations. Clearly emphasizing that physical compatibility is about work, defined in terms of the construction methods and maintenance schedules that materials and assemblies require, as well as the ways that materials themselves interact, would give clarity to contentious debates about compatibility and reassert the intent of the standard to protect the long-term physical integrity of heritage structures.

\section{Funding Heritage Values: Ontario's Provincial Heritage Framework}

Ontario's Provincial framework devolves powers for heritage policy making to municipalities. It does not directly prescribe heritage priorities, but it shapes the economic landscape of heritage work. It prescribes the values considered in heritage designation and it defines the work that can be paid for by developers in exchange for benefits through Section 37 agreements. These agreements sometimes, but not always, involve building rehabilitation and heritage trades contracts. Ontario's heritage legislation is intentionally hands-off. The province has always been reluctant to take responsibility 
for measures that would interfere with individuals' property rights. ${ }^{58}$ This reluctance in the legislation plays out differently for heritage tradespeople and heritage professionals. For professionals, it has meant support for work in assessment and documentation as an alternative to mandated intervention. For tradespeople, it has meant that the success of local heritage designation programs has not necessarily predicted significant new opportunity for the kinds of skilled work involved in the conservation and maintenance of heritage structures. There are two important characteristics of the OHA that have shaped the industry environment for heritage trades in Ontario. The first is this refusal to provide standards for the protection and maintenance of designated properties. The second is the Act's framework for determining heritage value that, in combination with the resources developed to support it, privileges heritage criteria that refer to abstract design qualities or to the history of architecture as a profession.

There is limited research on the history and application of the Ontario Heritage Act. The most complete work on the subject is Victoria Angel's 1998 Master's thesis, The Ontario Heritage Act and the Provincial Program: An Alternate Model for Heritage Conservation. ${ }^{59}$ Since then, the Act has gone through two substantial revisions, the first in 2005 introduced demolition controls and increased support for Heritage Conservation Districts, the second was due to come into effect in January of 2021 but is delayed as of this writing.$^{60}$ It represents development interests in heritage policy and stakes a claim to increased provincial control over conservation programs by introducing vague

\footnotetext{
58 Victoria Angel, The Ontario Heritage Act and the Provincial Program: An alternative model for heritage conservation, Mater's Thesis, Carleton University, Ottawa, ON: 1998, 99.

59 Angel.

60 The Ontario Heritage Act, 1974, 2005.
} 
prescriptive principles and sweeping regulatory powers. ${ }^{61}$ it is unclear what the implications of this change will be, and, while it erodes the authority of municipal programs, it seems unlikely that the provincial government will leverage it to reverse their longstanding hands-off position toward conservation work. There is a need for critical research bridging the last two decades of heritage policy development in the province.

Victoria Angel's work on the Ontario Heritage Program responds to the Province's unusual arrangement delegating responsibility for heritage programs to local authorities. She argues that devolving heritage responsibilities to the municipal level created opportunity for a heritage system that was more responsive to locally driven concepts of value and that the lack of demolition controls fostered an atmosphere of robust community engagement in conservation issues as an alternative tool to manage heritage resources. ${ }^{62}$ Much of the structure that she describes still exists in the heritage sector despite the implementation of demolition controls in 2005. In particular, the current system of consultation facilitated by documentation and assessment is still largely intact. This context is important to understand the status of professional heritage consultant work under this system. As well as facilitating community engagement, it acts as a costly disincentive discouraging demolition. Over the last twenty years, radical changes in the role of cities globally and in Toronto's economy in particular have changed the economic environment where these regulations operate. The heritage conservation programs that Angel studied were developed to save heritage fabric threatened by urban

\footnotetext{
61 Dan Schneider, "What to Make of Bill 108," OHA+M, Ontario Heritage Resource Centre, University of Waterloo: 2019.

${ }^{62}$ Angel.
} 
decline. Conservation issues today struggle with the consequences of runaway urban success. Heritage programs often participate in this process of change as components of urban revitalization and placemaking. ${ }^{63}$ Toronto's current Official Plan frames heritage policy in the context of "Building a Successful City" 64 That chapter begins with the idea that economic success is tied to qualities of place: "The policies in this Chapter will guide our growth by integrating social, economic and environmental perspectives in our decision making to create an attractive Toronto with a strong economy and complete communities. ${ }^{65}$ In this contemporary economic context, the province's hands-off approach to heritage policy makes conservation priorities a matter of negotiation between developers and municipal authorities.

The mechanism for that negotiation is a provincial tool, Section 37 benefits, which award new developments increased density beyond zoned limits in exchange for investment in public realm improvements. The administration of these benefits is controversial for reasons beyond the scope of heritage conservation. There is little transparency or consistency in the way that they are administered and the Ward-level negotiation process keeps benefits from new development in the communities where developers are investing. ${ }^{66}$ Nevertheless, Toronto has embraced these agreements as a flexible tool to raise funds for local initiatives, going so far as to publish a promotional brochure promoting Section 37 agreements as "An essential tool for building healthier

\footnotetext{
63 Vanessa Kristy Matthews, Place Differentiation: Redeveloping the Distillery District, Toronto, Doctoral Thesis, University of Toronto, Toronto: ON, 2010.

64 Toronto Official Plan, 3-1.

65 Toronto Official Plan, 3-1.

${ }^{66}$ Aaron A. Moore, "Trading Density for Benefits: Section 37 Benefits in Toronto" IMFG Perspectives 2, Toronto, ON, 2013.
} 
neighbourhoods." ${ }^{67}$ The specific priorities of Section 37 programs are set at the municipal level and will be discussed in more detail in the context of Toronto's local policy. Their importance in the provincial framework is that they encourage municipalities to link heritage conservation work with new private development investment. The role of developers in the heritage sector can sometimes be controversial among activists and professionals. ${ }^{68}$ Establishing a robust dialogue about the relationship between new development and heritage conservation requires an understanding that in dense urban settings with high property values, Ontario's policy effectively makes new development a necessary financial partner to heritage work.

Provincial policy also sets the framework for designation criteria. These provincial criteria reflect traditional values-based conservation theory. These definitions are not just important for designation. They have a direct impact on how scopes of work are determined and how funding for conservation is allocated. In the partial retention schemes that are dominant in Toronto's development-oriented conservation sector, determinations of heritage value are used to decide what elements will be conserved and how that conservation scope will be achieved. The Ontario Heritage Act splits values criteria into three categories, design or physical value, historical or associative value, and contextual value. ${ }^{69}$ Two of these criteria explicitly engage trades work. Section 1.i. recognizes design or physical value for properties that are "a rare, unique

${ }^{67}$ City of Toronto, Section 37 : An Essential Tool for Building Healthier Neighbourhoods, Toronto, ON: 2014, 1.

${ }^{68}$ Robert Shipley, Steve Utz, and Michael Parsons, "Does Adaptive Reuse Pay? A study of the business of building rehabilitation in Ontario, Canada," The International Journal of Heritage Studies, 12.6 2006, 505.

69 Ontario Regulation 9/06, The Ontario Heritage Act, 2005. 
representative or early example of a style, type, expression, material or construction method"70 (emphasis added) Section 1.ii. recognizes "craftsmanship or artistic merit,"71

Taken as a whole though, these criteria are overwhelmingly interested in values that stem from an academic rather than material appreciation of heritage resources. They play into the interests of historians, architects, and planners. While some passages do support trades related value, they are always accompanied by values related to design. "Craftsmanship" is set against "artistic merit" and "material or construction method" is lumped in with "style, type, [or] expression." ${ }^{2}$ The characteristics of historical or associative value and of contextual value are more uniformly abstract. They deal with qualities of cultural significance through association with significant people or events and in terms of relationships to public space. These distinctions give professional consultants tools to weigh in on contemporary issues of public space or the cultural dimension of heritage values. They create an important venue for heritage conservation projects to take public realm positions and they give professional consultants agency to advocate for objectives related to contemporary design or urban placemaking.

While these criteria tend to create more space for professional perspectives, they do also open up significant opportunities for trades engagement in the designation process. These opportunities have not been taken advantage of. A survey of the resources that have been developed to support the application of these criteria reveals a comparative lack of interest in criteria for designation that engage trades, materials, and building

\footnotetext{
70 Ontario Regulation 9/06, (2)1.i.

71 Ontario Regulation 9/06, (2)1.ii.

72 Ontario Regulation 9/06, (2)1.i.
} 
assemblies. The Toronto Public Library system and the independent Dictionary of Architects in Canada website both maintain lists of architects relevant to heritage designation. ${ }^{73,74}$ These resources support designation under historical associative value through association with a significant designer and by documenting people significant to a community of designers and urbanists whose relationship to heritage properties can be clearly demonstrated. There are also a range of guides that formalize the architectural styles that are considered significant in Ontario. John Blumenson's Ontario Architecture: A guide to styles and building terms 1784 to the present is the most prominent. ${ }^{75}$ Mark Fram's Well-Preserved: The Ontario Heritage Foundation's Manual of Principles and Practice for Architectural Conservation also includes a glossary of styles considered significant to the development of architecture in the province. Despite this publication's overall interest in the details of specific assemblies and the work that goes into building maintenance, it does not include a corresponding glossary of significant craft expressions that could be used to support designation. ${ }^{76}$

New publications follow the same trend. Ron Brown's Toronto's Lost Villages (2020) for instance, supports designation by defining geographical communities that might have a significant relationship to a property submitted for designation. ${ }^{77}$ Toronto's new Heritage

\footnotetext{
${ }^{73}$ Archindont, Architectural Index for Ontario, Toronto Reference Library, online resource (retrieved Jan 2021).

${ }^{74}$ Robert G. Hill, Biographical Dictionary of Architects in Canada 1800-1950, online resource (retrieved Jan 2021).

75 John Blumenson, Ontario Architecture: A guide to styles and building terms 1784 to the present. Markham, ON: Fitzhenry and Whiteside, 1990.

${ }^{76}$ Mark Fram, Well-Preserved : the Ontario Heritage Foundation's Manual of Principles and Practice for Architectural Conservation $3^{\text {rd }}$ ed. Erin, ON: Boston Mills Press, 2003.

77 Ron Brown, Toronto's Lost Villages, Toronto: Dundurn Press, 2020.
} 
Conservation District Policy provides detailed guidelines to apply designation criteria addressing architectural design or historical association including categories of information to collect and methodologies for documenting and presenting it, but they have nothing to say about how to interpret the values criteria for craftsmanship. ${ }^{78}$ There is no reference to support a consistent approach to designation under the criteria for craftsmanship, material, construction method, or association with a significant builder. Developing these resources should be broadly appealing across the heritage conservation community. Aside from the potential benefits to heritage specializing tradespeople, they would create more diverse evidence to support new designations and standardize interpretations of these criteria to make their application more transparent and predictable.

There is untapped opportunity in the Ontario heritage framework to make heritage trades expertise a significant perspective contributing to understanding and designating heritage assets as well as physically maintaining them. The heritage community has, so far, failed to support that role. Because of the financial and regulatory structure of Ontario's heritage sector, this lack of interest has economic consequences that impact the viability of careers in heritage trades. Ontario's heritage conservation system was developed to protect significant buildings from demolition under the assumption that the alternative to demolition was protection. New economic pressures on urban environments and new funding structures for conservation work have shifted the purpose of those regulations to a role managing the changes associated with the new development that is the necessary counterpart to financial investment in conservation

\footnotetext{
78 Heritage Preservation Services., 23.
} 
work. In this context, the way that statements of heritage value are articulated within the framework of Ontario's criteria for designation has a direct impact on the kinds of work that get specified in heritage conservation projects. Criteria that support heritage trades work are present in the Act, but if they are not considered in a property's statement of heritage values, they cannot be used to negotiate increased density in return for conservation funding and they will not be included in the resulting conservation plans.

\section{Conservation Theory at Work: How Toronto's Heritage Policy Shapes a Market with Asymmetrical Opportunities for Professionals and Tradespeople}

Heritage Policy in Toronto supports a competitive market for professional services and trades contractors, but there is still a perception that specialized heritage trades skills are in decline. This sector is loosely defined and largely unmeasured, so while this decline is widely recognized, it is difficult to quantify. ${ }^{79}$ It is also not well understood why these skills are increasingly difficult to find while the City's heritage program is increasingly integrated with overall planning goals and reports year-over-year growth measured by the City's Official Plan Key Indicators. ${ }^{80,81}$ This analysis looks at the policy that governs decision-making for conservation work in Toronto and the financial context that it operates in to understand this disparity. It shows how heritage policy shapes market conditions where professionals offering specialized heritage services can thrive

\footnotetext{
79 Cultural Human Resources Council, Human Resources in Canada's Built Heritage Sector: Mapping the workforce and setting strategic priorities. Government of Canada, 2004.

80 Heritage Toronto, Changing the Narrative. Toronto, ON: 2019, 4.

81 City of Toronto, City of Toronto Official Plan Indicators, Toronto, ON: 2018, 28.
} 
while corresponding advantages are not necessarily passed along to tradespeople practising specialist heritage conservation skills.

A survey of the City's heritage conservation policy turns up very few circumstances where heritage trades work is strictly required when a heritage property or district is involved in new development. In contrast, the policy does require heritage assessments and plans that are typically executed by professional consultants. For directives about how the work of conservation or adaptive reuse should be done, the policy defers to Canada's Standards and Guidelines and gives professional consultants the responsibility to interpret those standards. It provides some direct support for trades work where designated structures are publicly owned, but it does little to guarantee appropriately skilled heritage tradespeople access to private contracts. In different contexts, the policy has remarkably different implications for the viability of careers in skilled trades that range from forbidding trades work to tacitly supporting it.

The policy takes a range of positions on heritage trades work that vary from prohibiting to mandating it depending on the circumstance. Heritage trades work is specifically discouraged in only one section of the policy. For building relocation, the structure moved must not be "demolished, disassembled, and/or reconstructed." 82 The policy is most directly supportive of conservation work that could be undertaken by heritage tradespeople where publicly owned properties are involved. Chapter 3 Section 8 stipulates that, "When a City owned property on the Heritage Register is no longer required for its current use, the City will demonstrate excellence in the conservation,

\footnotetext{
82 Toronto Official Plan, 3-15.
} 
maintenance and compatible adaptive reuse of the property." ${ }^{83}$ Chapter 3 Section 9 extends this commitment to funding material work on heritage structures to municipally owned listed buildings that are transferred to private ownership. It requires heritage easement agreements for the ongoing conservation of the property. ${ }^{84}$

The policy also has several sections devoted to promoting and incentivizing conservation and maintenance work for privately owned structures. These standards should tend to create opportunity for skilled work maintaining these heritage structures, but there are no data available to measure their effectiveness. Section 12, dealing with the enforcement of property standards by-laws that protect against demolition by neglect, ${ }^{85}$ and Sections 18 and 19 , dealing with financial incentives for conservation and maintenance work, indirectly support heritage trades. It is beyond the scope of this study to assess how successful these policies have been in terms of creating work for skilled tradespeople or preventing demolition by neglect. In their study of developers' perspectives on heritage conservation, Shipley, Utz, and Parsons suggest that these types of incentives are not effective in Toronto's expensive, development-oriented real estate market. ${ }^{86}$ However, it is still possible that they could have a comparatively small but still significant impact in small-scale residential work on existing structures in the City.

\footnotetext{
83 Toronto Official Plan 3-8.

84 Toronto Official Plan 3-9.

85 Toronto Official Plan, 3-12.

${ }^{86}$ Robert Shipley, Steve Utz, and Michael Parsons, "Does Adaptive Reuse Pay?: A study of the business of building renovation in Ontario, Canada," International Journal of Heritage Studies 12.6 (November 2006): 513.
} 
Section 21 addresses requirements for density bonusing agreements. The new requirement to conserve the "three dimensional integrity" ${ }^{87}$ of heritage resources should tend to support trades work. It creates demand for forms of work that facade retention schemes omit and insists on the material value of the building as a whole. Section 27 repeats this priority, addressing new development on registered properties. It discourages facade retention strategies and encourages "the conservation of whole or substantial portions of buildings, structures and landscapes on those properties." 88 This, too, demands more targeted study. It is still a relatively new principle, and it is not yet clear whether the few remarkable projects that it has produced so far will be the norm, or if it will settle into a kind of facadism-plus once standards for the minimum requirements of the policy are well established.

The tendency among these policies is to encourage work that would typically be done by tradespeople with specific expertise in maintaining and restoring intact heritage structures. The strongest support for these workers in the policy is its commitment to maintenance, conservation, and adaptive reuse for municipally owned designated properties. The next most important is the general preference for the preservation of complete structures. There are significant gaps in this support. Even for municipally owned structures there is no explicit acknowledgement of the importance of heritage trades or of any specific forms of work that heritage tradespeople would be contracted to do. Nowhere does the policy require that appropriately skilled tradespeople should be hired to do certain kinds of work or insist that certain work done by skilled tradespeople

87 Toronto Official Plan, 3-21

88 Toronto Official Plan 3-27. 
is necessary under the City's heritage program. This is in sharp contrast to the ways that it addresses heritage professionals whose work and skills are explicitly recognized.

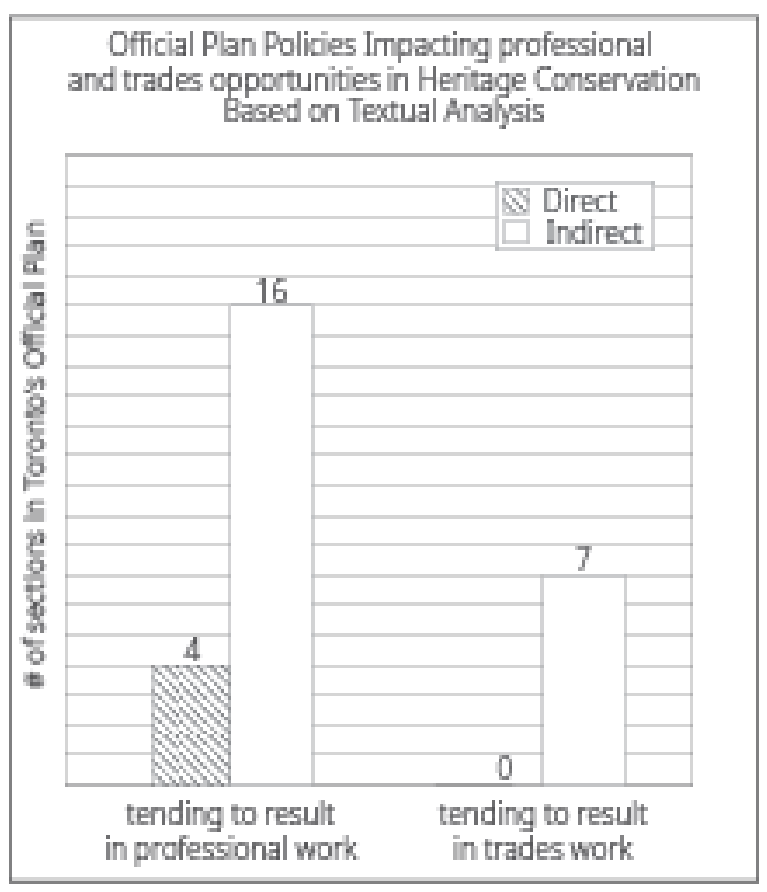

Figure 2: Official Plan Policies Impacting Professional and Trades Opportunities in Heritage Conservation

Work that benefits professionals but not tradespeople is encouraged in guidelines for the application of Section 37 Benefits which are set at the municipal level. As well as preservation, restoration, and adaptive reuse of heritage properties, these agreements can be made for heritage projects that involve "commemoration" and "designation." 89 This gives professionals more reliable access to the main source of funding in the sector and makes it difficult to estimate the extent of opportunity for heritage tradespeople.

89 City of Toronto, Implementation Guidelines for Section 37 of the Planning Act and Protocol for Negotiating Section 37 Community Benefits, Toronto, ON: 2016, 14. 
The policies deal extensively with situations where the assessment of heritage values or the documentation of heritage properties are required by the City, roles typically occupied by specialized heritage professionals. This appears in Sections 2, 3, 4, 5, 7 , $13,26,30$, and 32 . Policy support for professional heritage work breaks down into three main categories. Some policies imply forms of work that are typically done by professionals the same way that others imply work that is typically done by tradespeople. Others specifically require types of work that are typically done by professionals specializing in heritage or specifically require that the services of qualified professionals be engaged. The third group establishes methodologies for assessing value that privilege professional perspectives and marginalize trades expertise.

Several sections of the Official Plan call for forms of intervention that require specialized professional services but not specialized trades work. Section 9 deals with public access to heritage attributes. Section 21, which deals with density bonusing, mandates "excellence in the conservation of the values, attributes, [and] character" 90 of the heritage property alongside its "three-dimensional integrity." Section 29 lays out the criteria for assessing the appropriateness of building relocation. ${ }^{91}$ Other sections deal with interpretive work, promoting heritage properties and communicating their values. Sections $15,16,17$, and 40 support this kind of work which can be triggered independently of any conservation scope. For instance, Section 40 calls for interpretation of archaeological resources through "innovative architectural and/or landscape architectural design, public art installations, or other public realm projects,"92

\footnotetext{
90 Toronto Official Plan, 3-21.

91 Toronto Official Plan, 3-29.

92 Toronto Official Plan 3-40.
} 
and Section 17 encourages "commemoration of lost historical sites [...] whenever a new private development or public work is undertaken in the vicinity of those sites," as well as "interpretation of existing properties on the Heritage Register." ${ }^{33}$ These policies encourage types of work that are done by professionals in the same round-about way that they encourage types of work that are done by tradespeople. However, these categories of professional work are more extensive and more reliable than the categories of trades work that the policy encourages.

The policy also specifically requires certain forms of professional work in ways that it does not require any work typically done by skilled tradespeople. The most important of these are Heritage Impact Assessments, Heritage Property Conservation Plans, and Heritage Conservation District Plans. While there is generally no requirement for professional expertise involved in preparing these documents, they are typically produced by architects or planners often with specialist expertise in heritage conservation, especially where large private investments are involved. Policy for Heritage Conservation Districts makes this tendency official giving the City the option to require CAHP designated professionals, a voluntary, paid membership, be engaged. ${ }^{94}$ In Toronto's private sector funding model for conservation, Heritage Impact Assessments function as a tool in the bargaining process to negotiate increased density for new development on sites impacting heritage assets.

There are a range of circumstances where Heritage Impact Assessments are required, many involving no conservation scope of work, or even no direct intervention on a listed

\footnotetext{
93 Toronto Official Plan, 3-17.

${ }^{94}$ Heritage Preservation Services, 2012.
} 
heritage property. Heritage Impact Assessments are required to address not only the alteration or demolition of registered structures, but also proposed alterations or demolitions of non-heritage structures adjacent to them. ${ }^{95}$ Section 46 also requires Heritage Impact Assessments for new projects that might effect certain protected views of heritage buildings, structures, or landscapes. ${ }^{96}$ This means that the City's priority to increase the number of municipally recognized heritage structures is very likely to result in an increase in commissions for professionals with specialist heritage skills who can produce Heritage Impact Assessments, but is not necessarily related to any increase in projects including scopes of work that specify heritage trades expertise. ${ }^{97}$

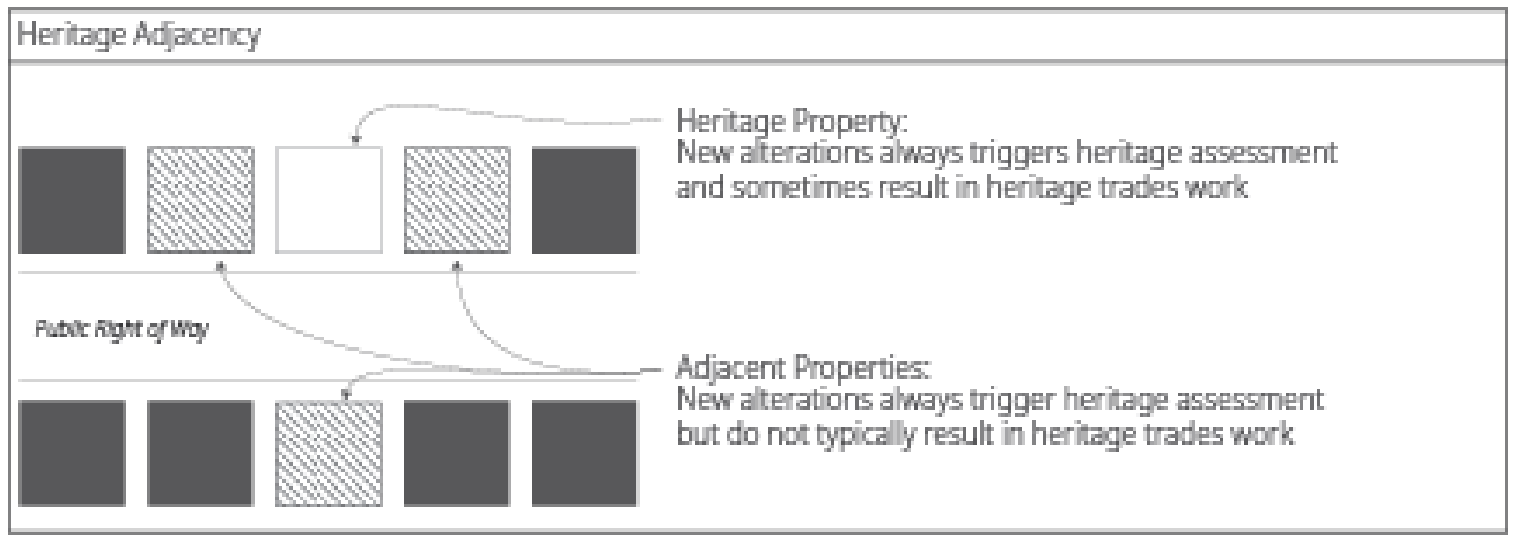

Figure 3: Heritage Adjacency as per Toronto Official Plan Section 23

Toronto's policy supports professional services in a third way that has no benefit to heritage tradespeople through policies that articulate the benefits of heritage to the City in terms of visual streetscape character. This is an example of a broader tendency for the City's heritage policy to reflect its overall planning approach. Understanding the

\footnotetext{
95 Toronto Official Plan, 3-23.

96 Toronto Official Plan 3-46

${ }^{97}$ City of Toronto Official Plan Indicators, 28.
} 
value of heritage properties in terms of visual public character is in line with the Official Plan's treatment of facades as a key component of the public realm. The plan devotes a significant proportion of the section on built form to the role of facades, saying,

“Toronto's streets, parks and open spaces are defined by the facades of many buildings. The facade presents the building to the public, telling people about the building, what it is, where to enter, and what the character and functions of interior uses are. The individual facades of buildings that form the edge of a street or park are read together as a common wall that defines the public realm and are an expression of Toronto's collective vision, identity and history." 98 This concept of visual streetscape character is the foundation for the policy's treatment of the intangible values of heritage. It asserts that, "consciously or unconsciously, our heritage resources are part of our daily experience of the city. [...] The heritage policies of this plan not only promote the preservation of important heritage buildings and structures but also the public views of them for the enjoyment of Torontonians." 99 The policy explicitly recognizes the intangible elements of heritage. ${ }^{100}$ However, it operates within a framework based on the Ontario Heritage Act and Canada's Standards and Guidelines for Heritage Conservation that has no tools to directly address the protection of intangible heritage assets. The focus throughout on the perceived, visual character of heritage suggests that, for the purposes of Toronto's policy, intangible heritage means visually accessible public experiences.

\footnotetext{
98 Toronto Official Plan, 3-6.

99 Toronto Official Plan 3-11.

100 Toronto Official Plan 3-11.
} 
Establishing the City's heritage goals in terms of "sustainable development and place making" ${ }^{101}$ lines up neatly with the trend in Ontario's development industry identified by Shipley to see heritage properties as assets for a place branding approach to marketing for new development. ${ }^{102}$ This focus on visual character over material fabric is consistent with the Official Plan's broader policies addressing the quality of built form and public space. The plan commits to promoting, "Quality architecture, landscape architecture and urban design and construction," ${ }^{103}$ but the strategies it sets out to guarantee this quality are exclusively focused on professional design services, not the material quality of construction. They involve strategies to seek "design excellence"104 through competition and review, promoting public interest in design quality, "encouraging the use of skilled professionals in the design and construction process," 105 and presenting private sector awards for "creativity and excellence in architecture, landscape and urban design." 106 These contemporary goals and priorities set the standards for the qualities that are prioritized when professionals determine the "values, attributes, [and] character" 107 of heritage resources.

There is a strong tendency in the language dealing with mitigation and assessment for heritage resources to repeat the language used to describe planning priorities for the

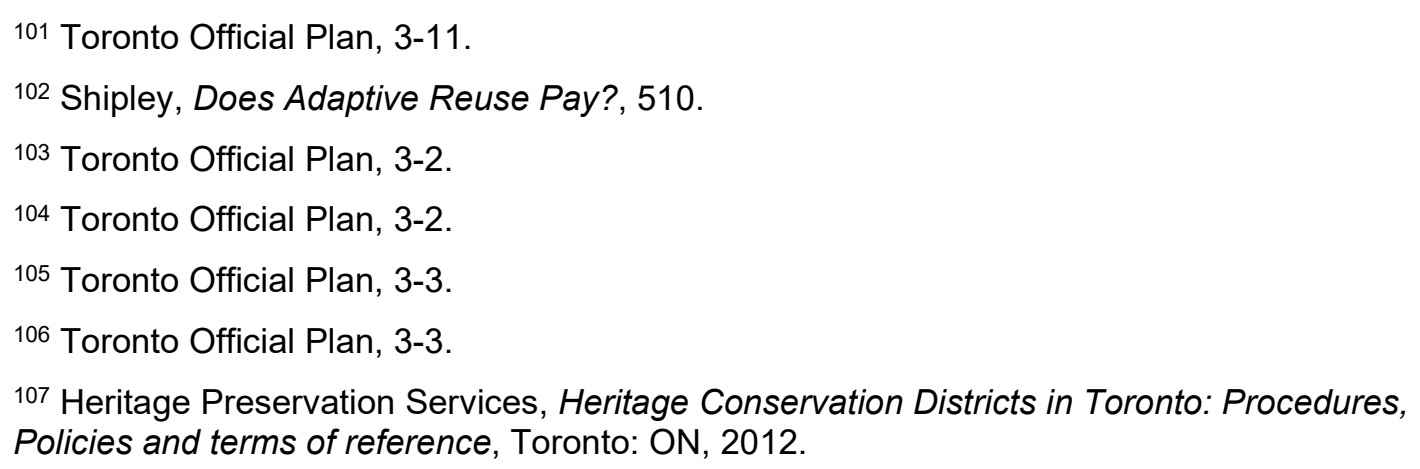


desirable character of new development. Both are concerned with abstractions like "massing, form, scale, and proportion." ${ }^{108}$ And they both address material but not assemblies or technologies. This tendency is even more pronounced in Toronto's Heritage Conservation District policies, where the policy tools to describe the overall character of neighbourhoods and districts are entirely concerned with these abstractions to the near exclusion of material assemblies and construction techniques. ${ }^{109}$ Where these policies do deal with materials, they tacitly acknowledge that new additions will apply them as a surface veneer. This approach is useful for visual consistency, but not for the continuity of the skills and knowledge involved in working on heritage structures. It supports cost-efficient new construction, but it does not support the industry's capacity to work with assemblies that exist in heritage structures and need to be maintained and conserved as functioning building systems.

In these ways, Toronto's policy creates an environment where professional work is a source of stable income for heritage specialists who provide services that are required under heritage regulations and that are reliably and increasingly required as more properties are added to the heritage register. Heritage-specializing tradespeople do not enjoy the same support. They pursue forms of work that are specified on a case-by-case basis, typically by professionals under contract to private-sector clients. There is no clear standard for when the work of appropriately skilled tradespeople should be required or how to distinguish appropriate qualifications. Their access to funds available in the heritage conservation market does not increase reliably with the number of designated

\footnotetext{
108 Toronto Official Plan, 3-7.

109 Heritage Conservation Districts in Toronto, 22-30.
} 
buildings or even with the amount of money acquired by the City for heritage conservation projects. This disconnect between the success of heritage programs at professional, academic, and policy levels and the opportunities available to tradespeople practising the specialist skills necessary to maintain heritage structures should concern anyone interested in heritage conservation in Toronto. In the simplest terms, it makes it harder to maintain existing buildings. From the perspective of heritage theory, it sets a pragmatic limit to the kinds of conservation programs that can be carried out, reducing conservation decision-making to market-driven expedience. Strategically, it hampers heritage advocates by jeopardizing the sector's ability to align heritage programs with government priorities by integrating new theory addressing the sustainability of conservation, or by demonstrating meaningful job creation that fills overall trades skills shortages in the construction industry. 


\section{Comparing the Status of Skilled Trades in Heritage to Trades in other}

\section{Culture Industries}

Heritage conservation is one of the primary sectors of the culture sector economy and benefits from culture sector advocacy. However, conservation discourse exists in parallel to the rest of the culture sector, with its own academic forum, its own theories of value, and its distinct grounding in architecture's insular professional practice. The tendency to think of conservation as an object-oriented process, where value is attached to the completed work rather than the labour that goes into it, separates conservation from prominent culture industry subsectors like music, film, and theatre, where the line between the work and the product is blurred by the characteristics of performance and spectacle. Like heritage conservation, these arts sectors struggle to compete with private development for urban space and advocate for funding and policy support from local government. They also have an ambivalent relationship with the increasing concentration of wealth in the city that makes it easier for them to access certain sources of revenue but makes it more difficult to do work that is not highly valued economically, or whose economic value is not realized in direct, short-term profit. Heritage site management and heritage architecture are both strongly associated with the culture economy and benefit from the political consideration that comes with that category, but trades work in heritage conservation isn't explicitly recognized as part of the cultural economy component of heritage. This is at odds with the way that labour is considered in other culture sectors, notably film and music, and to a lesser extent, fashion, which have their own industry specific advocacy. It is remarkable that, despite being much better represented in municipal legislation and urban planning policy, heritage 
conservation does less than any of these industries to bring attention to the challenges it faces from growing skills shortages.

The question of whether or not heritage specializing tradespeople participate in the culture economy is ultimately academic and arbitrary but useful because it establishes a connection to ideas that are politically meaningful and have concrete benefits in the form of government attention, funding opportunities, and advocacy. The culture economy model based on Richard Florida's influential concept of a "Creative Class"110 and the transition to a post-industrial knowledge economy where immaterial services replace manufactured goods, valorizes work like computer programming as a contemporary expression of a fundamental human craft impulse at the same time that it disparages the physical work of tradespeople who participate in that craft tradition. ${ }^{111,112}$ In spite of the classist overtones of creative class discourse, it also accommodates positions that situate trades and crafts skills within the emerging knowledge economy. De Munck traces the historical development of trades guilds and unions and the division of labour during and after the industrial revolution to argue that the instrumentalization of skilled workers, separating them from decision making associated with knowledge work, is a product of economic forces and class tensions, not a characteristic of either handwork or technological progress. ${ }^{113}$ New research on the contemporary relevance of craft and trades knowledge supports the relevance of tradespeople in the culture economy. Djabarouti's recent work in architecture and trades education explores the transfer of

\footnotetext{
110 Richard Florida, Cities and the Creative Class, New York: Routledge, 2005.

111 Richard Sennett, The Craftsman, New Haven: Yale University Press, 2008.

112 Bert De Munck, "Artisans as knowledge workers: Craft and creativity in a long term perspective," Geoforum, 99, 2019. 227-237

113 De Munck 2019.
} 
technical and embodied knowledge between these disciplines. ${ }^{114}$ Fox Miller's thesis work on the craft brewing sector describes the ways that this traditional craft work engages with contemporary culture economy exchanges in carefully staged working environments where performative labour and consumption coexist. She also identifies the economic benefits of this kind of craft-based knowledge work that is embedded with regional supply chains and has a sense of local identity compared to more mobile, internationally networked forms of knowledge work. ${ }^{115}$ Trevor Marchand's body of work in anthropology explores the nature of embodied knowledge in these trades occupations and the economic and cultural context of contemporary craft work. ${ }^{116,117}$ Peggy Deamer eloquently argues that, in the context of architecture, these distinctions between physical and immaterial work, while sometimes useful, are fundamentally simplistic and damaging. ${ }^{118}$ For the purpose of this research, it is enough to say that we should be asking why heritage tradespeople have not typically been included in the culture economy and culture sector advocacy, not whether or not they belong. The culture sector already includes a range of tradespeople under its broad umbrella, from carpenters building film sets to camera operators filming music videos to sound technicians working live venues to textile workers producing fashion items. However, skilled tradespeople delivering specialized heritage conservation services typically are

\footnotetext{
114 Djabarouti 2019.

115 Chloe Fox-Miller, "'Glorified Janitors:' Creativity, cachet, and everyday experiences of work in Portland, Oregon's craft brewing sector," Geoforum, 106, 2019. 78-86.

116 Trevor Marchand and Hugh James, The Masons of Djenné, Indianna University Press, 2009.

117 Marchand 2021.

118 Peggy Deamer Architecture and Labor, New York: Routledge, 2020, 69.
} 
not considered in culture economy documents and don't appear in culture economy advocacy.

This is unusual because architectural services related to heritage do feature as does heritage site management. This gap is reflected in the tone of recent heritage advocacy in Toronto. The 2019 State of Heritage Report includes a section on heritage and economic development, but only briefly mentions the jobs involved in conservation work. It does advocate for workers but only for the precarious, part-time, and volunteer positions that serve heritage site tourism. ${ }^{119}$ This report highlights the precarity facing heritage employees, meaning the service sector workers who facilitate access to heritage properties, and advocates for better recognition for heritage volunteers. ${ }^{120}$ It mentions job creation in construction as an economic benefit of conservation but omits it from its metrics for heritage economic development, focusing on tourism programming, and spillover economic effects related to improved urban quality of life. ${ }^{121}$ Because heritage conservation in Toronto is mostly engaged with private clients rather than public works, emphasizing the economic benefits associated with jobs created through the costs incurred during conservation work may not be an appealing argument despite the overall benefits of that investment documented in other jurisdictions. ${ }^{122}$

\footnotetext{
119 Heritage Toronto, Changing the Narrative: State of Heritage Report 2019, 2019 13-15.

120 Heritage Toronto, 15

121 Heritage Toronto, 13.

122 Rypkema and Mason, 2011.
} 
Job creation in trades did feature prominently in the Architectural Conservancy of Ontario's recent advocacy campaign to "make save and reuse the norm." ${ }^{123}$ It appears as an economic benefit associated with heritage designation programs in the provincial government's 2005 report that accompanied new changes that year to the Ontario Heritage Act. However, leveraging job creation as a benefit of conservation is not the same as addressing concerns about the availability of skilled workers needed to execute heritage scopes of work. This kind of advocacy does draw attention to the value that skilled trades work in the sector brings to communities, but it assumes that qualified tradespeople will be available to meet new demand and realize those economic benefits without considering the complexities of the market for that work. Individually, heritage architects and advocates are concerned with skills shortages that could make it difficult to realize some of the economic benefits of job creation in heritage trades. Collectively, industry advocates haven't taken a coherent position on this issue.

Advances made through heritage advocacy in the City deal with new ways to categorize heritage resources, view corridors and heritage conservation districts. ${ }^{124}$ They continue to treat the production of heritage as a conversation between designers, planners and developers on the one hand, and 'users,' that is residents, commuters, and tourists, on the other. The step of the process where work happens is typically missing, and while job creation in skilled trades is sometimes leveraged as a benefit of conservation

\footnotetext{
${ }^{123}$ Architectural Conservancy Ontario, "Make Save \& Reuse the Norm: Aligning preservation with Provincial Prorities," Heritage Week at Queen's Park, 2020. [https://acontario.ca/files/res/68/ACO\%20Heritage\%20Advocacy\%20Day\%202020.pdf] 124 Toronto Official Plan, 3-11.
} 
programs, advocacy to support the skilled tradespeople aspiring to do that work is not usually a part of heritage advocacy.

There are some organizational differences in the sector that effect the relationship between heritage trades and heritage advocates. For instance, in film, actors, animators, and writers as well as crew and technicians are served by industry guilds and unions, while in heritage conservation the history of professional organization divides unionized trades and professionally organized designers. ${ }^{125}$ Given this context, it's important to acknowledge the conventional assumption that the construction industry is hostile to heritage conservation. It is certainly true that, like many architects and developers, some tradespeople and contractors are antagonistic towards heritage programs. However, a superficial look at publicly available information on donors to Heritage Toronto, the charitable agency of the City of Toronto that published the State of Heritage report, suggests that on the contrary, trades partners with a stake in conservation are an untapped resource for heritage advocacy.

Heritage Toronto already receives donations from a range of unions and heritage contractors. Their website recognizes three unions and one contractor as donors at the $\$ 10,000+$ level (Carpenters and Allied Workers Local 27, International Association of Bridge, Structural, Ornamental and Reinforcing Ironworkers Local 721, LiUNA Local 183, and Clifford Restoration Limited) compared to two developers (Tricon Residential and Camrost Felcorp). Assuming that all listed sponsors donate the minimum amount assigned to their sponsorship tier, three construction unions donate almost as much as

\footnotetext{
125 Peggy Deamer, "Architectural Production and Consumption: Architectural Work in the Capitalist Context," Architecture and Labor, New York: Routledge, 2020, 53-62.
} 
nine developers. Construction unions and contractors donate more than three times as much as architects and their professional organizations. And individual contractors donate, on average, about two and a half times more than individual architects. ${ }^{126}$ Stereotypical assumptions that the construction industry isn't interested in conservation aren't reflected in trades unions' and contractors' actual engagement with heritage advocacy groups. Trades unions and heritage specializing trades contractors are already investing in heritage advocacy in Toronto, but that advocacy doesn't reflect their perspectives.

\begin{tabular}{|c|c|c|c|c|c|}
\hline \multicolumn{6}{|c|}{ Heritage Toronto Sponsors } \\
\hline & Developers & Trades Unions & Contractors & Architects & Professional Associations \\
\hline Count & 9 & 3 & 10 & 12 & 3 \\
\hline Total Donation & $\$ 34,000$ & $\$ 30,000$ & $\$ 23,500$ & $\$ 11,000$ & $\$ 6,200$ \\
\hline Average Donation & $\$ 3,778$ & $\$ 10.000$ & $\$ 2,350$ & $\$ 917$ & $\$ 2,067$ \\
\hline
\end{tabular}

Figure 4: Donations to Heritage Toronto by Industry Group

No other sector cuts labour out of the culture economy narrative so completely. Film, music, and fashion are all concerned with the working conditions, education, and career opportunities of technicians and tradespeople who work with artists, designers, and patrons to realize each industry's products. Fashion has the least developed industry advocacy but still showcases labour issues among designers' concerns. A 2017 City Council Report developed in response to Toronto's Fashion Week being cancelled by private organizers puts skilled labour issues at the forefront of new municipal advocacy for the fashion sector. The report is primarily concerned with the needs of fashion

\footnotetext{
126 Heritage Toronto, "Our Supporters," online resource, [https://www.heritagetoronto.org/joingive/our-supporters]
} 
designers who are also entrepreneurial business owners. Despite this, the interests of skilled tradespeople in the sector, specifically sewers, sample makers, pattern makers, cutters, and graders, loom large. ${ }^{127}$ Issues around ensuring the local availability of these skilled workers and facilitating design business owners' access to their work feature prominently in the key challenges the report brings to city council for consideration. ${ }^{128}$

In the music sector, advocacy is more developed, with a municipal committee, the Toronto Music Advisory Council, dedicated to raising issues pertinent to the industry and advocating for municipal action. The committee's 2016 Toronto Music Strategy adopts a holistic concern for workers' living and working conditions. It describes the industry as a community of "music creators" that includes technical workers, like recording engineers and music videographers, alongside artistic creators, like musicians and songwriters. ${ }^{129}$ It advocates for typical business incentives such as access to opportunity, education, and favourable regulatory environments, as well as industry specific issues like access to performance and rehearsal space and fair compensation models for performers. It also advocates for programs that address these workers' ability to live in the city, including affordable housing and health and dental insurance. ${ }^{130} \mathrm{~A}$ new document focusing on Toronto's disappearing live venues emphasizes the importance of these working spaces to retain locally developed talent, including technicians and producers along with musicians, and to ensure that existing training programs lead into industry

\footnotetext{
127 General Manager, Economic Development and Culture, Supporting the Growth of Toronto's Fashion Sector, Report for Action, City of Toronto, 2017.

128 Supporting the Growth of Toronto's Fashion Sector, 9.

129 Toronto Music Advisory Council, Toronto Music Strategy: Supporting and Growing the City's Music Sector, City of Toronto, 2016, 5.

130 Toronto Music Advisory Council 2016, 6,8.
} 
opportunities. ${ }^{131}$ This holistic approach to advocacy emphasizes the connection between appropriate education and access to career opportunities that can support Toronto's costs of living and establishes artists and technicians specializing in the music industry as a cohesive community of workers who share common interests that are served by mutually supportive advocacy.

The film industry is a particularly interesting case for this discussion because the organizational relationships between producer/director, art director/DOP, and crew invite comparisons to the relationships in architecture and heritage conservation between owner, architect, and contractor. Like heritage conservation, the film industry also has its own well-developed advocacy that promotes the sector's unique economic advantages separately from broader culture-economy advocacy. One of the key advocacy positions in the 2017 Spotlight on Toronto report deals with skills development. The report "calls on the City, sector and education partners to create a new workforce development strategy for the screen industry, supporting the development of top-tier talent both on and off camera." ${ }^{132}$ That document was developed in consultation with labour groups (industry guilds and unions) as well as owners and patrons (producers, distributors, and studio operators) and more glamourous creative class workers (actors, animators, and writers). ${ }^{133}$ Given the common concerns with labour in these three creative sector industries and their active advocacy to address skills shortages, it is remarkable that heritage conservation, despite its privileged treatment in municipal policy and its central

\footnotetext{
131 Nordicity, Re:Venues: A Case and Path Forward for Toronto's Live Music Industry, Toronto: Canadian Live Music Association, 2020, 26.

132 Toronto Film, Television and Digital Media Board, Spotlight on Toronto: A strategic action plan for the film, television and digital media industry, Toronto, 2017, 6.

133 Toronto Film, Television and Digital Media Board 2017, 11.
} 
place in the culture economy, does not pursue similar advocacy for skills development in the specialized trades that are needed to carry out conservation scopes of work.

Looking at heritage in the context of culture sector advocacy shows that this broader framework is already being used to address heritage issues that are typically outside the bounds of heritage policy. Re:Venues: A Case and Path Forward for Toronto's Live Music Industry, published in 2020 by Nordicity for the Canadian Live Music Association, calls attention to the ways that the concept of heritage value was used by local communities as a tool to advocate for the protection of music venue programs in new development on the site of The Silver Dollar Room. ${ }^{134}$ From the Ground Up, a creative culture report on the spatial organization of creative enterprises clustered in the King and Spadina area that was co-authored by ERA, a prominent heritage conservation firm in Toronto, is concerned with the interior organization and structural systems of the industrial heritage buildings in the area and their flexibility to accommodate a wide range of culture sector uses. ${ }^{135}$ It advocates to protect specific program types in those heritage buildings through permissive zoning that includes light industrial programs in the City's existing broader language stipulating non-residential uses. ${ }^{136}$ In both cases, heritage advocates use tools borrowed from creative economy discourse to engage issues related to interior quality and program, two characteristics of Toronto's built heritage that typically have not been protected by designation.

\footnotetext{
134 Nordicity 2020, 17.

135 Martin Prosperity Institute et al. From the Ground Up: Growing Toronto's Cultural Sector, City of Toronto, 2011, 36.

136 From the Ground Up, 2011, 56.
} 
Comparing Toronto's heritage conservation program to advocacy for other creative economy industries reveals a gap in the conversation around heritage-specialising tradespeople. Fashion, music and film all directly deal with problems related to the availability of skilled workers and, following the political and economic means each industry has at its disposal, they advocate for specific goals to support careers in the skilled trades they depend on. Heritage conservation advocates use skilled trades work as a component of arguments for the economic value of conservation programs, but the way they make those arguments assumes that appropriately skilled tradespeople will be there to meet demand. They stop short of promoting access to education and career opportunities for people working in or trying to enter the market for that skilled trades work.

This comparison also provides precedents for heritage advocates to follow to fill this gap. Conservationists are already using arguments from creative economy advocacy to address internal spatial organization and specific existing uses, both issues that, like trades skills, are important to heritage advocates but are not typically supported by the City's heritage policy. Heritage advocates should integrate the culture sector's concern for skilled workers into the discourse of heritage conservation starting by treating tradespeople, unions, and contractors with the attention given to skilled culture economy workers in other industries and engaging them in consultation alongside architects, planners, and developers. 


\section{Conclusion}

Toronto's heritage framework currently reflects the interests of heritage professionals and neglects the perspectives of skilled tradespeople pursuing work in the sector. Canada's Standards and Guidelines have limited influence and don't offer tools to directly support trades work. Ontario's heritage framework sets criteria related to craft and skilled trades work in parallel with excellence in design. Craft criteria lack the supporting resources to facilitate designation that have been developed for criteria related to design quality and to architects as historically significant figures. Toronto's heritage program depends on financial instruments that don't distinguish between material conservation or rehabilitation and professional designation, or commemoration. It is integrated with planning goals that prioritize visual character and streetscape quality with comparatively little emphasis on material maintenance or built environment resilience. Existing best practices and new policy for heritage conservation reflect these priorities with detailed instructions for documenting and categorizing visible design qualities like massing and proportion and urban planning features like setbacks and building heights, but no similar guidance for material assemblies, or best practices for maintenance or physically compatible new construction. Heritage advocacy in the city tends to overlook the challenges posed by skills shortages in sharp contrast to similar advocacy documents in comparable culture sector industries.

There is nothing to say that any of these are intended outcomes. The market for work in heritage conservation is complicated and the interaction of these three overlapping layers of regulation in their shifting economic, social, and political context is 
unpredictable. Individual heritage professionals are typically concerned about skilled trades shortages and supportive in the ways that they can be of skilled tradespeople who want to pursue work in the sector. Assessing heritage policy in terms of its ability to support careers for skilled tradespeople demonstrates that, even though individual practitioners may have limited opportunities to work against the pressures driving skills shortages in the sector, the heritage community does have tools to address them.

\section{Recommendations}

This research shows that heritage policymakers, professionals, and advocates have a clear role to play counteracting the skilled trades shortages facing the sector. Heritage conservation is not simply a victim of external forces. It has policy tools to influence its own market conditions and it can either create or suppress demand for skilled trades work. Making sure that skilled trades work is a valued part of the heritage conservation system gives trades practitioners space to grow, gives heritage professionals access to the range of skilled work that they need to make meaningful decisions about appropriate intervention, and strengthens our capacity to sustainably maintain and reuse our existing buildings.

There are international precedents for heritage policy that directly supports the careers in the skilled trades needed to continue to sustainably maintain heritage properties. Cost effective preventive maintenance approaches and sustainable practices calling for rehabilitation and reuse both depend on appropriately skilled trades workers. Making sure that these workers can access appropriate training and stable careers should be a priority for heritage advocates interested in implementing these new best practices. In Canada, market failure for skilled trades work leads to a vicious cycle where the 
perceived lack of available skilled workers creates an industry environment where there are no opportunities for tradespeople interested in pursuing specialization in those skills. Policy makers who shape the legislation and best practices that determine what kinds of work are acceptable on heritage sites, and professionals who interpret that policy and specify heritage scopes of work have critical roles to play to break this cycle.

Canada's Standards and Guidelines are already generally supportive of work that engages skilled tradespeople. They are limited by the ways they are interpreted in local jurisdictions. Emphasizing the principle of physical compatibility and finding ways to act on their explicit support for building trades as a form of intangible heritage could have positive results for heritage tradespeople.

Ontario's heritage framework gives municipalities criteria for determining heritage value that include exemplary craftsmanship and association with significant builders, but the resources to support these criteria are missing. Developing new resources similar to the dictionaries of significant architects and glossaries of historical styles used to support other criteria for designation would emphasize the value of a set of key trades skills to the heritage system as a whole. It would make designation under these categories more predictable and more transparent, and it would make it more likely that skilled trades work would be included in future scopes of work related to those designations.

Toronto's municipal heritage program gives heritage professionals tools to support access to opportunity in the skilled trades needed to sustainably maintain existing buildings. Heritage Impact Assessments and Heritage Conservation Plans are flexible tools that let professionals weigh in on the kinds of work that are appropriate to specific conservation projects. However, shifting the responsibility for capacity building to 
individual professionals is just as unfair as shifting the blame for skills shortages to individual tradespeople. Individual professionals acting as agents for private clients have limited opportunities to address the root causes behind skilled trades shortages.

Heritage Easements and Heritage Conservation District Plans represent interesting opportunities to explore because they can dictate long-term standards for new intervention. With enthusiastic community partners, they could be used to test new best practices related to maintenance and physical compatibility. Current standards for Heritage Conservation Districts rigorously define appropriate forms of visual imitation in terms of proportion, massing, and other design qualities. Providing similar detailed guidance about built details, assemblies, and physically compatible construction would give planners tools to contribute to the overall resilience of these districts by taking measures to promote the skills needed to sustainably maintain their existing heritage properties.

The City also administers financial tools that could address skills shortages. Monitoring Section 37 Benefits to measure the percentage of heritage funding awarded to projects involving material intervention and trades scopes of work, and the percentage going to purely professional designation and commemoration is the first step to understanding what the size of the market for heritage trades work in the city really is. Alternatively, implementing standards for designation and commemoration that would engage the skilled workers typically involved in conservation and rehabilitation projects would bolster demand for those skills and establish a collaborative dialogue about conservation priorities in the early stages of designation where heritage values are set. 
Heritage advocates who are concerned about the skilled trades shortages facing the sector can learn from the examples set by other industries in the City that depend on skilled workers. Heritage legislation and theoretical best practices are slow moving, but advocates interested in addressing skilled trades shortages now can start by integrating trades groups into industry advocacy and engaging with them in new consultation. They can highlight the challenges those trades shortages pose to heritage programs, and advocate on economic and ecological grounds for access to education and stable careers for heritage specializing tradespeople. The benefits associated with the work that these tradespeople do already feature in economic arguments for conservation programs. Those arguments should be complemented by a focus on education and access to opportunity to make sure that appropriately skilled workers are ready to realize the benefits of job creation in heritage trades.

This change in approach is more important now than ever. It's too early to say what the long-term consequences of the disruption COVID-19 is causing to the tourism economy and related heritage economic frameworks will be or whether the shift to more distributed work in the knowledge economy jobs that cities typically compete to attract will diminish political interest in urban public realm improvements aimed at attracting businesses and knowledge workers. What's clear is that there is an opportunity to accelerate a shift in heritage priorities away from tourism and placemaking, to the economic and ecological value of sustainably maintaining our built environment. Conservation and building rehabilitation can take on new significance post-COVID-19 if heritage advocates have the foresight to re-assess their priorities and to promote sustainable heritage work that engages skilled tradespeople for inclusion in the new, green stimulus programs that will shape the post-COVID economy. 


\section{Bibliography}

Angel, Victoria. The Ontario Heritage Act and the Provincial Program: An alternative model for heritage conservation. Master's thesis, Carleton University, Ottawa, ON: 1998.https://curve.carleton.ca/system/files/etd/089df2ef-0ac8-4372-b4fa5728d091457f/etd_pdf/0d62acf74395aac5cfb95642e93deef5/angeltheontarioheritageactandtheprovincialprogram.pdf (accessed: 2020-10-05).

Algonquin College. New Degree Program Proposal: Bachelor of Applied Science (Building Conservation) (Honours). April 6, 2021.

Archindont, Architectural Index for Ontario, Toronto Reference Library. http://archindont.torontopubliclibrary.ca/Arch/main.dov (accessed: 2021-01-07).

Architectural Conservancy Ontario. "Make Save and Reuse the Norm: Aligning heritage preservation with Provincial priorities." Heritage Week at Queen's Park 2020, Toronto, ON: 2020. https://acontario.ca/show_res.php?r_id=68 (accessed: 2020-12-23).

The Australia ICOMOS Charter for Places of Cultural Significance. The Burra Charter, 2013. Retrieved from the Australia ICOMOS website: https://australia.icomos.org/wpcontent/uploads/The-Burra-Charter-2013-Adopted-31.10.2013.pdf.

Bandarin, Francesco, and van Oers, Ron. The Historic Urban Landscape : Managing Heritage in an Urban Century, John Wiley \& Sons, Incorporated, 2012. ProQuest Ebook Central, http://ebookcentral.proquest.com/lib/oculcarletonebooks/detail.action?doclD=843404. 
Bill 9/06: The Ontario Heritage Act. (1974) https://www.ontario.ca/laws/statute/90018 (accessed: 2020-12-05).

Blumenson, John. Ontario Architecture: A guide to styles and building terms 1784 to the present. Markham, ON: Fitzhenry \& Whiteside, 1990.

Brand, Stewart. How Buildings Learn: what happens after they're built?. (New York: Viking, 1994).

Brown, Ron. Toronto's Lost Villages. Toronto: Dundurn Press, 2020.

Canada's Historic Places, Standard's and Guidelines for the Conservation of Historic Places in Canada, ${ }^{\text {nd }}$ ed., 2010. https://www.historicplaces.ca/en/pages/standardsnormes.aspx.

Carr Chantel and Chris Gibson. "Geographies of Making: Rethinking materials and skills for volatile futures." Progress in Human Geography 40.3, Sage: 2016: 297-315.

Carroon, Jean, Sustainable Preservation: Greening existing buildings, Hoboken, N.J.: Wiley, 2010.

Catungal, John Paul, Deborah Leslie, and Yvonne Hill. "Geographies of Displacement in the Creative City: The case of Liberty Village." Toronto, Urban Studies 46.5/6 (2009) 1095-1114. http://www.jstor.com/stable/43198016 (accessed: 2020-10-07).

CBC News, New program teaches restoration of heritage buildings in Quebec, CBC News, Montreal, 2021. https://www.cbc.ca/news/canada/montreal/new-programteaches-restoration-of-heritage-buildings-in-quebec-1.5843400 (accessed: 2021-01-07). 
City of Toronto, Creative Capital Gains: An action plan for the City of Toronto. Toronto, ON: 2011. https://www.toronto.ca/wp-content/uploads/2017/08/968d-creative-capitalgains-report-august9.pdf (accessed: 2020-10-07).

City of Toronto, Implementation Guidelines for Section 37 of the Planning Act and Protocol for Negotiating Section 37 Community Benefits. Toronto, ON: 2016. www.toronto.ca/section37 (accessed: 2020-10-07).

City of Toronto, King-Spadina Cultural Spaces Retention Study: Strengthening the creative economy in Toronto's Downtown Core. By R.E. Millward and Associates LTD. Toronto, ON: 2017. https://www.toronto.ca/wp-content/uploads/2017/10/90a0-CityPlanning-TOcore-REM Cultural-Spaces.pdf (accessed: 2020-06-10).

City of Toronto. City of Toronto Official Plan Indicators. Toronto, ON: 2018. https://www.toronto.ca/wp-content/uploads/2018/12/84a1CityPlanning OfficialPlanlndictors 2018 AODA.pdf (accessed: 2020-10-07).

City of Toronto, Making Space for Culture: Community consultation summaries. Toronto, ON: 2014. https://www.toronto.ca/legdocs/mmis/2014/ed/bgrd/backgroundfile-69273.pdf (accessed: 2020-10-07).

City of Toronto, Section 37: An essential tool for building healthier neighbourhoods. Toronto, ON: 2014. www.toronto.ca/section37 (accessed: 2020-10-07).

City of Toronto, Toronto Housing Market Analysis: From insight to action. Toronto, ON: 2019. https://www.toronto.ca/legdocs/mmis/2019/ph/bgrd/backgroundfile-140633.pdf (accessed: 2020-09-15). 
City of Toronto, Toronto Music Strategy: Supporting and growing the city's music sector. Toronto, ON: 2016. https://www.toronto.ca/legdocs/mmis/2016/ed/bgrd/backgroundfile90615.pdf (2020-10-07).

City of Toronto. Toronto Official Plan. Toronto, ON: 2019. https://www.toronto.ca/wpcontent/uploads/2019/06/8f06-OfficialPlanAODA Compiled-3.0.pdf (accessed: 2020-12$07)$.

City of Toronto, Trends, Issues, Intensification: Downtown Toronto. Toronto, ON: 2014. https://www.toronto.ca/legdocs/mmis/2014/te/bgrd/backgroundfile-69192.pdf (accessed: 2020-10-07).

Cultural Human Resources Council, Human Resources in Canada's Built Heritage Sector: Mapping the workforce and setting strategic priorities, 2004. https://www.historicplaces.ca/media/5689/built heritage en.pdf.

Deamer, Peggy. Architecture and Labor. (New York: Routledge, 2020.)

Deamer, Peggy. "Architectural Production and Consumption: Architectural Work in the Capitalist Context." Architecture and Labor. (New York: Routledge, 2020.)

DeMunck, Bert. "Artisans as Knowledge Workers: Craft and creativity in a long-term perspective." Geoforum. 99. (2019) 227-237.

Djabarouti, Johnathan and Christopher O'Flaherty. "Architect and Craftsperson: Project perceptions, relationships and craft." The International Journal of Architectural Research 14.3 (2020): 423-438. https://doi.org/10.1108/ARCH-01-2020-0010. 
Djabarouti, Jonathan. Conservation Education: Examining the Impact of a pedagogic interface between the practical and theoretical aspects of building conservation. Master's Thesis, University of Central Lancashire, 2018.

Federal Provinicial Territorial Historic Places Collaboration, Building Resilience: Practical Guidelines for the sustainable rehabilitation of buildings in Canada, 2016.

Florida, Richard. Cities and the Creative Class. (New York: Routledge, 2005).

Fram, Mark. Well-Preserved : the Ontario Heritage Foundation's Manual of Principles and Practice for Architectural Conservation 3rd rev. ed. Erin, ON: Boston Mills Press, 2003.

Fox-Miller, Chloe. « 'Glorified Janitors': Creativity, cachet, and everyday experiences of work in Protland Oregon's Craft Brewing Sector." Geoforum. 106 (2019) 78-86.

General Manager, Economic Development and Culture. Supporting the Growth of Toronto's Fashion Sector. Report for Action, City of Toronto, 2017.

Gunn, Cynthia, et al. Human Resources in the Preservation of Heritage Buildings. Research Report. (Ottawa: Heritage Canada Foundation, 2003).

Government of Ontario. Strengthening Ontario's Heritage: Identify, Protect, Promote. 2005. https://www.publications.gov.on.ca/strengthening-ontarios-heritage-identifyprotect-promote-an-introductory-guide-to-identifying-protecting-and-promoting-theheritage-of-our-communities (accessed: 2020-10-06).

Greenberg, Ken. Toronto Reborn. Dundurn Press: 2018. 
Hayes, J. et al. "Digitally-Assisted Stone Carving of a Relief Sculpture for the Parliament Buildings National Historic Site of Canada." ISPRS Annals of the photogrammetry remote sensing and spatial information sciences. II-5/W3. 5 (2015) 97-103.

Heritage Canada Foundation, Human Resource Issues in the Preservation of Heritage Buildings. 2004.

https://archive.nationaltrustcanada.ca/sites/heritagecanada.org/files/HumanResourcesls suesPreservation.pdf.

Heritage Preservation Services, City of Toronto, Heritage Conservation Districts in Toronto: Procedures, Policies and Terms of Reference. By Barrett Scott et al. Toronto, ON: 2012. https://www.toronto.ca/legdocs/mmis/2012/pg/bgrd/backgroundfile-44992.pdf (accessed: 2020-10-07).

Heritage Toronto, Changing the Narrative: State of heritage report. Toronto, ON: 2019. http://www.heritagetoronto.org/wpcontent/uploads/PDFs/SOH Reports/State of Heritage Report 2019.pdf (accessed: 2020-10-29).

Hill, P. R. and J. C. E. David, Practical Stone Masonry. (Wimbledon: Donhead Publishing, 1995).

Hill, Robert G., Biographical Dictionary of Architects in Canada 1800-1950, online resource Retrieved from Dictionary of Architects in Canada Website: http://www.dictionaryofarchitectsincanada.org/. 
House of Commons, Committee on Environment and Sustainable Development. Preserving Canada's Heritage: The Foundation for Tomorrow. 2017.

Huuhka, S., \& Vestergaard, I. (2019). "Building Conservation and the Circular Economy: A Theoretical Consideration," Journal of Cultural Heritage Management and Sustainable Development, 10(1), 29-40. https://doi.org/10.1108/JCHMSD-06-2019-0081.

ICOMOS National Committees of the Americas. The Declaration of San Antonio, 1996. Retrieved from the ICOMOS website: https://www.icomos.org/en/charters-and-texts/179articles-en-francais/ressources/charters-and-standards/188-the-declaration-of-sanantonio.

Larsen, Knut Einar, and Nils Marstein. "Conservation of Historic Timber Structures: An ecological approach." Series in Conservation and Museology. Oslo, 2016.

Marchand, Trevor. "The Pursuit of Pleasurable Work: craftwork in $21^{\text {st }}$ century England." RAI Research Webinar: Trevor Marchand. 4 February 2021.

Marchand, Trevor and Hugh James. The Mason's of Djenné. (Indianna University Press, 2009).

Martin Prosperity Institute et al. From the Ground Up: Growing Toronto's cultural sector. City of Toronto, 2011.

Mason, Randall. "Be Interested and Beware: Joining Economic Valuation and Heritage Conservation." The International Journal of Heritage Studies, 14.4 (2008): 303-318. 
Mason, Randall. Economics and Historic Preservation: A guide and review of the literature. The Brookings Institute: 2005.

Matthews, Vanessa Kristy. "Incoherence and Tension in Culture-Led Redevelopment." International Journal of Urban and Regional Research 38.3 (2014) 1019-1036.

Matthews, Vanessa Kristy. Place Differentiation: Redeveloping the Distillery District, Toronto. PhD Dissertation. University of Toronto department of Geography. Proquest Dissertations Publishing. 2010.

Ministry of Culture and Communications. A strategy for conserving Ontario's heritage, 1990. https://books.scholarsportal.info/en/read?id=/ebooks/ebooks2/ogdc/2013-0719/2/109250 (accessed: 2020-10-06).

Moore, Aaron A., "Trading Density for Benefits: Section 37 agreements in Toronto." IMFG Perspectives 2 (2013). https://munkschool.utoronto.ca/imfg/uploads/221/imfg perspectives moore \%28feb 2013\%29.pdf (accessed: 2020-10-07)

Nordicity, Re:Venues: A Case and Path Forward for Toronto's Live Music industry. Toronto, Canadian Live Music Association, 2020.

Osbaldeston, Mark. "The Origins of Heritage Preservation Law in Ontario." ACORN: The Journal of the Architectural Conservancy of Ontario. 29.4 (2005) 7-10.

Pajot, Robert, Building Strength - Heritage Trades in Canada, National Trust for Canada - Stories, 2020. https://nationaltrustcanada.ca/online-stories/building-strength-heritagetrades-in-canada (accessed: 2020-10-06). 
Parks Canada, "Directory of Federal Heritage Designations," Government of Canada (2021) website. https://www.pc.gc.ca/en/culture/dfhd (accessed: 2021-04-30]

Ross, Susan M. "Re-Evaluating Heritage Waste: Sustaining Material Values through Deconstruction and Reuse." The Historic Environment: Policy and Practice 11.2-3 (2020): 382-408.

Ross, Susan and Victoria Angel, "Heritage and Waste." Journal of Cultural Management and Sustainable Development 10.1 (2020).

Rypkema, Donovan, Randall Mason, and Caroline Cheong. Measuring Economic Impacts of Historic Preservation: A report to the advisory Council on Historic Preservation. The Advisory Council on Historic Preservation (2011).

Schneider, Dan. "What to Make of Bill 108." OHA+M (Ontario Heritage Resource Centre, University of Waterloo: 2019). https://uwaterloo.ca/heritage-resourcescentre/blog/post/what-make-bill-108 (accessed: 2021-01-19)

Sennett, Richard. The Craftsman. (New Haven: Yale University Press, 2008).

Shipley, Robert, Steve Utz, and Michael Parsons. "Does Adaptive Reuse Pay? A study of the business of building rehabilitation in Ontario Canada." The International Journal of Heritage Studies, 12.6 (2006) 505-520. http://dx.doi.org/10.1080/13527250600940181 (accessed: 2020-10-06).

Shipley, Robert and M. Snyder, "The role of heritage conservation districts in achieving community economic goals." The International Journal of Heritage Studies, 19.3 (2013) 304-321. http://dx.doi.org/10.1080/13527258.2012.660886 (accessed: 2020-09-07). 
Shipley, Robert, Kayla Jonas, and Jason F. Kovacs. "Heritage Conservation Districts Work: Evidence from the Province of Ontario, Canada." The Urban Affairs Review, 47.5 (Sage: 2011) 611-641. https://doi.org/10.1177/1078087411400559 (accessed: 202010-05).

Shipley, Robert and Karen Reyburn. "Lost Heritage: a survey of historic building demolitions in Ontario, Canada." The International Journal of Heritage Studies 9.2 (Routledge: 2003) 151-168. https://doi.org/10.1080/1352725032000085278 (accessed: 2020-11-12).

Shipley, Robert. "Heritage Designation and Property Values: Is there an effect?" In The International Journal of Heritage Studies, 6.1 (Routledge: 2000).

Toronto Film, Television and Digital Media Board, Spotlight on Toronto: A strategic action plan for the film, television and digital media industry, Toronto, ON: 2017. https://www.toronto.ca/wp-content/uploads/2017/11/972e-spotlight-on-toronto-filmstrategy-2017.pdf (accessed: 2020-10-08).

Toronto Music Advisory Council. Toronto Music Strategy: Supporting and growing the City's music sector. City of Toronto, 2020.

Toronto Workforce Innovation Group. Constructing Toronto. (2015).

Van Balen, Koen, and Aziliz Vandesande. "Innovative built heritage models based on preventive and systemic approaches." Innovative Built Heritage Models ed. Van Balen and Vandesande, Taylor and Francis (London: 2018). 


\section{Part II: Design Project}

Vital Traditions: Heritage Trades in Toronto's Conservation Sector Luke McElcheran

Supervisor: Prof. Mario Santana

Master of Architecture, 2021 


\section{Contents}

A Proposal for Heritage Documentation at Wychwood Library, Toronto 4

Precedents $\quad \mathbf{5}$

$\begin{array}{ll}\text { Carlisle Cathedral Addition } & 7\end{array}$

Nithurst Farm 9

15 Clerkenwell Close 11

Site Documentation $\quad 12$

Project Site Heritage Context Plan 13

West Context Elevation - Bathurst Street $\quad 14$

EAst Context Elevation - Wells Hill Avenue 15

South Context Elevation - Melgund Road 16

1915: Original Eden Smith Library 17

West Bathurst Street Elevation 18

$\begin{array}{lr}\text { East Melgund Road Elevation } & 19\end{array}$

North Elevation 20

South Melgund Road Elevation 21

Section Through Tudor Styled Window with Stone Surround 23

Section Through Roof At Wall showing Timber Frame Bearing on Brick Masonry 25

Section Through Stone Fireplace and Brick Chimney 27

1978: Philip Carter Addition $\quad 28$

West Bathurst Street Elevation $\quad 29$

East Wells Hill Avenue Elevation $\quad 30$

North Elevation

South Melgund Road Elevation $\quad 32$

Section Through Casement Window in Brick on CMU Cavity Wall 34

Section Through Roof At Wall

Section Through Forced Air Heating Ducts Over Drop Ceiling 38

2020: SZA Addition $\quad 39$

West Bathurst Street Elevation $\quad 40$

East Wells Hill Avenue Elevation $\quad 41$

North Elevation $\quad 42$

South Melgund Road Elevation 43

Section Through Curtain Wall Window in Light Gauge Steel Frame 45

Section Through Roof At Wall 47

Section Through Forced Air Heating Ducts in Bulkhead 49

Speculative Proposal for Compatible Design Based on The Study of Heritage Details $\mathbf{5 0}$

Speculative Mass Masonry Aperture $\quad 52$

Section Through Roof At Wall

Cutaway Section Through Thermal Mass Column 56 


\section{A Proposal for Heritage Documentation at Wychwood Library, Toronto}

Standards for documentation reflect the ways that we see heritage value. The following drawings contrast conventional techniques focused on heritage elevations with an imagined methodology focused on details that would locate value in built assemblies rather than visual qualities. This is in direct opposition to some current trends, notably the tendency to allocate funding to heritage based on perceived economic value stemming from public, visual experiences, and the corresponding rise of digital tools that measure and represent infinitely thin exterior surfaces with better and better accuracy.

The resulting details are not the result of documentation on site. They are imaginary, approximate, and speculative, based on the best research availble into standard practices of their time. Executing such a methodology in practice would require a truly collaborative approach engaging heritage professionals versed in the regulatory structure and value theory of heritage and tradespeople with the knowledge to sensitively intervene on existing structures and to read the techniques implied in their assemblies.

“The 'details' of architecture shift attention away from the architectural object and focus it instead on its maker, the subject. Unlike composition, spatial sequence, or structure, which can be read as inherent in the object's own logic, details, even conceptually, don't make themsleves."

Deamer, "Craft and Design 'Detail: The subject of the object."' Architecture and Labor. (New York: Routledge, 2020) 9. 


\section{Precedents}

The following built precedents are representative of contemporary design that engages traditional building craft to achieve contemporary goals related both to built heritage and to contemporary design and material sustainability.

Feilden Fowles' addition to Carlisle Cathedral employed the work of the same masonry contractors for the restoration of a 19th century arched doorway and for the self-supporting stone shell of the new contemporary addition.

Adam Richards' Nithurst Farm uses an external brick masonry shell to express continuity with its context while taking a radically contemporary approach to massing and proportion.

15 Clerkenwell Close is a material experiment in the structural potential of stone. It is now the subject of an exhibition, The New Stone Age, and a proof of concept for the use of structural stonemasonry as an ecologically superior and cost competitive alternative to concrete construction.

These projects challenge the idea that certain trades skills and building techniques belong to heritage properties and are not appropriate for new interventions. They show that innovative design can produce contemporary solutions in partnership with the traditional trades skills that are needed to maintain existing heritage structures. 


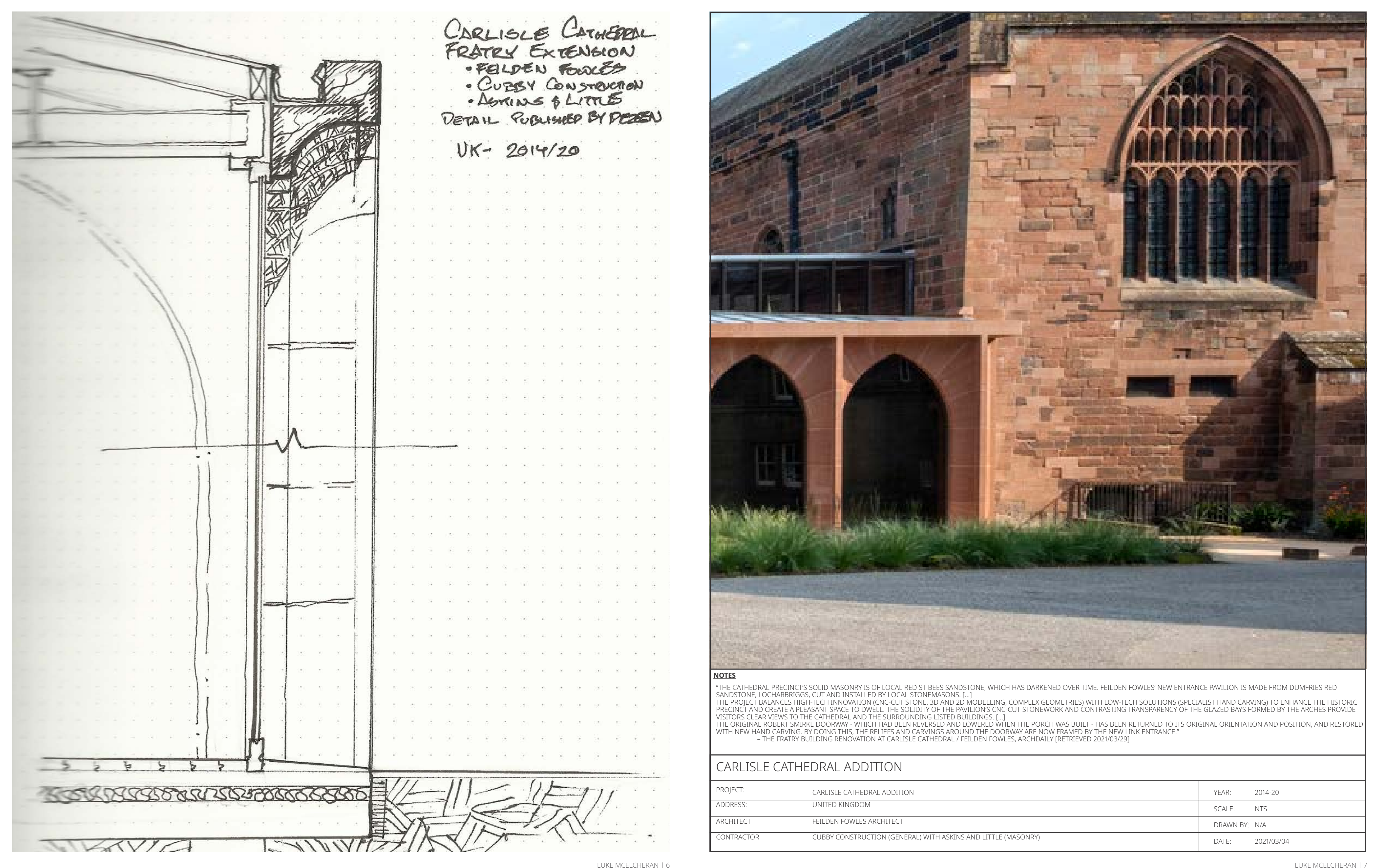




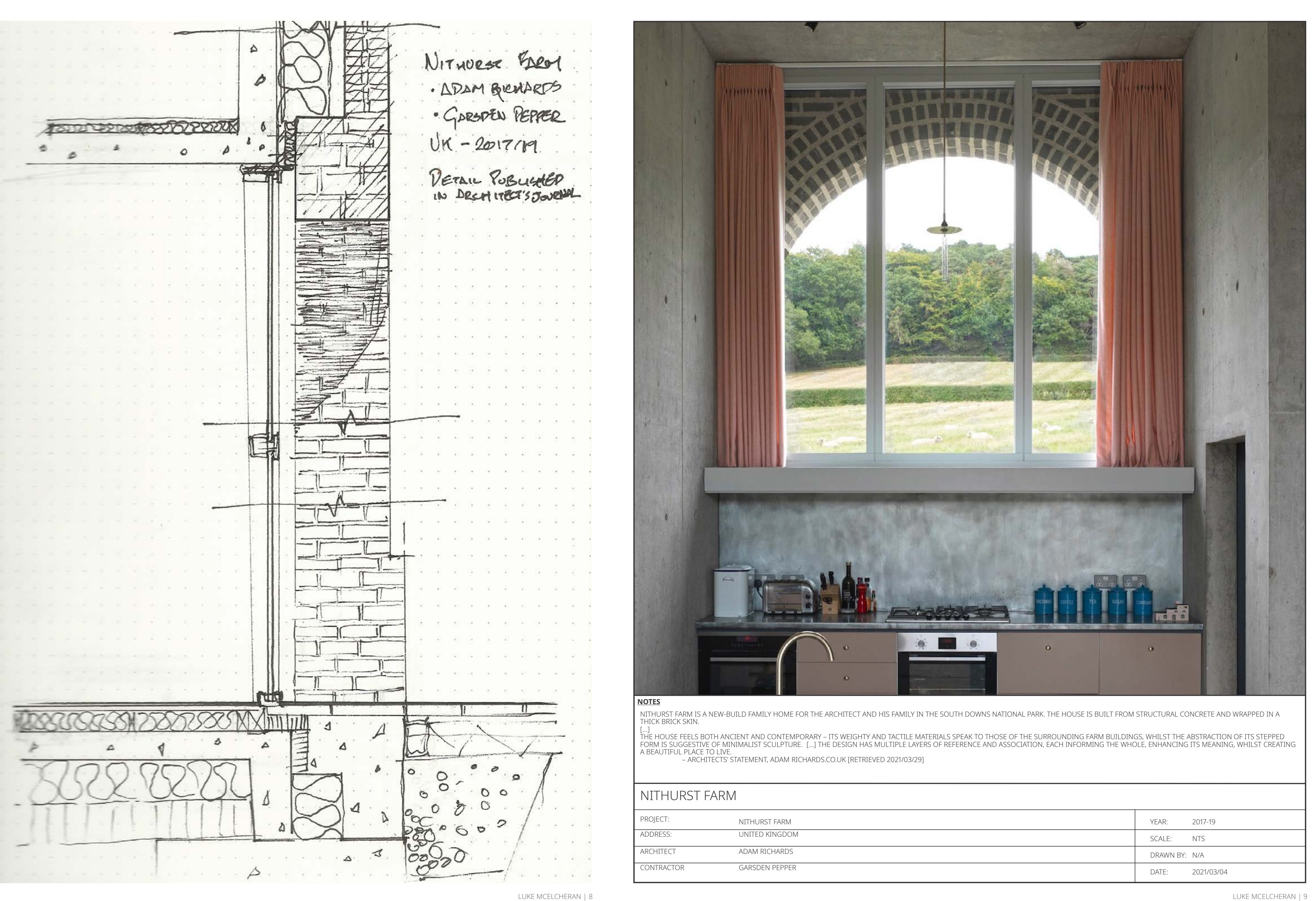



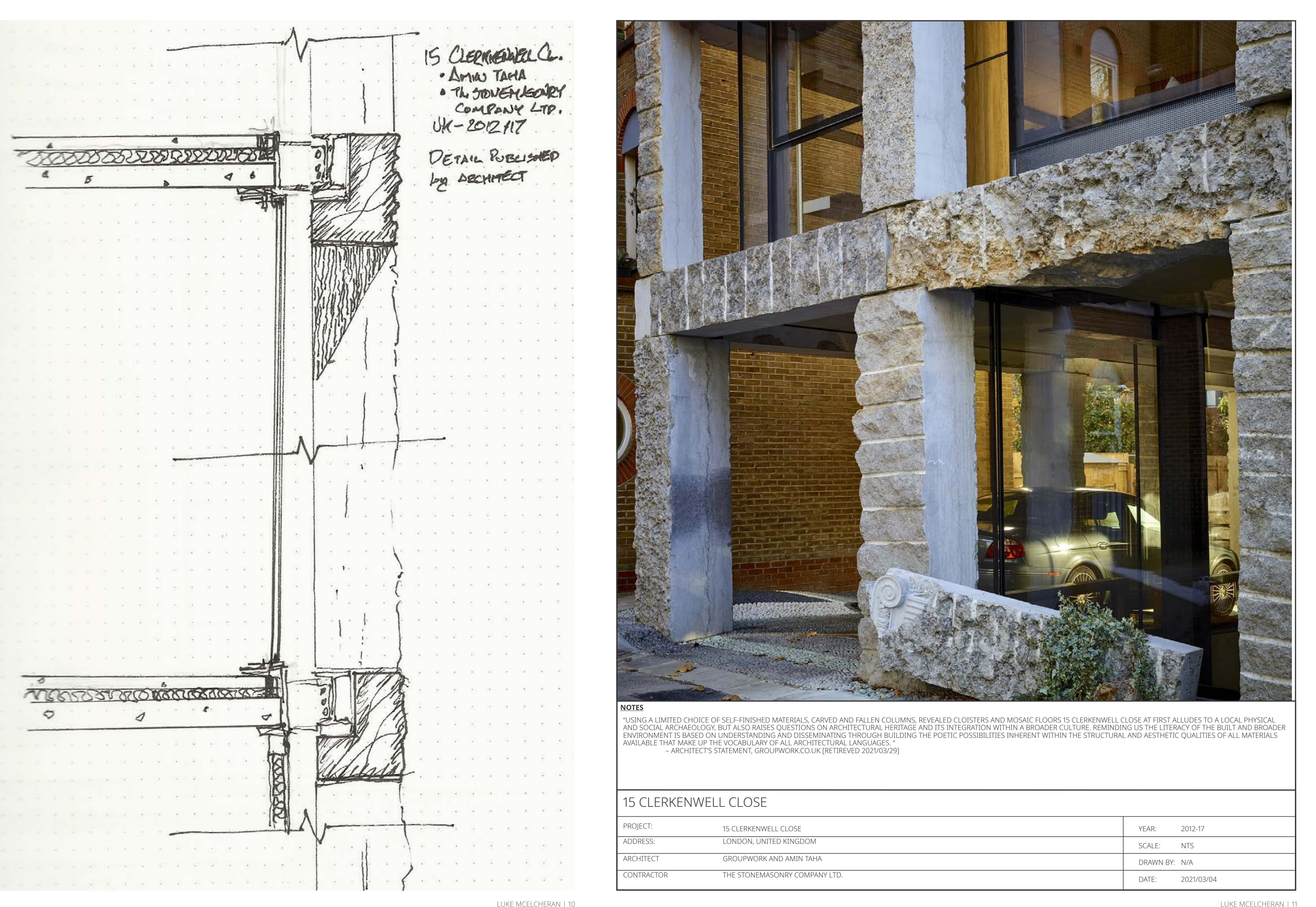


\section{Site Documentation}

This project proposes a methodology for an imagined future intervention on the site of the Wychwood Library, a heritage designated structure in Toronto. It is situated near the crossing point of two densifying 'avenues' and adjacent to two new heritage conservation districts. The following drawings establish the significance of the site in terms of Toronto's heritage and planning goals, in particular, heritage adjacency, the relationship between stable residential areas and intensifying growth areas, and appropriate transition in scale. It expresses the tensions playing out in the connection between heritage work and market driven development that is created by the financial tools available to the conservation sector and their underlying economic logic.

"To the extent that economics recognizes civic or social virtues, it generally assumes that price incentives complement, or reinforce, the intrinsic values which already encourage that behavior. It doesn't anticipate that intrinsic and monetary incentives are at best substitutes and that there are circumstances where commodifying the social space, putting a price on values, can corrode those values." (146)

"[Neoclassical economist Milton] Friedman only implicitly and tragically acknowledges the importance of [...] moral sentiments when observing that a company might devote resources to provide amenities to its community (in expectation of returns on attracting employees), and that it could engage in 'hypocritical window dressing' by calling this social responsibility, lest it 'harm the foundations of free society' to admit that this 'fraud' was all in the pursuit of profit alone. This is how corrosion happens and did happen in the ensuing decades." (396)

Mark Carney, "Value(s)," (Toronto: McClelland \& Stewart, 2021). 


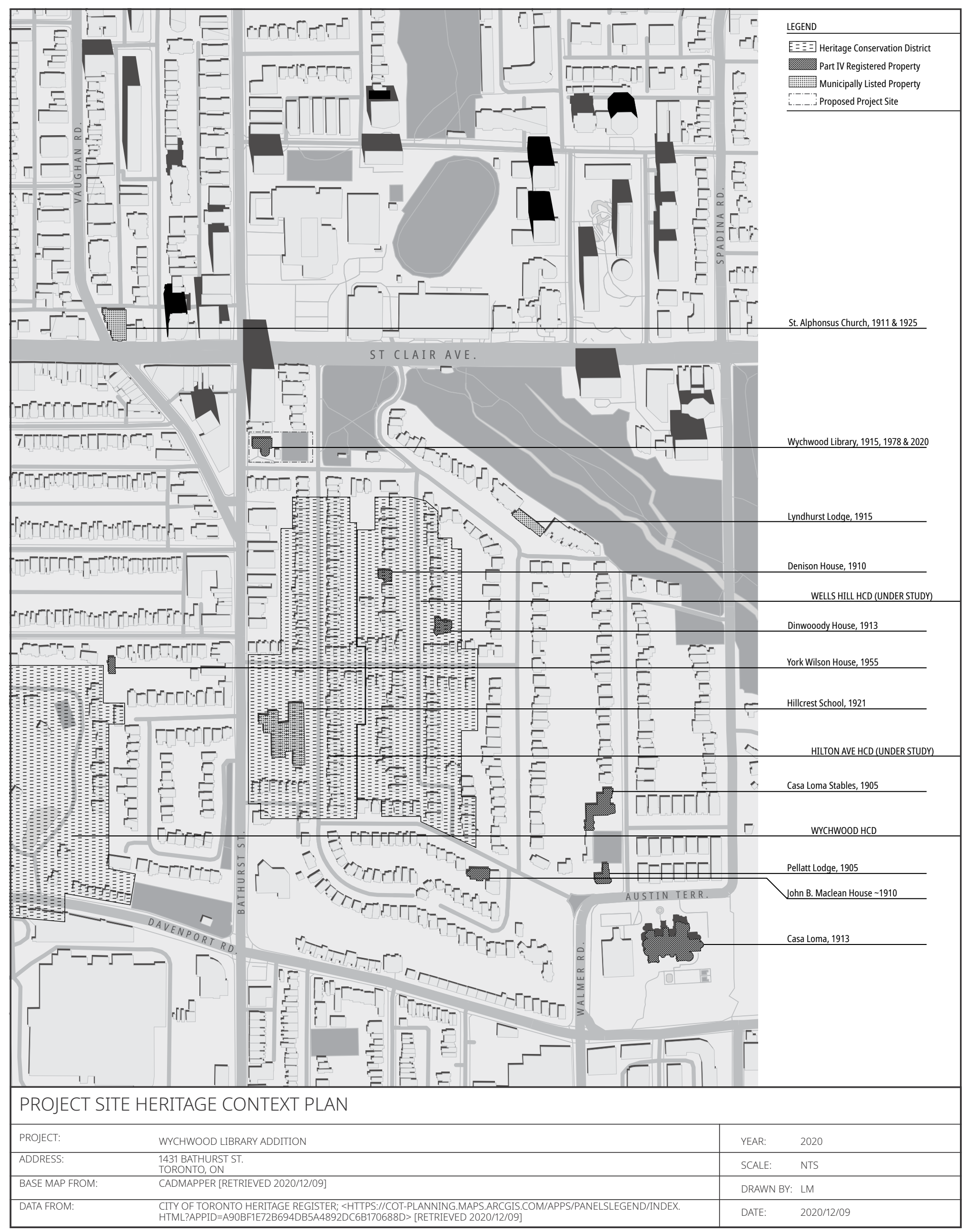



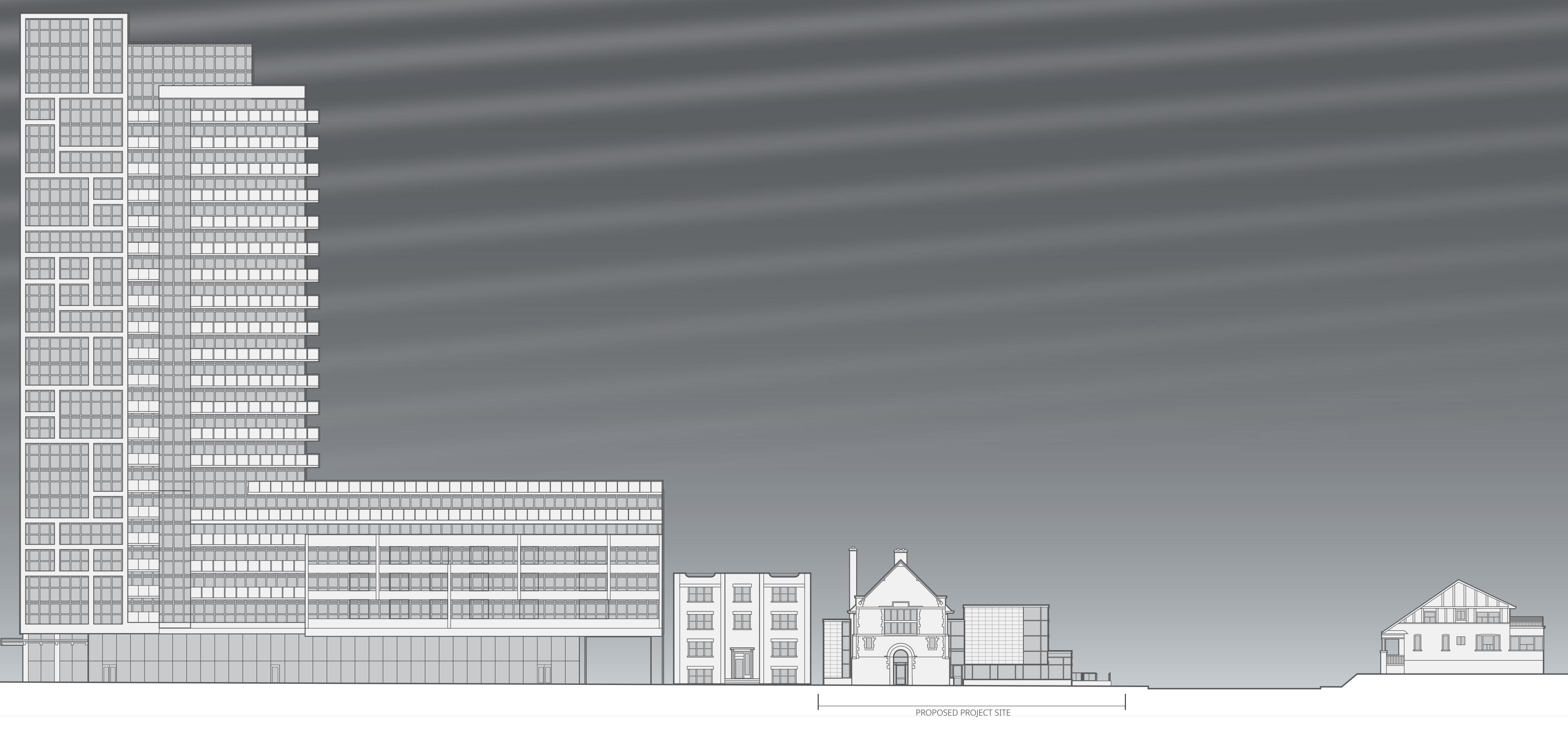

Toronto is far from perfect (or perfectible). Constantly under construction, it feels eclectic, ad hoc, and 'accidental,' not orderly or formally grand, although it has its special places. It is certainly not conventionally beautiful in an ordered, composed way. It has a kind of homely frontier roughness - exterior hydro poles and streets hung with wires, buildings of all sizes
and shapes cohabiting streets - but it is incredibly robust and energetic. It embraces modernity and struggles to retain its heritage, but the most interesting places occur where styles mix and overlap in eclectic combination.
- Ken Greenberg, Toronto Reborn, Toronto: Dundurn Press, 2019.

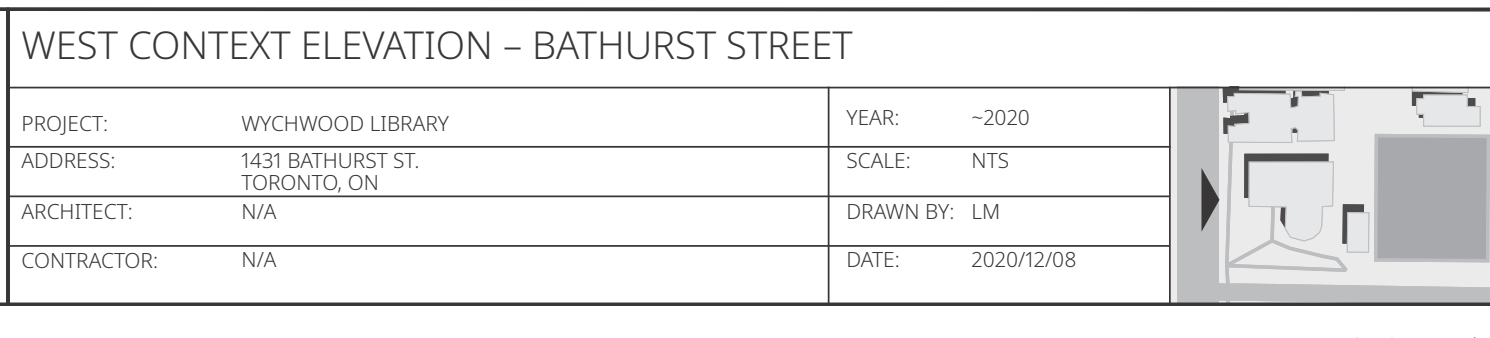




\begin{tabular}{|c|c|c|c|c|c|}
\hline \multicolumn{6}{|c|}{ EAST CONTEXT ELEVATION - WELLS HILL AVENUE } \\
\hline PROJETT: & WYCHWOOD LIBRARY & & -2020 & \multirow{4}{*}{$\sqrt{\Gamma}$} & \\
\hline ADDRESS: & $\begin{array}{l}1431 \text { BATHURST ST } \\
\text { TORNTO ON }\end{array}$ & SCALI & NTS & & \\
\hline ARCHITECT: & NORANIOOON & \multicolumn{2}{|c|}{ DRAWN BY: LM } & & 1 \\
\hline CONTRACTOR: & N/A & DATE: & $2020 / 12108$ & & \\
\hline
\end{tabular}




\section{5: Original Eden Smith Library}

The original library building was constructed with a Carnegie grant in an Arts and Crafts, English Tudor style. It was the first of three libraries built to the same plan in the city. It served the new adjacent garden suburb communities in the area that are now incoporated into proposed Heritage Conservation Districts. The Architect, Eden Smith, was a prominent Toronto architect whose commitment to the principles of the arts and crafts movement reflected a dedication to craft born out of early experiences as a builder, which he later suppressed in his professional persona, as well as a nostalgia for England and the English vernacular. Research on the building does not currently give any information about the buiders and tradespeople involved in its construction.

Brown, W. Douglas. Eden Smith: Toronto's Arts and Crafts Architect. (Toronto: W. Douglas Brown, 2003.)

Goldsmith, Philip. Heritage Impact Assessment: Wychwood Library, 1433 Bathurst St, Toronto. 16 March 2016. 


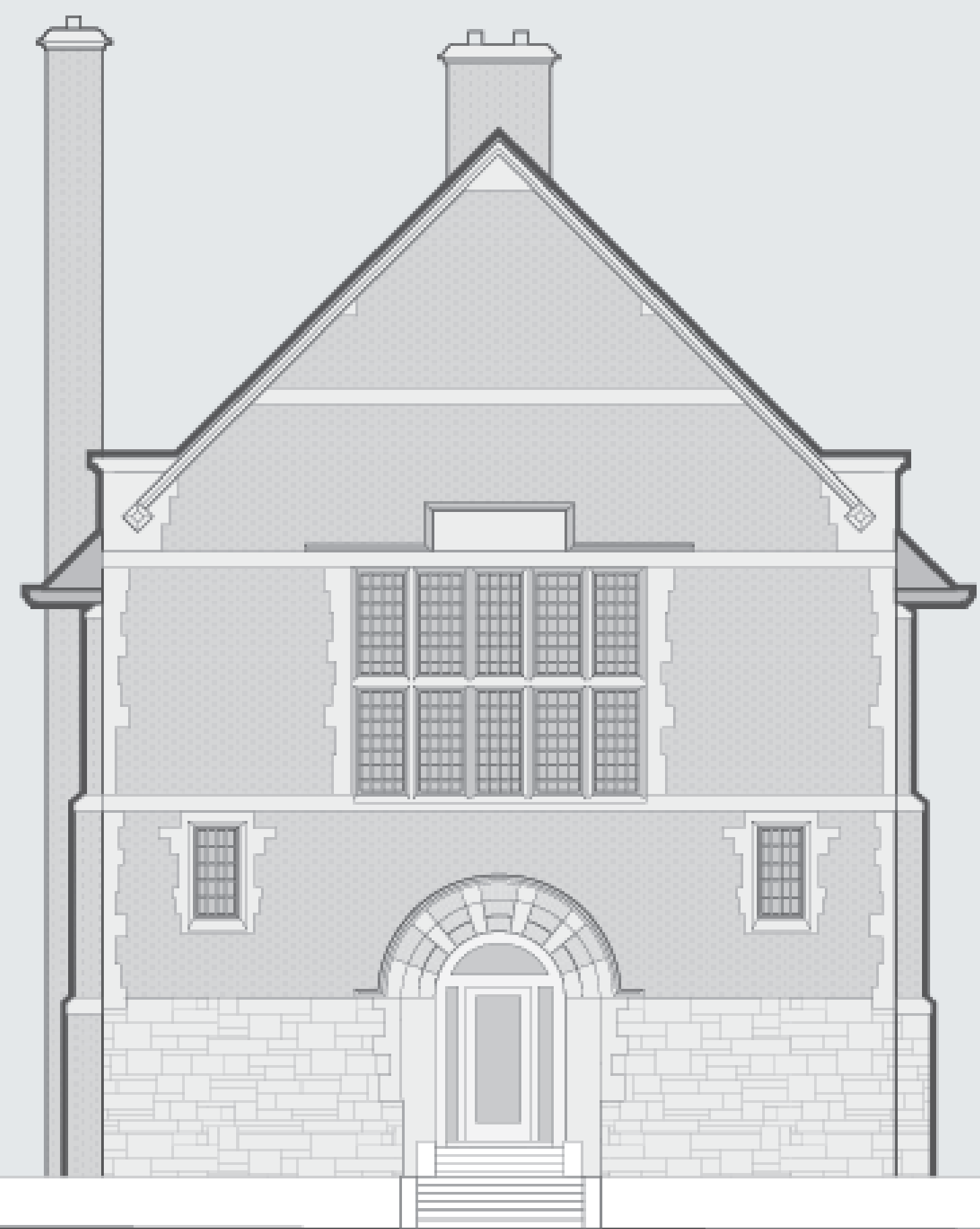

"The Wychwood Library has cultural heritage value as an excellent example of a custom designed library with features of the early-20th century Neo-Gothic style influenced by the
Arts and Crafts Movement with its features drawn from English medieval architecture and traditional craftsmanship. Its design is distinguished by the steeply-pitched gable roof, the stepped buttresses, and the Tudor-styled windows with the stone embellishments, as well as the first floor interior reading room that resembles a medieval Great Hall with its high - City of Toronto By-Law 1367-2017, Schedule A, "Statement of Significance Reasons for Designation 1433 Bathurst Street" (emphasis added)

\begin{tabular}{|c|c|c|c|c|c|}
\hline \multicolumn{6}{|c|}{ WEST BATHURST STREET ELEVATION } \\
\hline PROEET: & WYCHWOOD LBRARY & YEAR: & 1915 & $=$ & 5 \\
\hline ADDRESS: & $\begin{array}{l}1431 \text { BATHURST ST. } \\
\text { TOPONT ON }\end{array}$ & SCALE: & NTS & 1 & \\
\hline ARCHITECT: & EDEN SMITH & DRAWN BY: & LM & 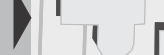 & \\
\hline CONTRACTOR & UNKNOWN & DATE: & $2020 / 1 / 30$ & & \\
\hline
\end{tabular}




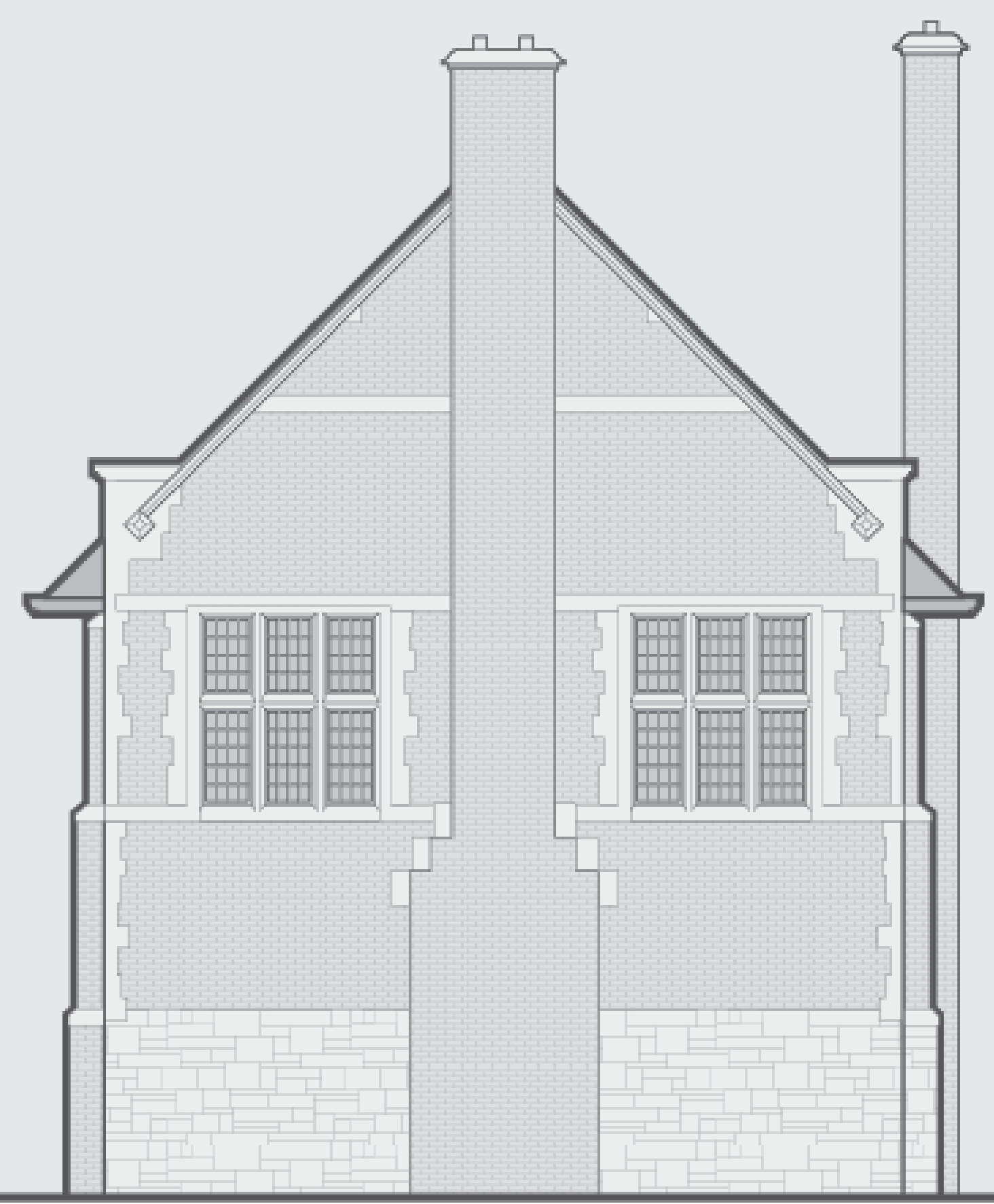

"The Wychwood Library is valued for its historical association with the Toronto Public Library Board [...] [and also] also through its connection to Toronto architect, Eden Smith, who designed the building. Eden Smith was considered Toronto's foremost Arts and Crafts practitioner who was best known for his design of St. Thomas Anglican Church on Huron Street, Conservation District in the city. With his commissions for the Wychwood Library and the near-identical branches for High Park and the Beaches, Eden Smith was the first architect engaged by the Toronto Public Library Board to design a collection of buildings."

\begin{tabular}{|c|c|c|c|c|c|}
\hline \multicolumn{6}{|c|}{ EAST MELGUND ROAD ELEVATION } \\
\hline PROJECT: & WYCHWOOD LIBRARY & YEAR: & 1915 & \multirow{4}{*}{$\sqrt{5:}$} & 5. \\
\hline ADDRESS: & $\begin{array}{l}\text { 1431 BATHURST ST. } \\
\text { TORNTO ON }\end{array}$ & SCALE: & NTS & & \\
\hline ARCHITECT: & EDEN SMITH & DRAWN BY: & LM & & 1 \\
\hline CONTRACTOR: & UNKNOWN & DATE: & $20200 / 1 / 130$ & & \\
\hline
\end{tabular}




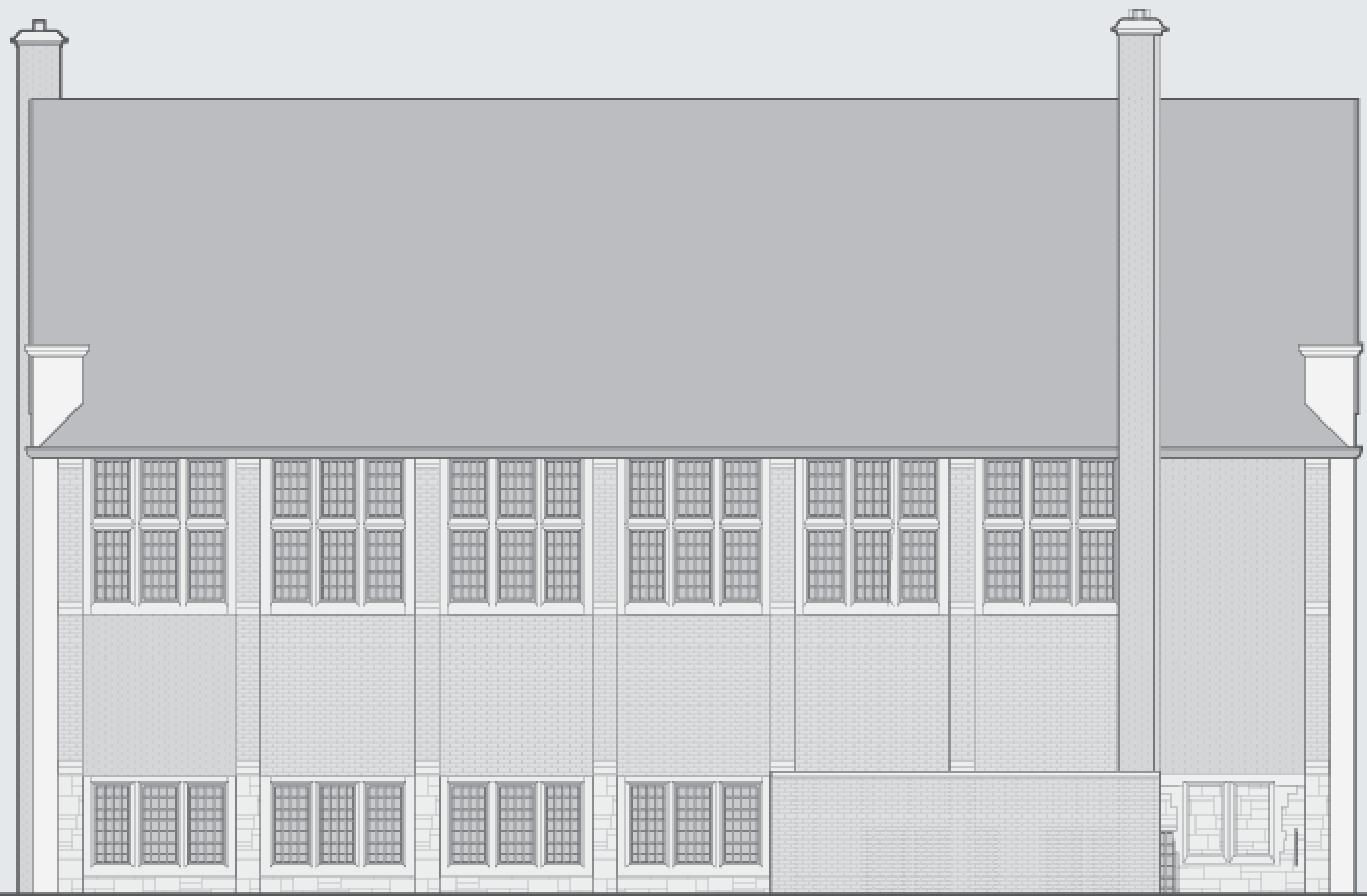

\begin{tabular}{|c|c|c|c|c|}
\hline NORTH & VATION & & & \\
\hline PROJECT: & WYCHWOOD LIBRARY & YEAR: & 1915 & $=$ \\
\hline ADDRESS: & $\begin{array}{l}1431 \text { BATHURST ST. } \\
\text { TOPNTO }\end{array}$ & SCALE: & NTS & - \\
\hline ARCHITECT: & EDEN SMITH & DRAWN BY: & LM & 1 \\
\hline CONTRACTOR: & UNKNOWN & DATE: & $2020 / 11 / 30$ & \\
\hline
\end{tabular}




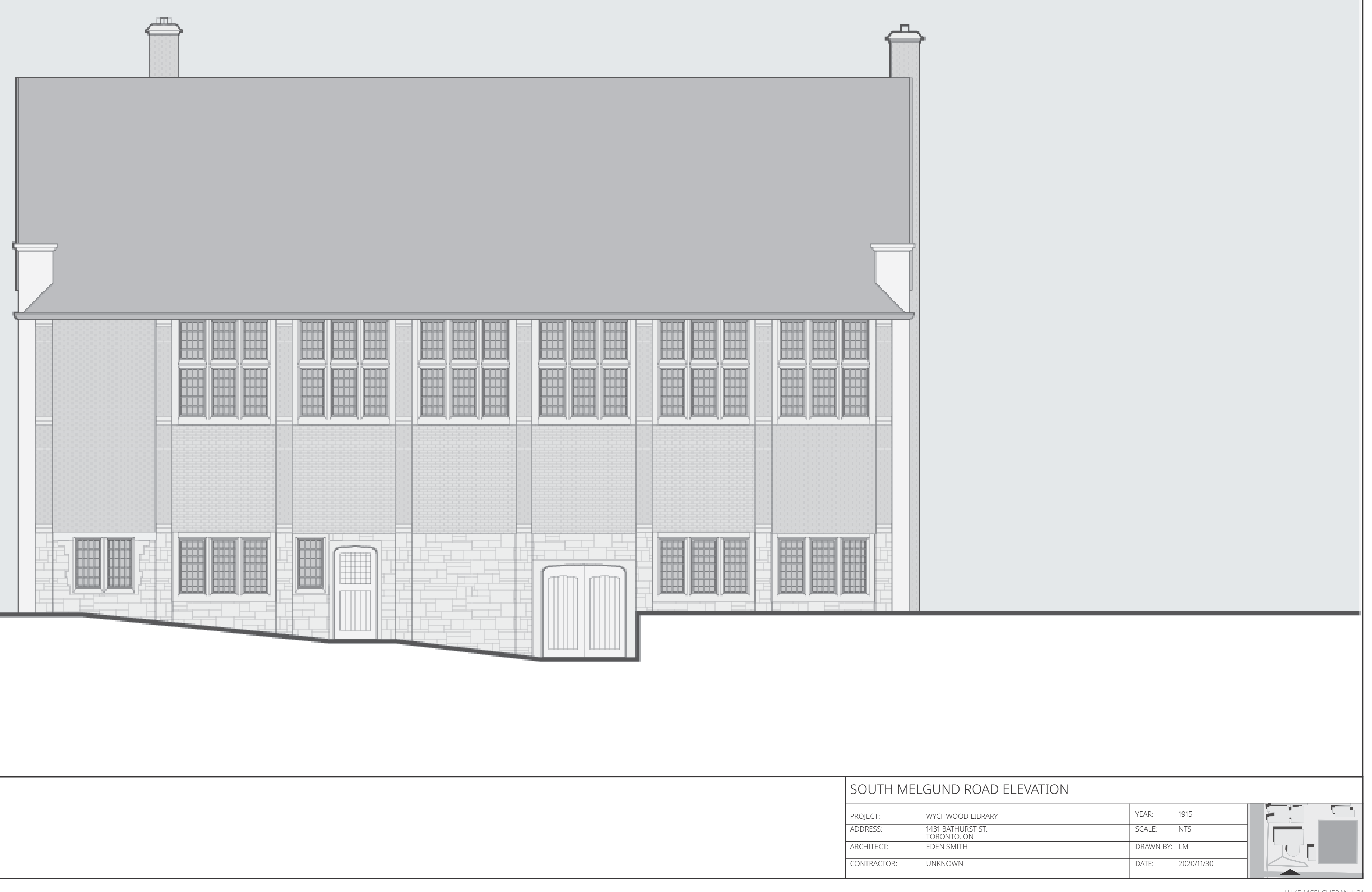




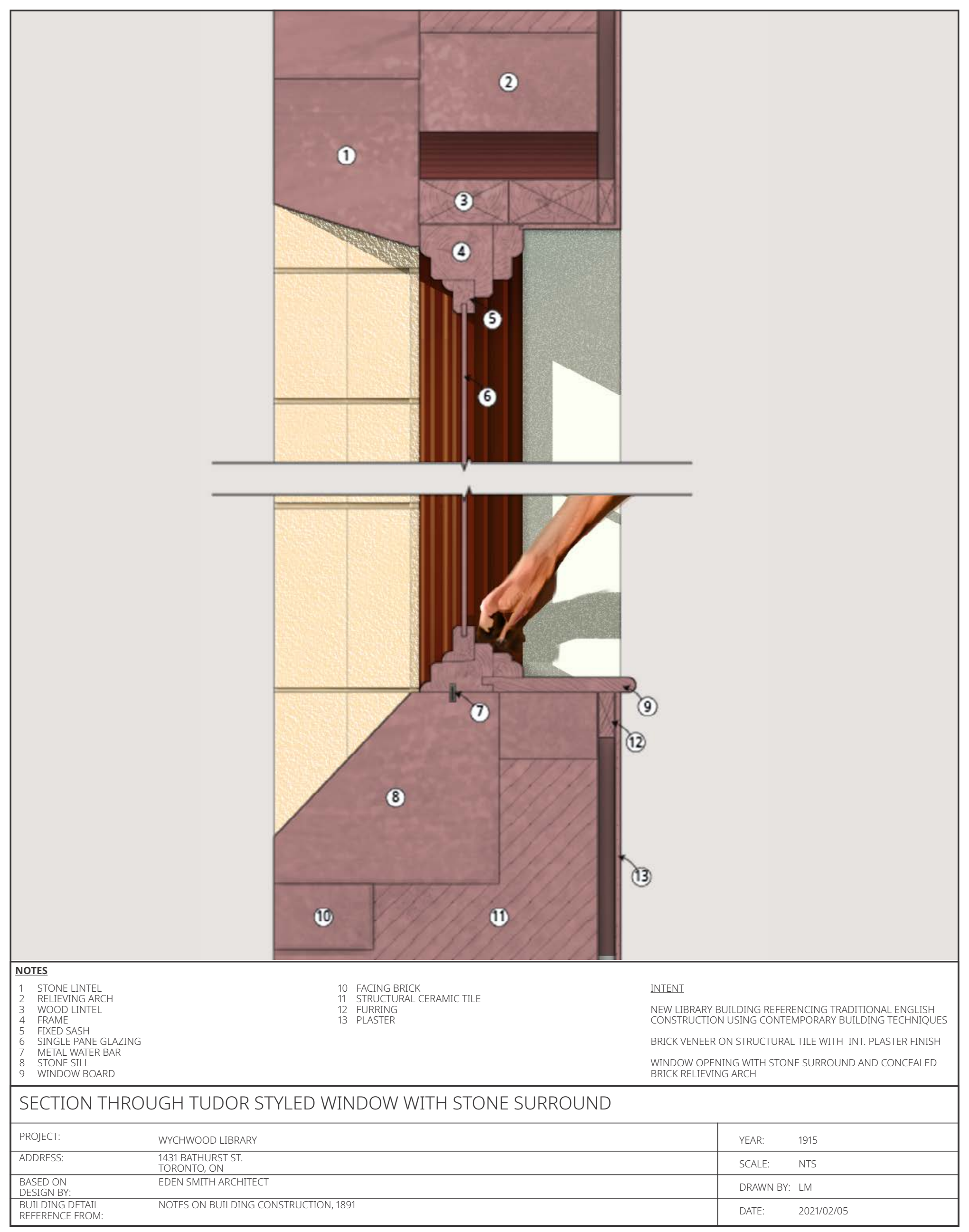




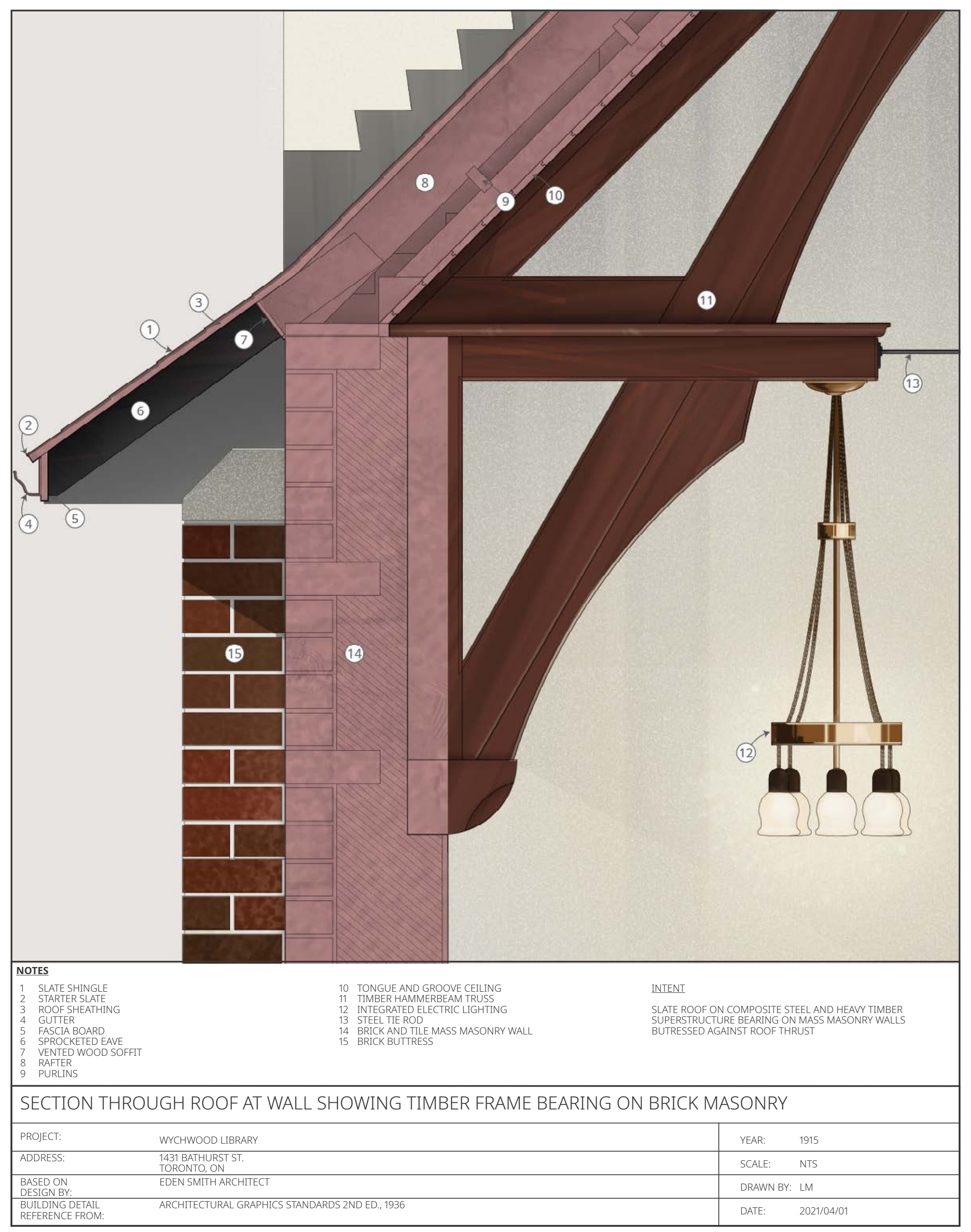




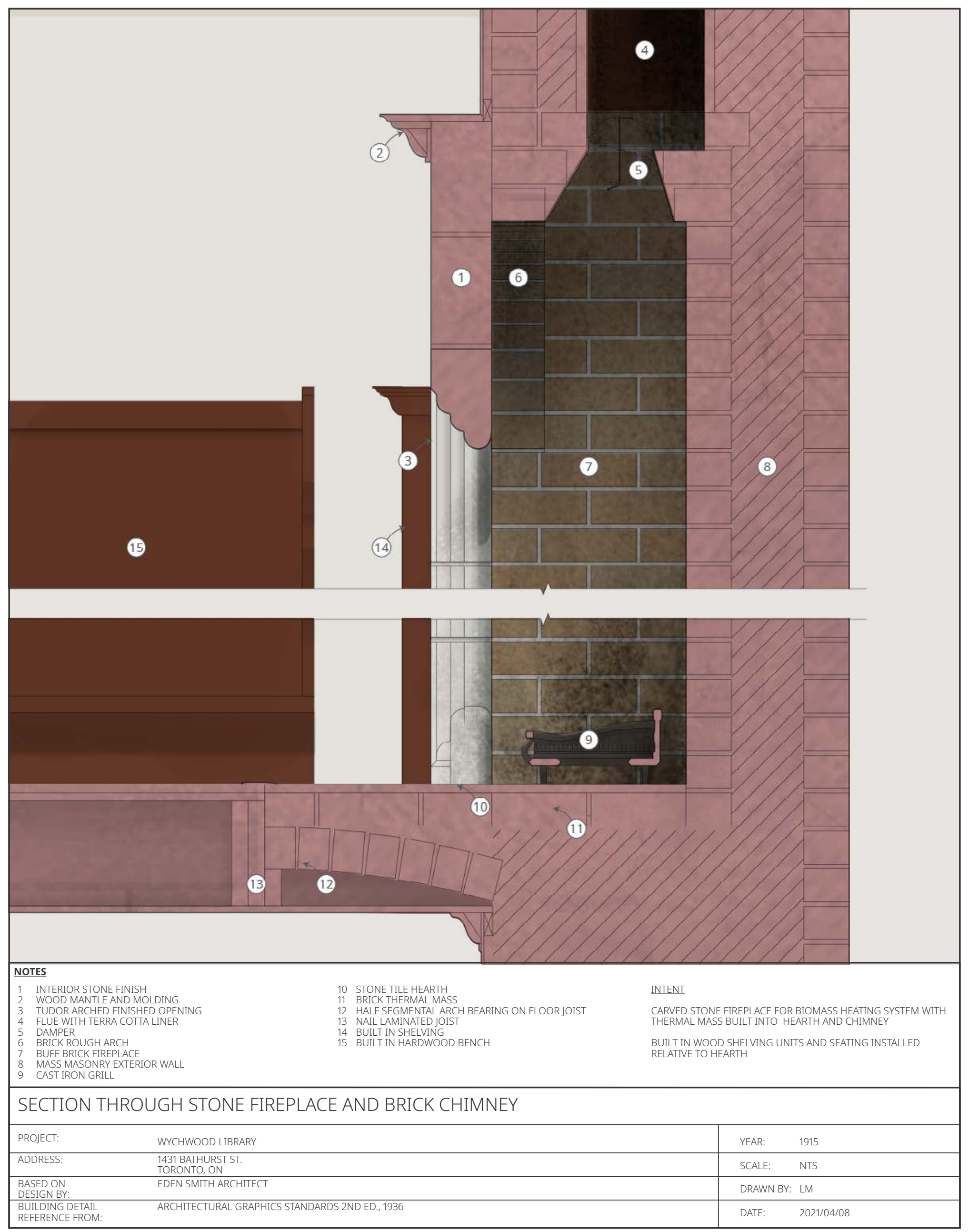




\section{8: Philip Carter Addition}

The 1978 addition to the building is sensitive to the existing building in a way that extends its design logic using contemporary practices and materials and reflects an approach that values overall coherence. This reflects the designers' approach to heritage. The original building was listed on the City's heritage registry in 1976. The project was awarded the 1978 Canadian Architect Award of Excellence. Philip Carter is known for his designs for libraries in Toronto and also designed additions for the other two libraries built to the same Eden Smith Plan as the Wychwood branch. In 2020, he received a lifetime achievement award from the Architectural Conservancy of Ontario, in part for his work on these contextually sensitive library additions. Research on the building does not currently give any information about the buiders and tradespeople involved in its construction.

ACO Heritage Awards, "Philip Carter: Recipient of the 2020 Eric Arthur Lifetime Achievement Award" 2020. < https://acoheritageawards.ca/phillip-carter/>

Carter, "Philip H. Wychwood Library. 1978." <http://www.philliphcarter.ca/index_files/ WychwoodHome.htm>

Toronto Public Library. Carnegie Library: Wychwood. <https://www.torontopubliclibrary. ca/about-the-library/library-history/carnegie-wychwood.jsp> 


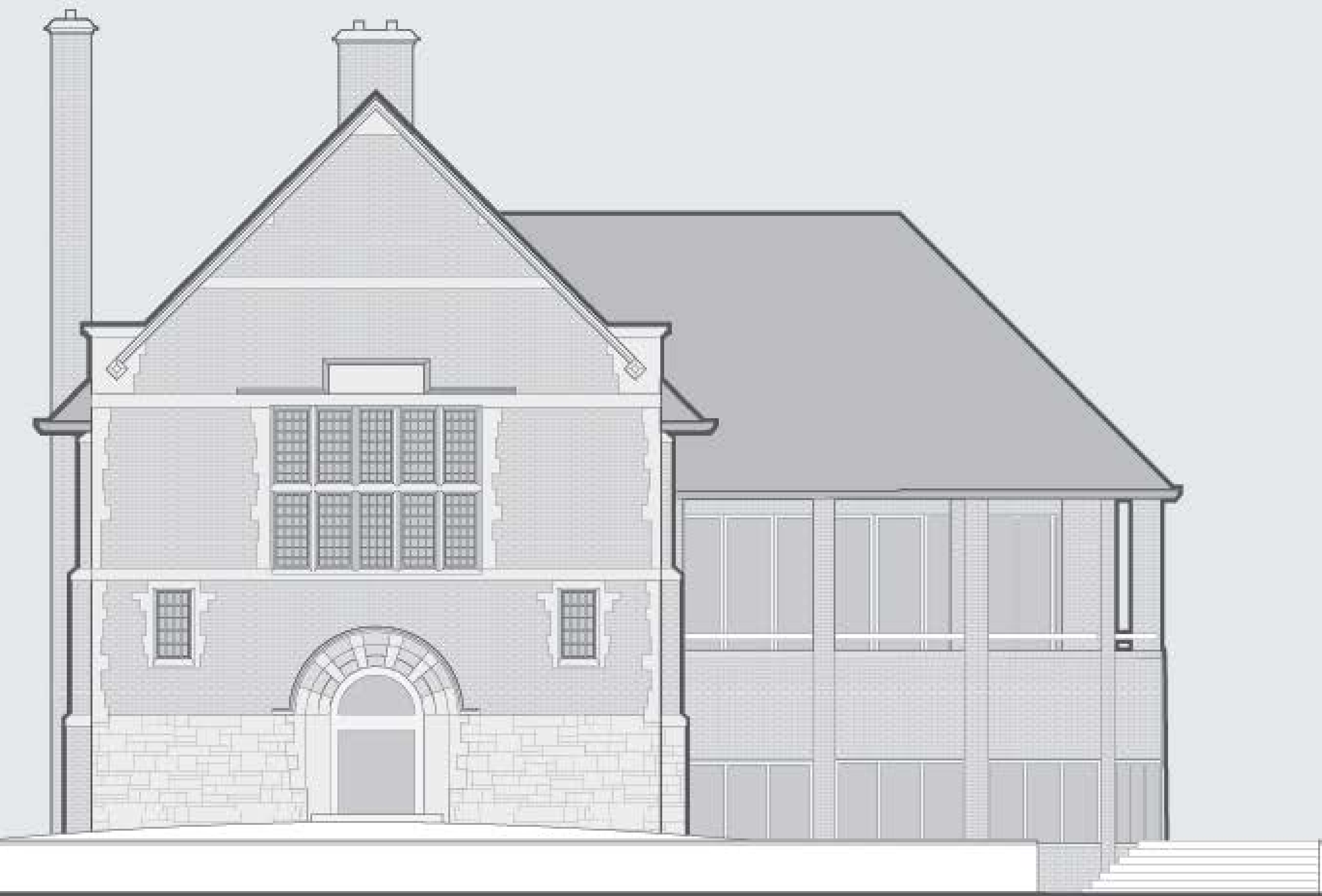

"A substantial addition was made to the building in c.1978. This required the closing of two of the upper windows to the library Hall, the encapsulation of a third where the addition roof WEST BATHURST STREET ELEVATION line meets the historic wall and alteration to the S-W corner at the basement level where a new entrance was created. At the front wall the original doorway was removed and a window inserted in part of the opening above grade with the lower wall closed off and filled in.

"This addition was designed in a period style and with brick and stone materials that blend with and obscure where old wall ends and newer addition begin. I do not consider this addition to be a significant heritage element."
- Philip Goldsmith Architect, "Heritage Impact Assessment: Wychwood Library, 1433 Bathurst Street, Toronto," 16 March, 2016.

\begin{tabular}{|c|c|c|c|c|}
\hline PROJETT: & WCHWWOOD LBBAARY ADDITION & & 1978 & $=$ \\
\hline ADDRESS: & $\begin{array}{l}1431 \text { BATHURST ST. } \\
\text { TORONTO ON }\end{array}$ & SCALE: & NTS & \\
\hline ARCHITECT: & $\begin{array}{l}\text { PHILIP CARTER } \\
\end{array}$ & DRAWN BY: & LM & 1 \\
\hline CONTRACTOR: & UNKNOWN & \begin{tabular}{|l|l|} 
DATE: \\
\end{tabular} & $20201 / 1 / 30$ & \\
\hline
\end{tabular}




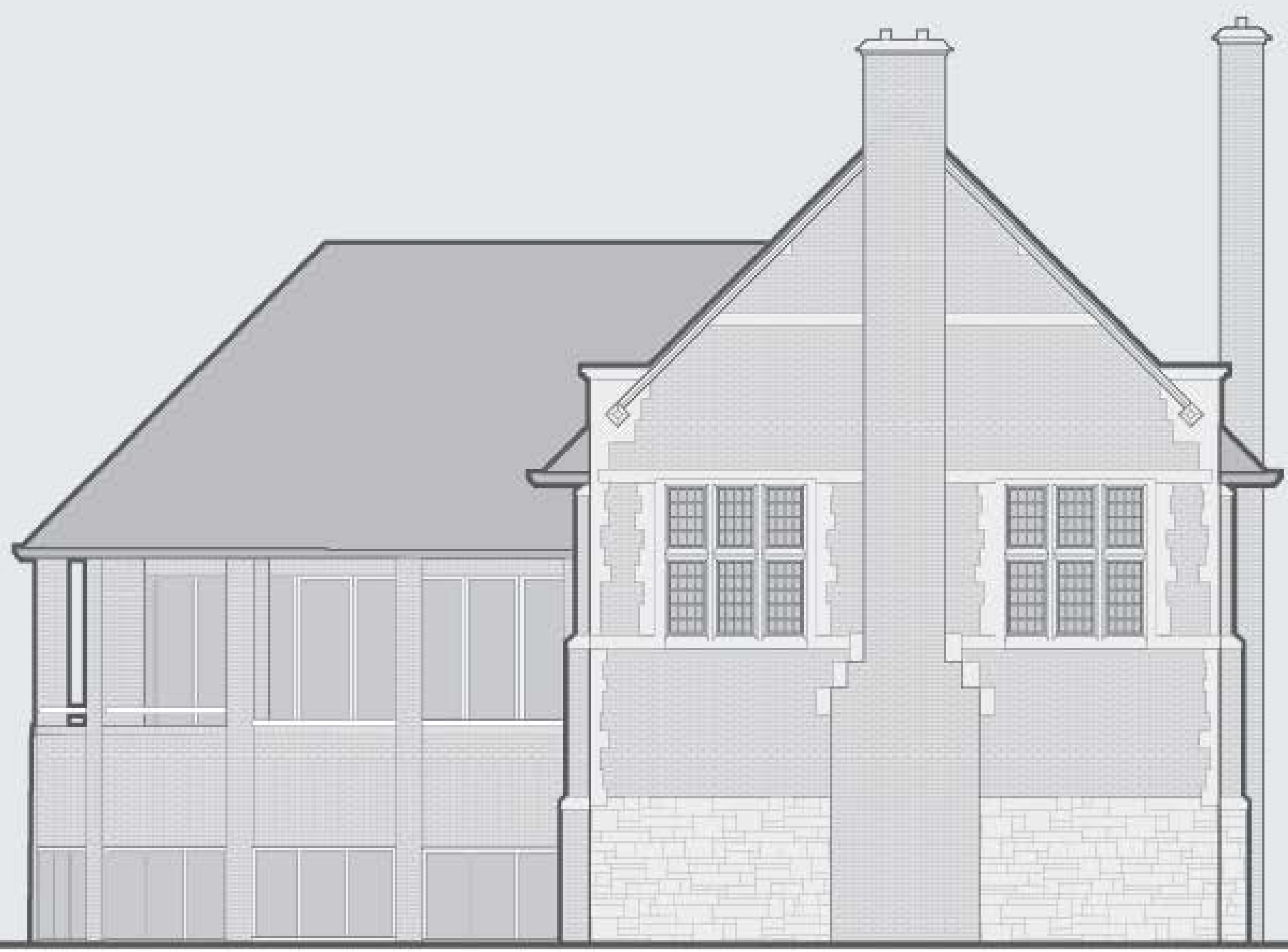

[P]hysical compatibility with the historic place [.... includes using materials, assemblies and construction methods that are well suited to the existing materials. New materials and assemblies should also have compatible service lives or durability, so that maintenance and repair work can be undertaken concurrently. Not doing so can lead to prematurely - Canada's Standards and Guidelines for the Conservation of Historic Places, 2nd ed. Standard 11, (34) 2020.

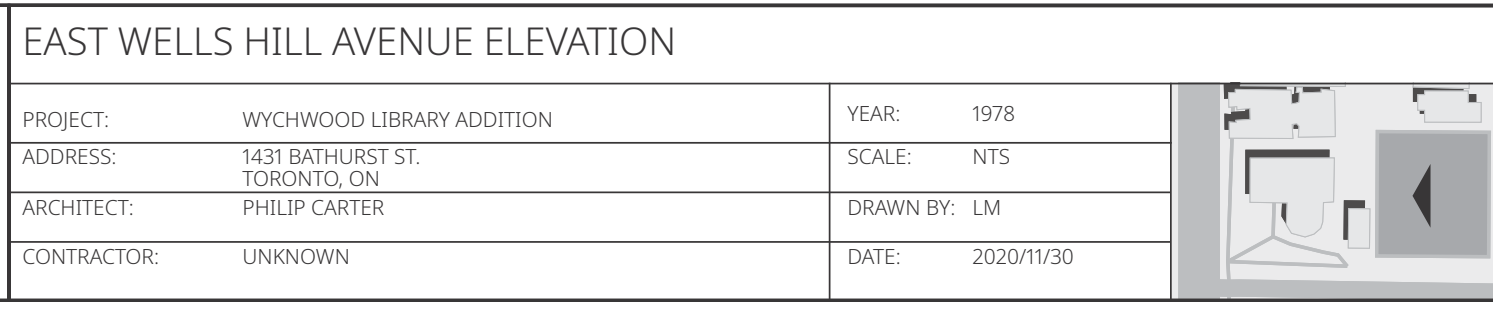




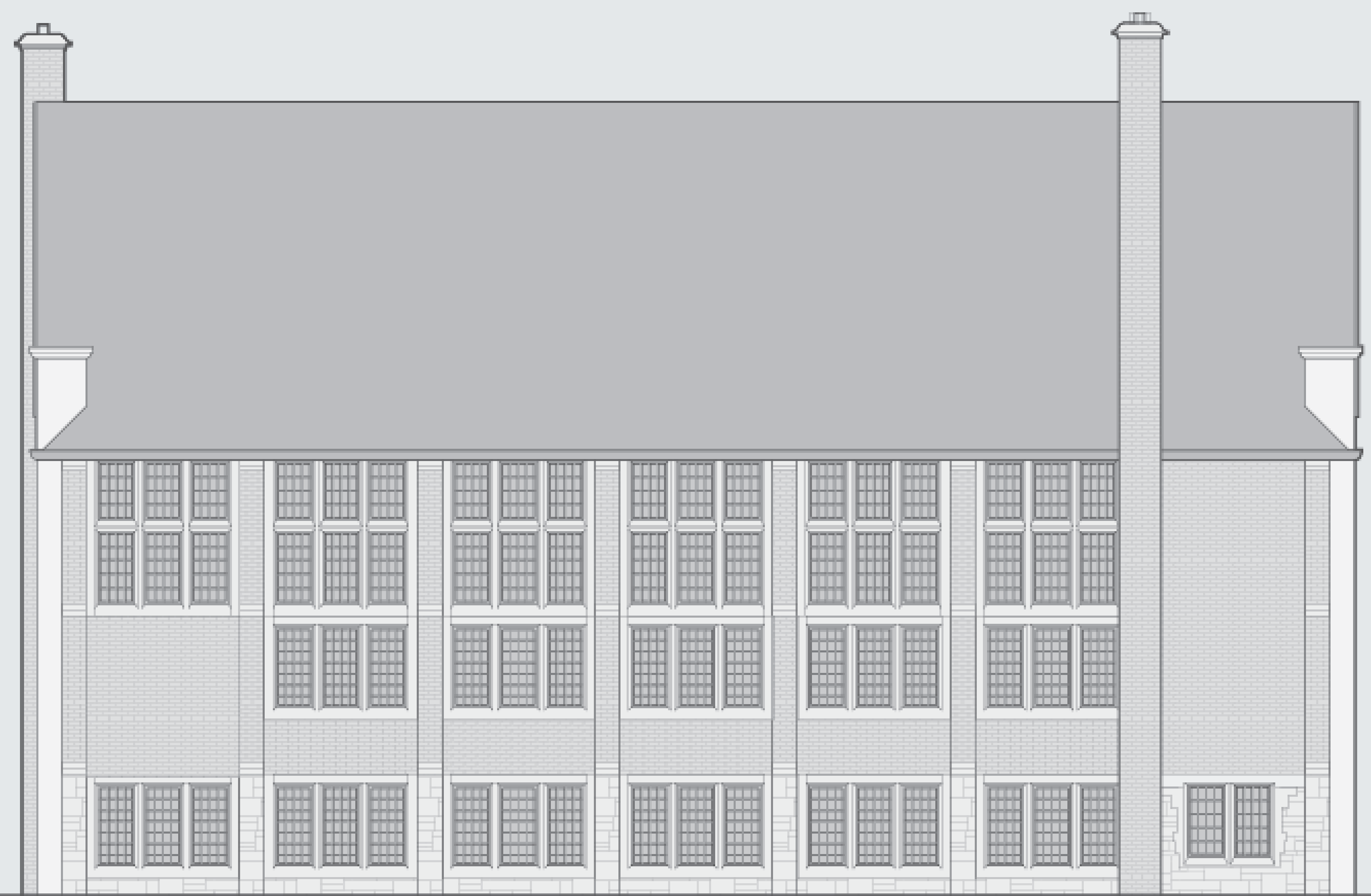

"The principal pitched roof is clad in composite tile the colour and texture of slate and is a reasonable substitute for natural slate in appearance. The roof is in good condition. The Roof of the addition is similarly clad in composite tiles and in good condition.

Designed with a brick exterior and with a "retro" historic appearance the addition, although inspired by the Smith design, somewhat obscures the extent and form of the original Tudor -Philip Goldsmith Architect, "Heritage Impact Assessment: Wychwood Library, 1433 Bathurst Street, Toronto," 16 March, 2016

\begin{tabular}{|c|c|c|c|c|}
\hline NORTH & VATION & & & \\
\hline РROІЕСТ: & WYCHWOOD LIBRARY ADDITION & YEAR: & 1978 & 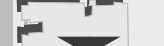 \\
\hline ADDRESS: & $\begin{array}{l}1431 \text { BATHURST ST. } \\
\text { TPBNT }\end{array}$ & SCALE: & NTS & \\
\hline ARCHTECT: & $\begin{array}{l}\text { PORNIICONA } \\
\text { PHILP CARTER }\end{array}$ & DRAWN BY: & LM & 1 \\
\hline CONTRACTOR: & UNKNOWN & DATE: & $2020 / 1 / 130$ & \\
\hline
\end{tabular}




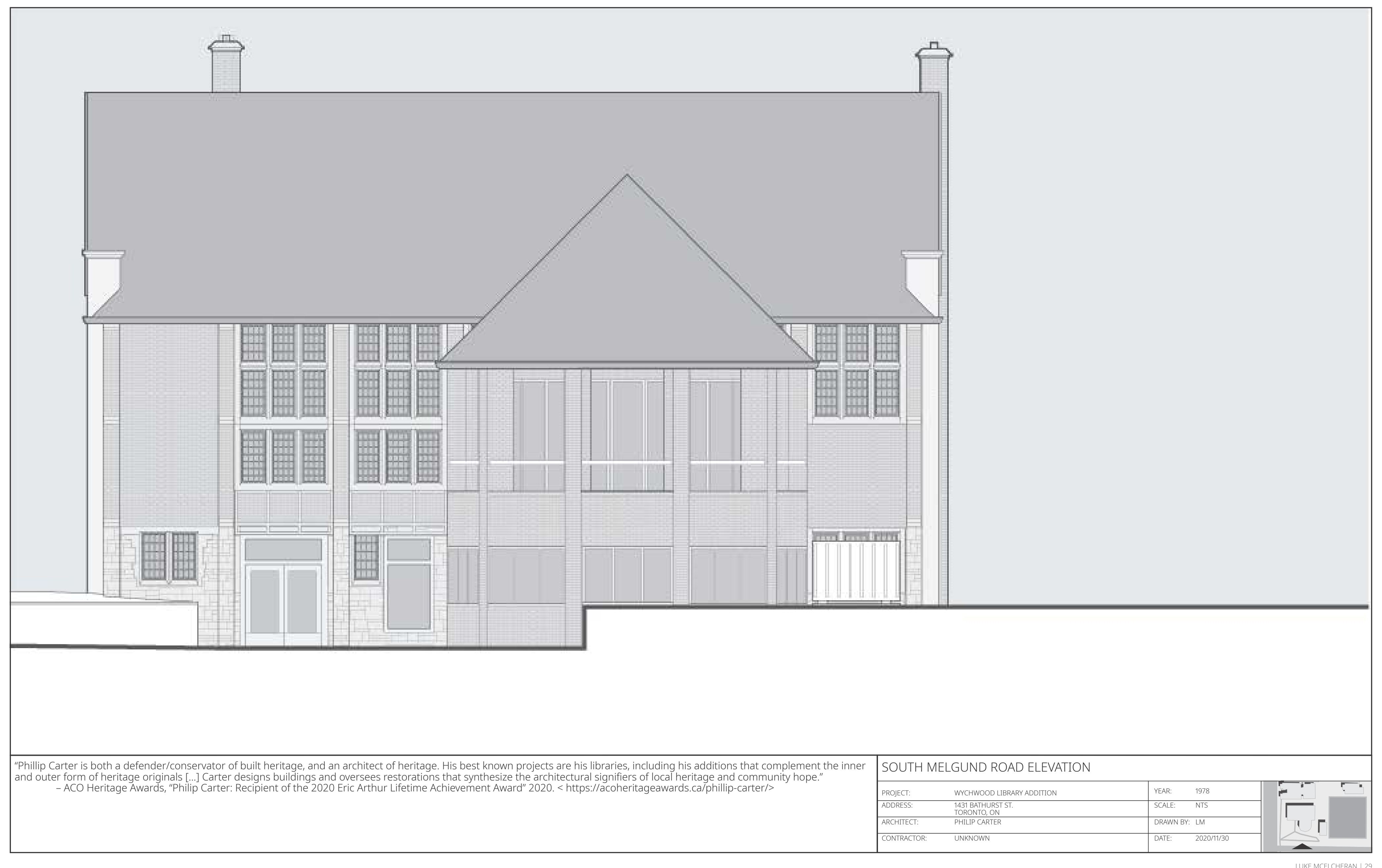




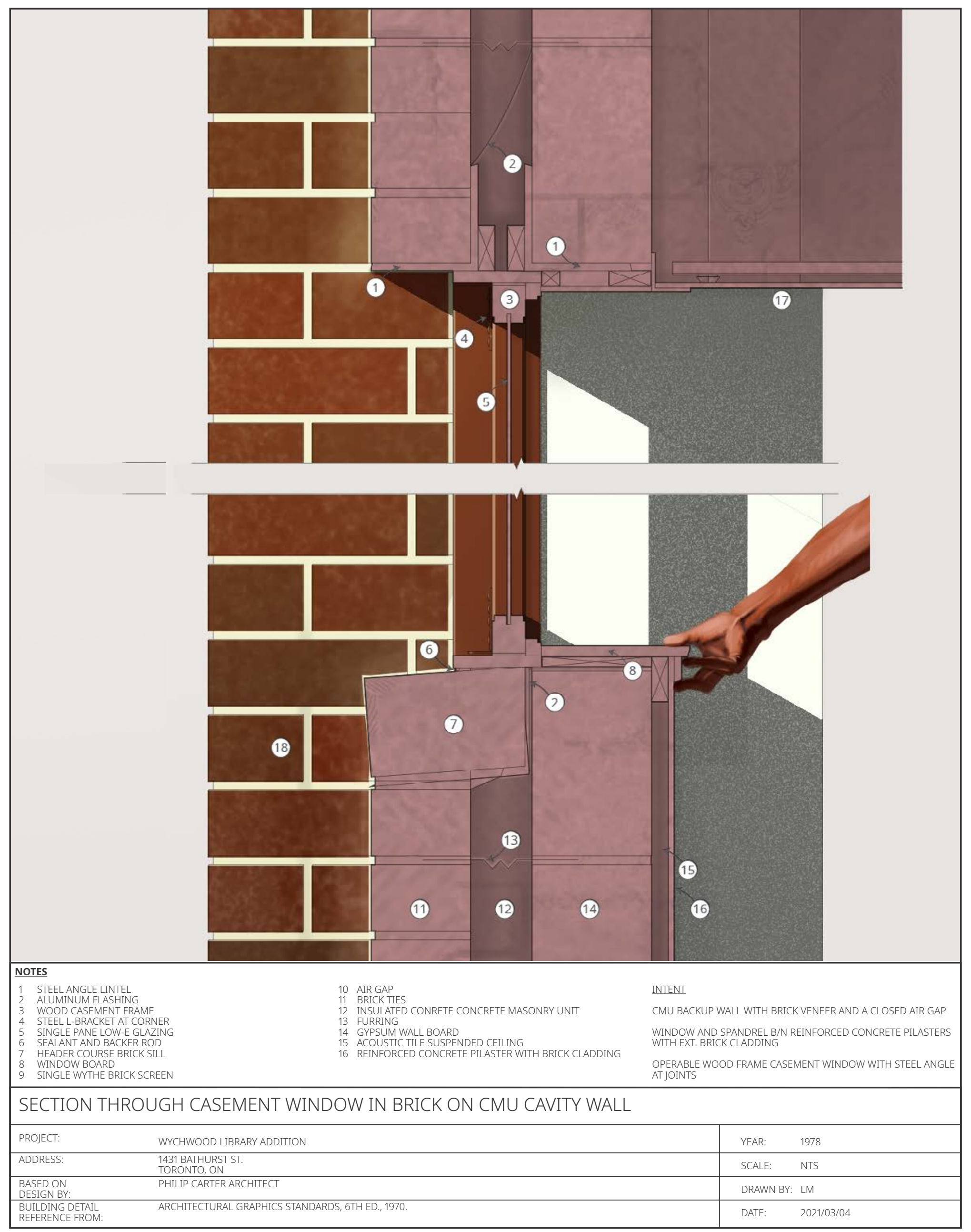




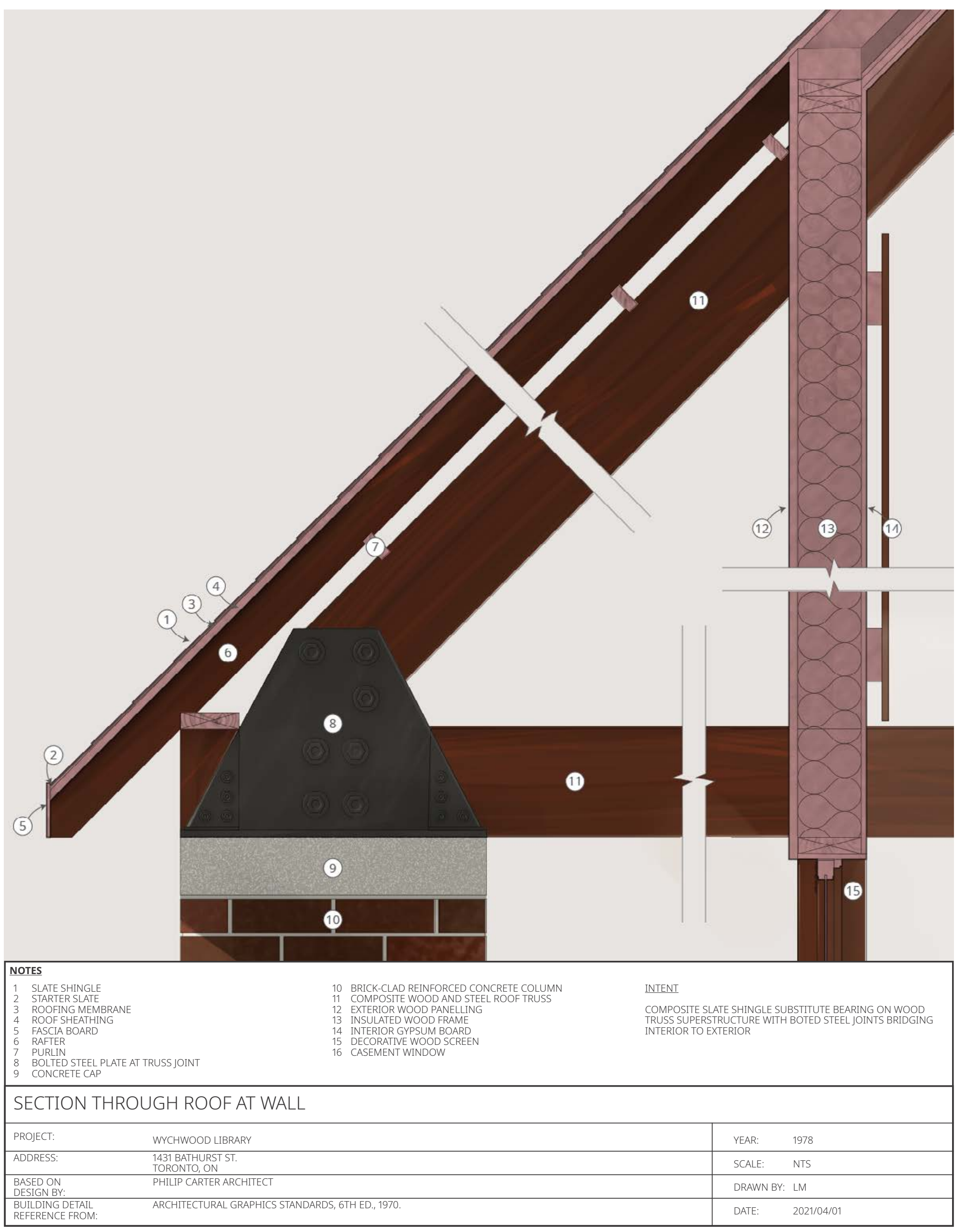




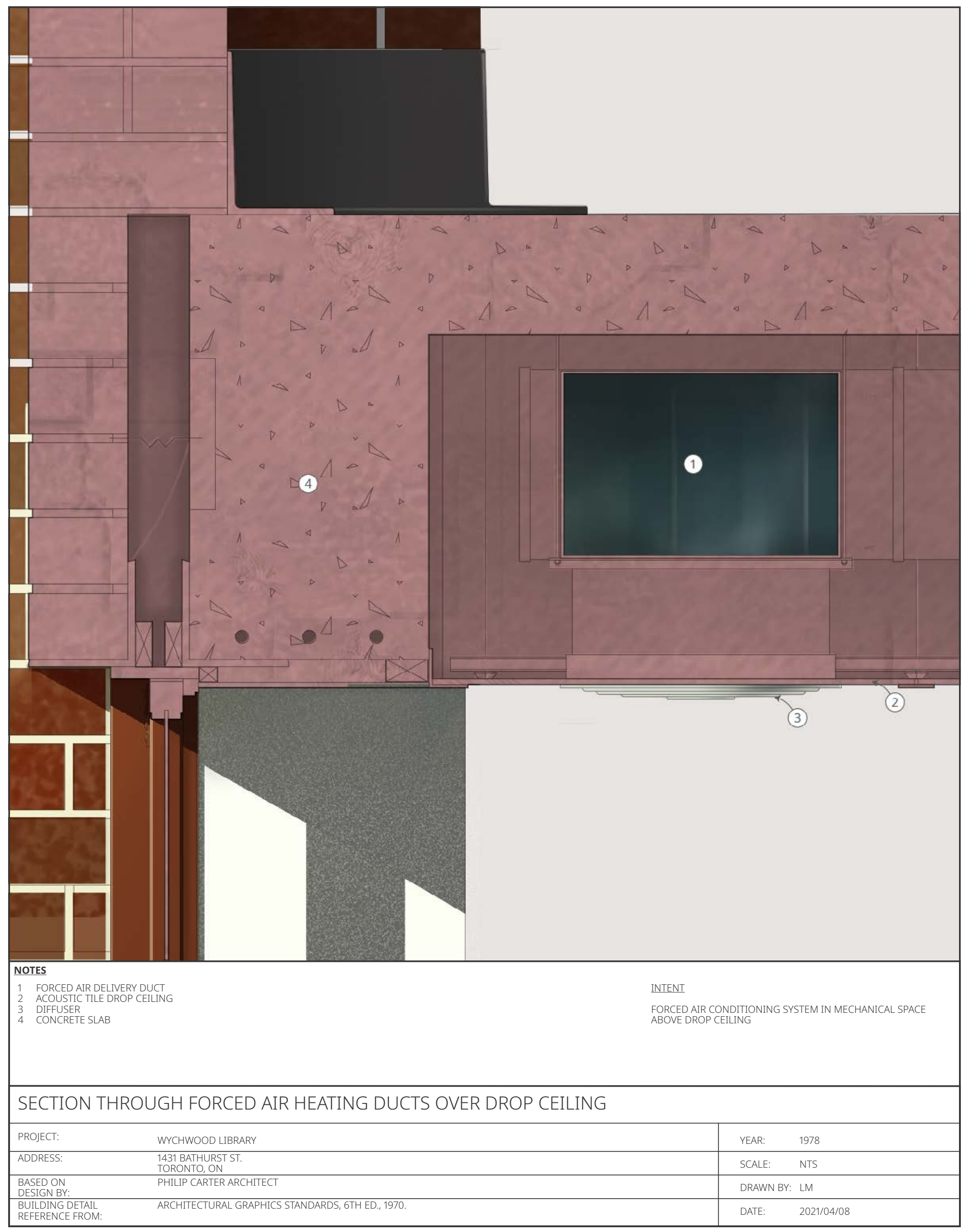




\section{0: SZA Addition}

The new addition currently under construction is designed with contemporary standards for heritage in mind. Part of the design process involved formally designating the original Eden Smith structure under Part IV of the Ontario Heritage Act. It reflects an approach that values distinctness between old and new. Part of this heritage approach involved removing the 1978 addition partly on the grounds that it confused the relationship between the original fabric and later additions. This new addition uses a distinct structural system and design sensibilty while establishing continuity with the heritage structure through reference to some of its significant qualities, for instance, using a slate cladding system in reference to the original slate roof or massing the new structure to line up roughly with the existing roof line. Information published on the hoardings at the construction site names Steelcore Construction, a Toronto based general contractor that advertises expertise renovating and adding to historic properties alongside a principal focus on new construction, as the primary contractor on the project.

Goldsmith, Philip. Heritage Impact Assessment: Wychwood Library, 1433 Bathurst St, Toronto. 16 March 2016.

Steelcore Construction Ltd. Historical Projects. < https://www.steelcore.ca/historical> 


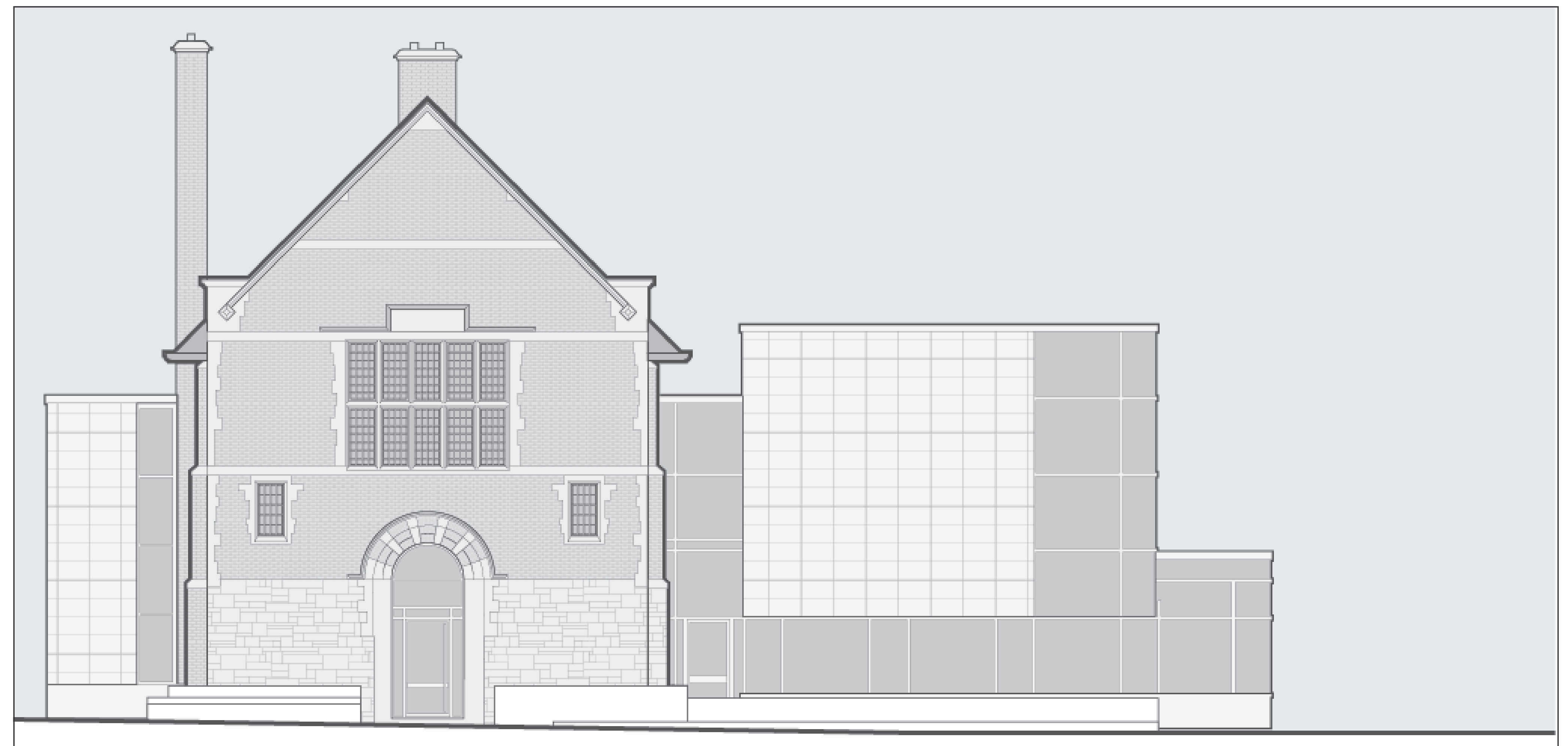

WEST BATHURST STREET ELEVATION

\begin{tabular}{ll|ll}
\hline PROJECT: & WYCHWOOD LIBARY HERTAGGE BUILDING ADDITION & YEAR: & 2021 \\
\hline ADDRESS: & 1431 BATHURST ST. & SCALE: & NTS \\
\hline
\end{tabular}

ARCHITECT: $\quad$ SOROANTO, ON

CONTAACTOR: STEELCORE CONSTRUCTION 


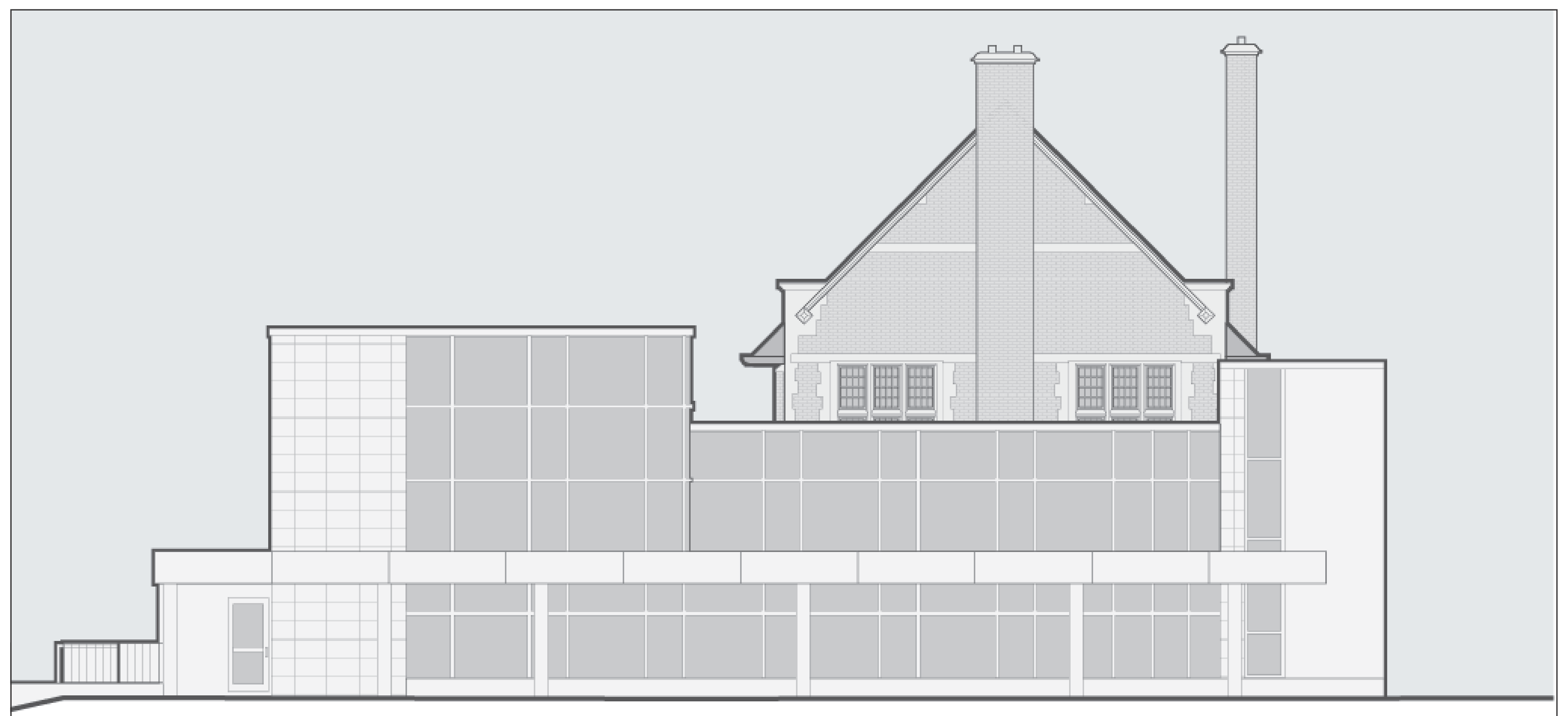
"The original English Arts and Crafts approach to the design of the historic Library Hall is not repeated in the new addition which is of a distinctive contem
strategy ensures that the original aesthetic is clearly demarcated and the arts and crafts original design respected as fundamental to the historic building

A relationship with the historic building is developed through the use of slate, derivative of the slate used in the historic building, the use of vertically proportioned grouped windows - Goldsmith, Philip. Heritage Impact Assessment: Wychwood Library, 1433 Bathurst St, Toronto. 16 March 2016.32
(1)

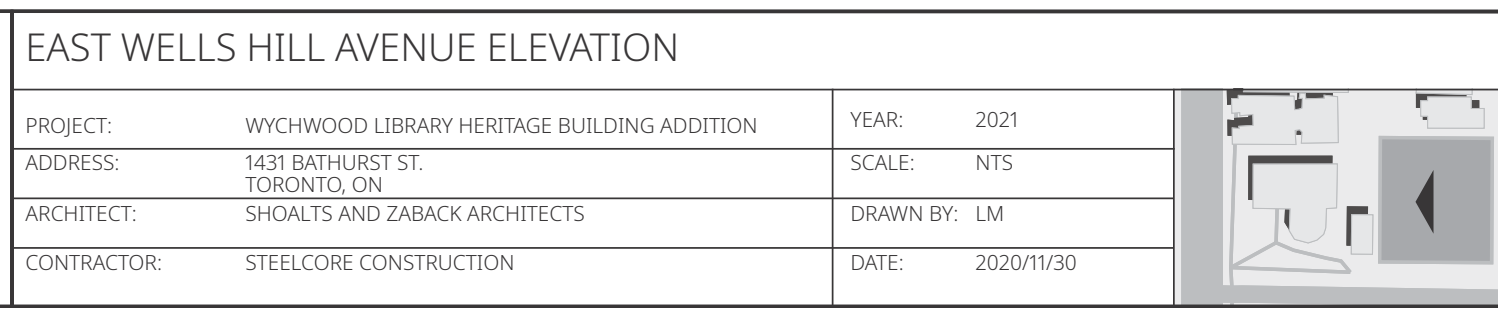




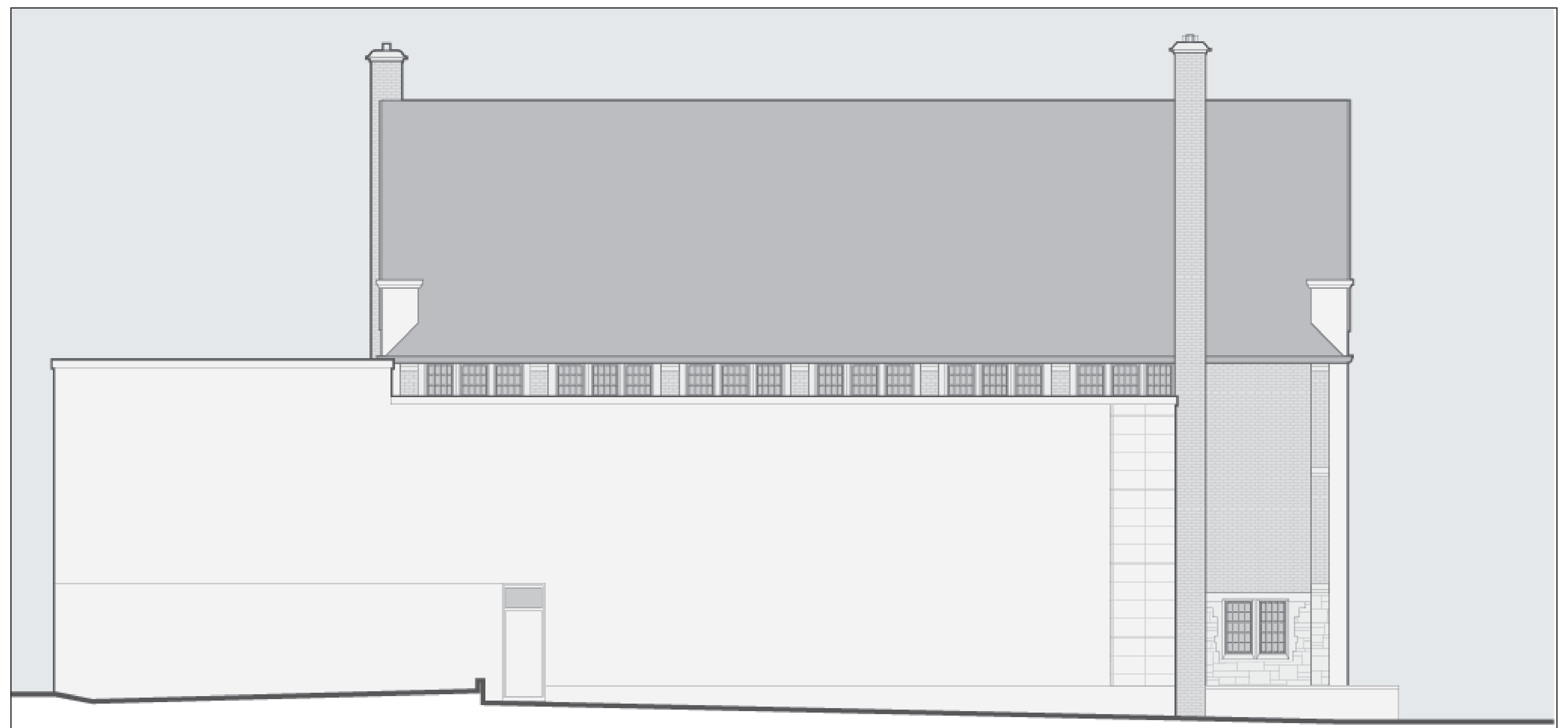

"The north addition is also set back from the west elevation of the historic Hall and is located between the Hall and the existing apartment building to the north. This elevation of the historic building has never been highly visible.
Similar to the main pavilion on the south, this north rear addition is enclosed in a mix of glass walls and solid panels with a slate cladding derivative of the slate in the historic building's large roof in a neutral grey colour."

\begin{tabular}{|c|c|c|c|c|c|}
\hline \multicolumn{6}{|c|}{ NORTH ELEVATION } \\
\hline PROJECT: & WYCHWOOD LIBAARY HERTAGE BULLDING ADDTITION & & 2021 & -1 & $=$ \\
\hline ADDRESS: & $\begin{array}{l}\text { 1431 BATHURST ST. } \\
\text { TORONT, ON }\end{array}$ & SCALE: & NTS & & \\
\hline ARCHITECT: & SHOALITS AND ZABACK ARCHITECTS & DRAWN BY & LM & 1 & \\
\hline CONTRACTOR: & STEELCORE CONSTRUCTION & DATE: & $2020 / 1 / 130$ & & \\
\hline
\end{tabular}




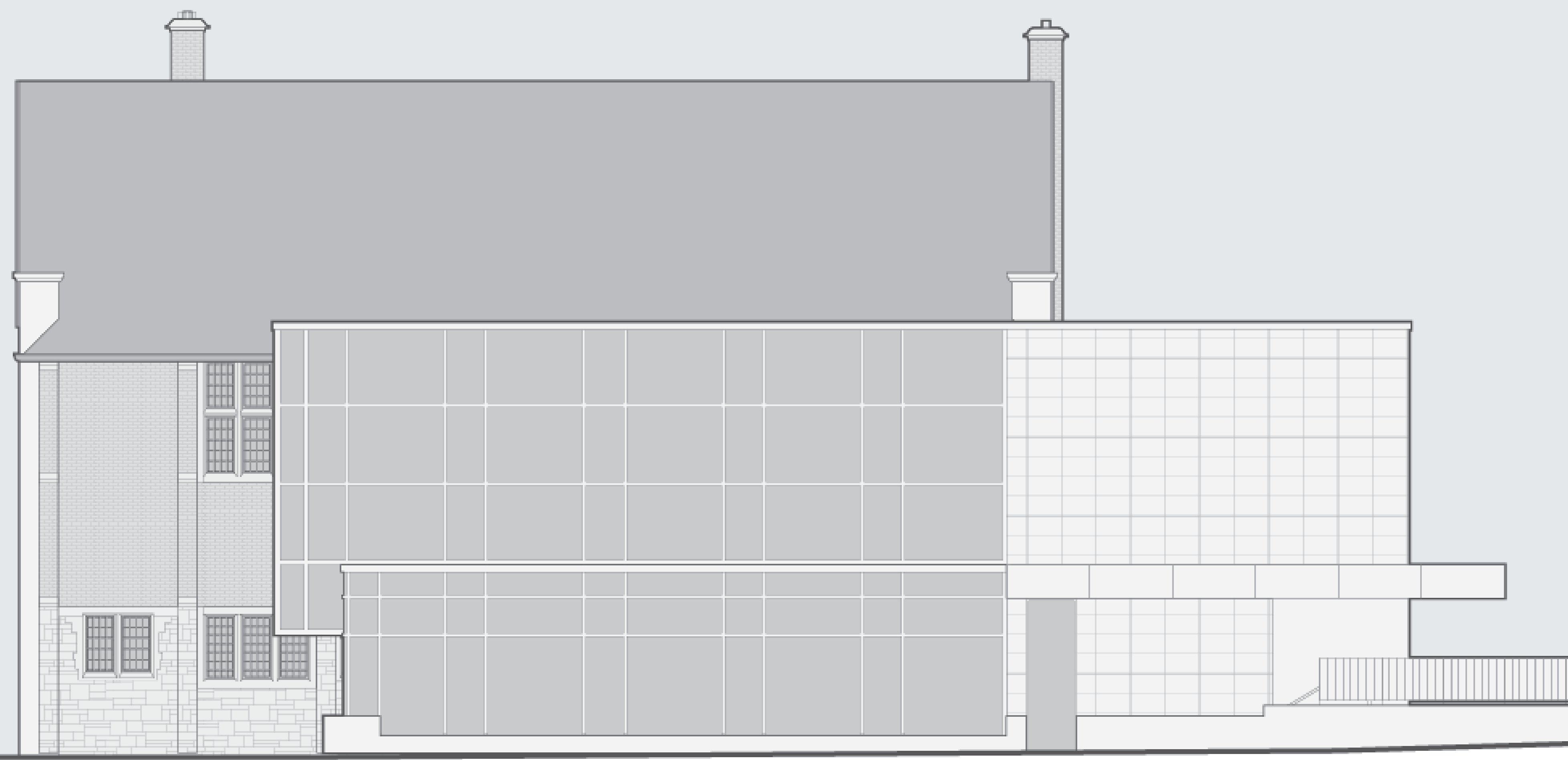




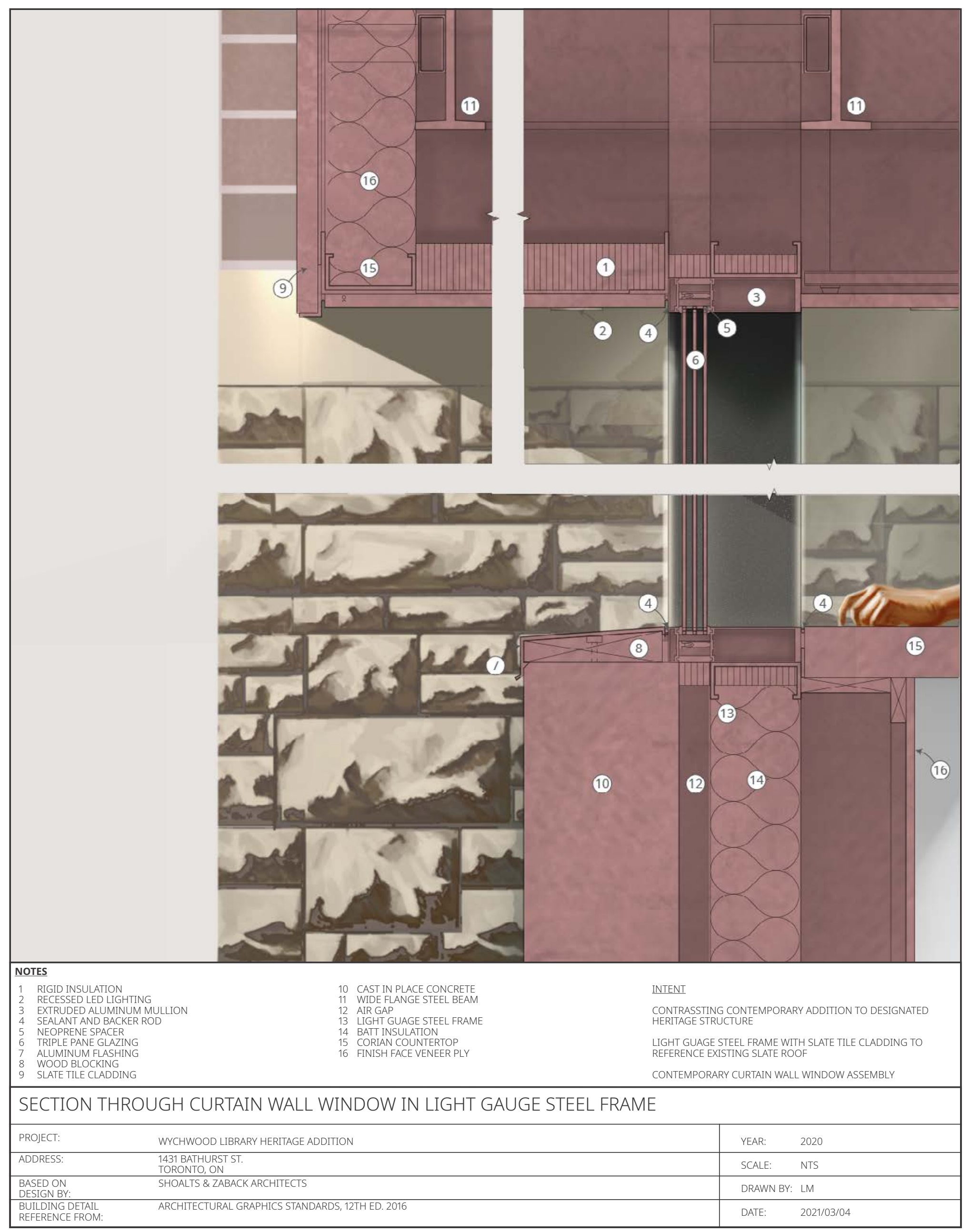




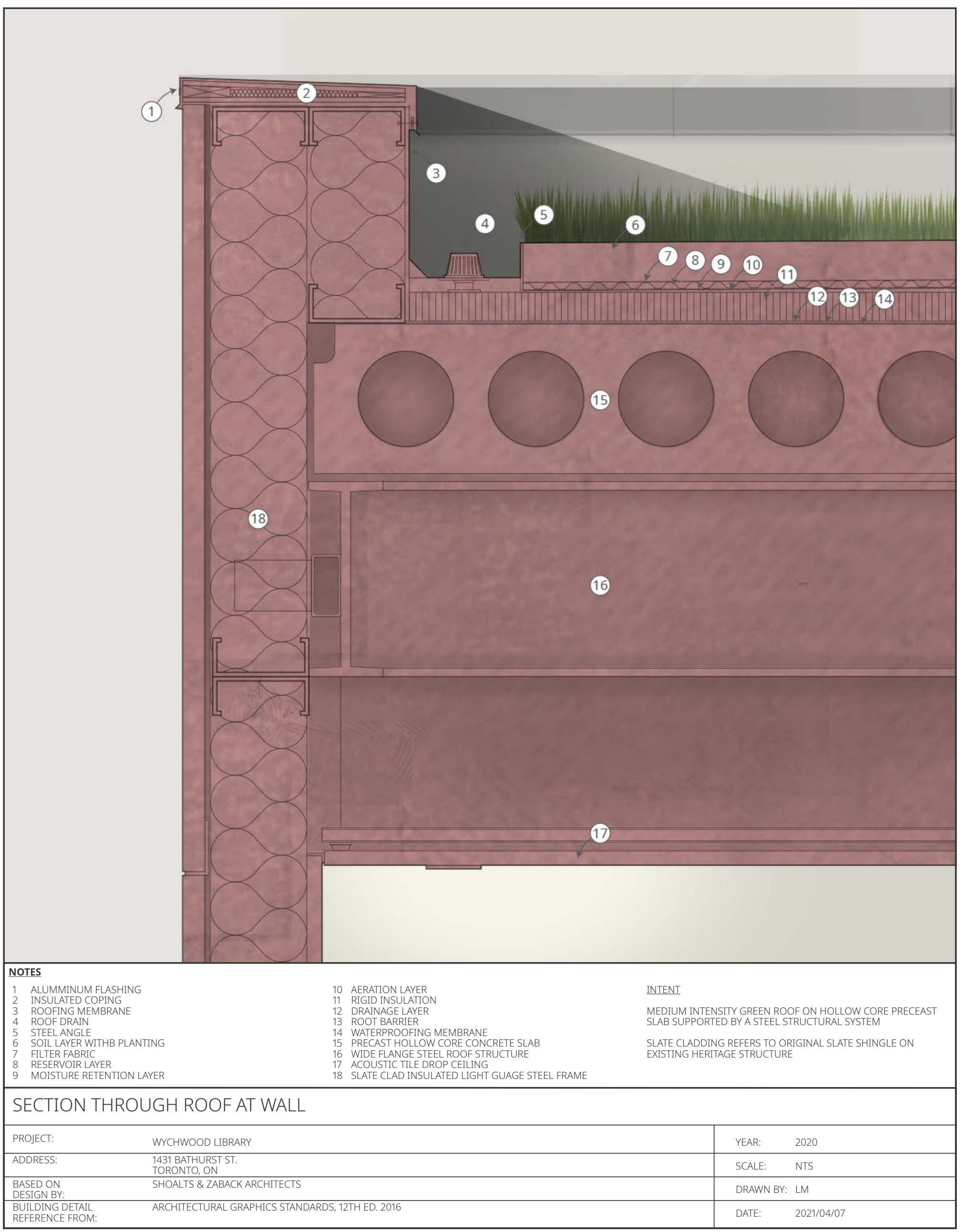




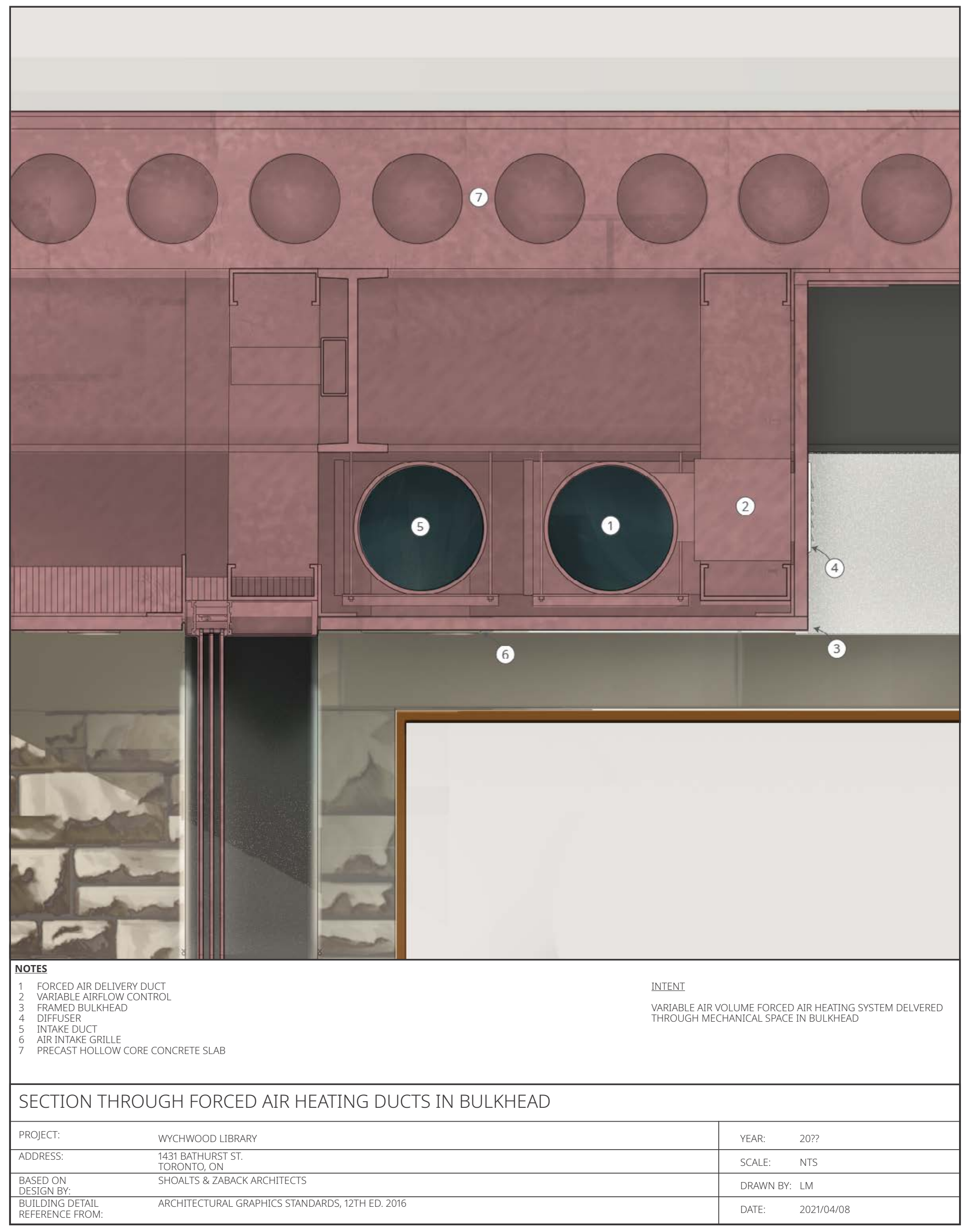




\section{Speculative Proposal for Compatible Design Based on The Study of Heritage Details}

The following fragments are meant to stimulate conversation about how a shift in the way we document heritage properties and where we locate their values could result in different approaches to appropriate addition and intervention. If heritage value were located in the material assemblies and physical integrity of the heritage structure, and heritage documentation provided insights into the nature of those assemblies and the capacities required to maintain and, eventually, replace them, how would we think differently about contemporary compatible design? What would heritage look like if we weren't so concerned with what it looks like? How could the principle of physical compatibility, be deployed in the context of contemporary design empowered by access to appropriately skilled workers?

There needs to be a larger recognition of heritage among urban managers - not just as a relic from the past to be cherished and preserved for posterity, but as an asset that could play a more proactive role in ensuring the continuity of skills and knowledge, positive change that ensures fulfilment of new needs and aspirations as well as long term sustainability. Concern for continuity is one of the key elements missing in the conventional conservation approach. Indeed, it is believed that the traditional continuity between the past and the present is always broken, and that heritage can be frozen in time and place.

Reconnecting the City: The Historic Urban Landscape Approach and the Future of Built Heritage, ed. Francesco Bandarin et al. Wiley: 2014. 


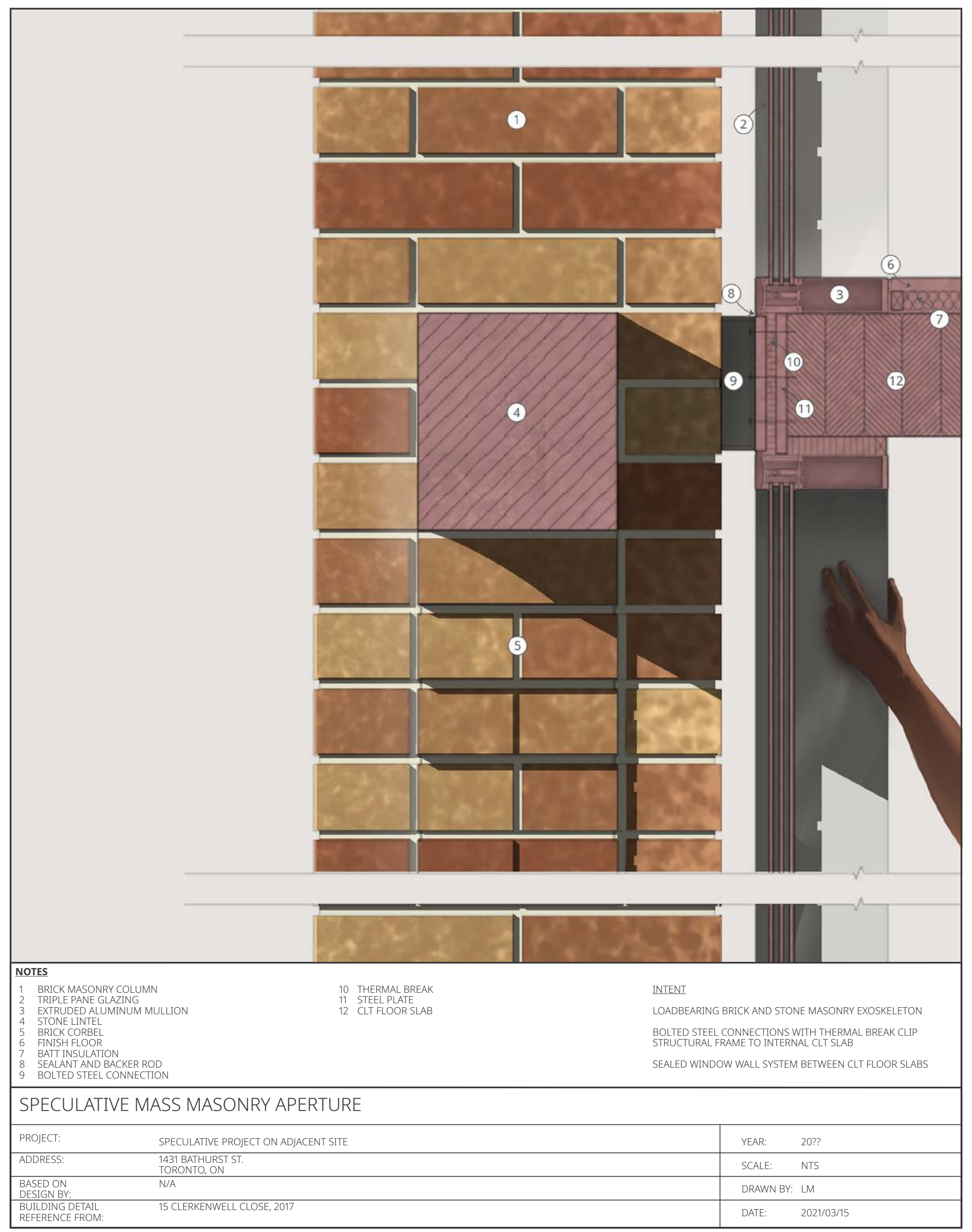




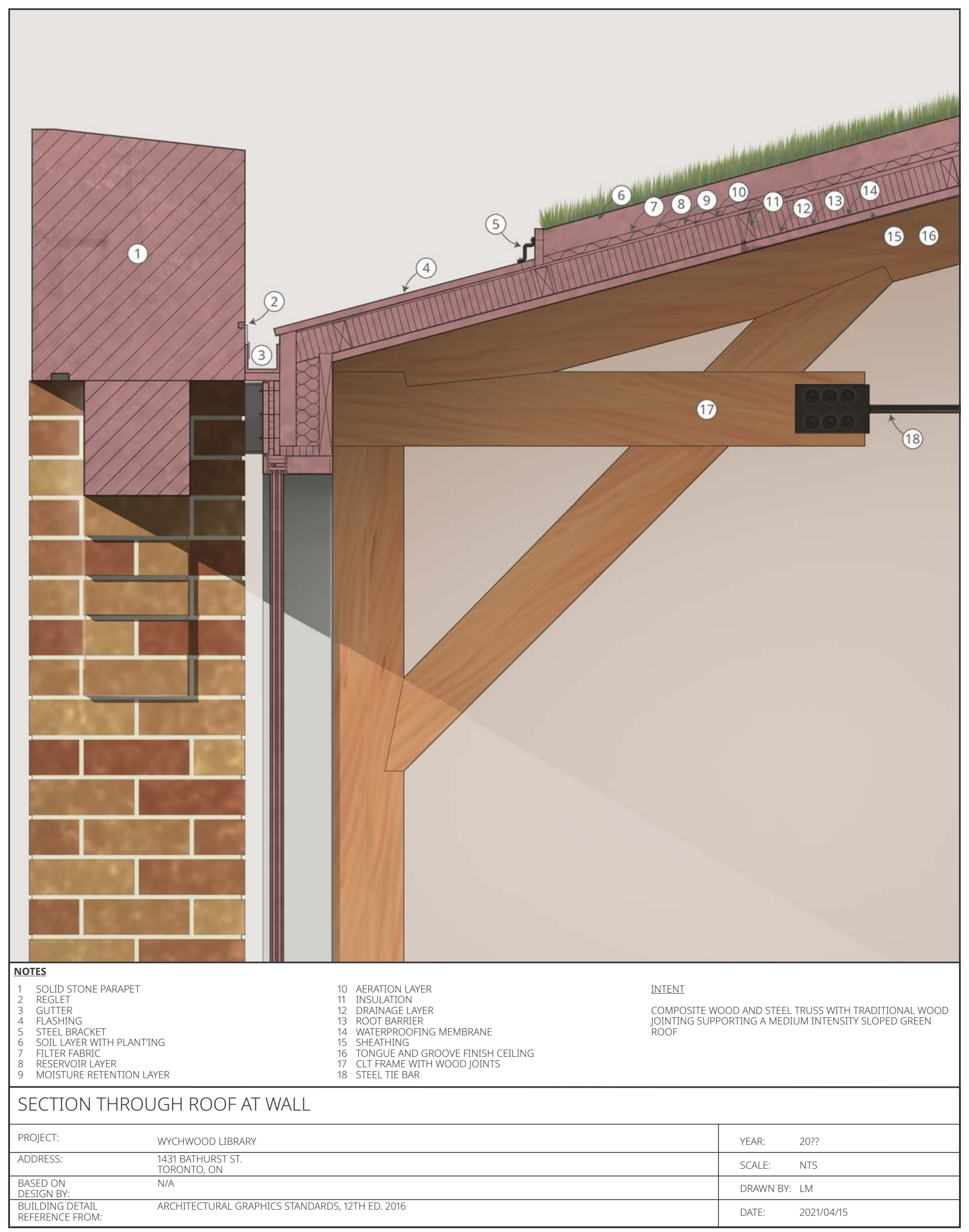




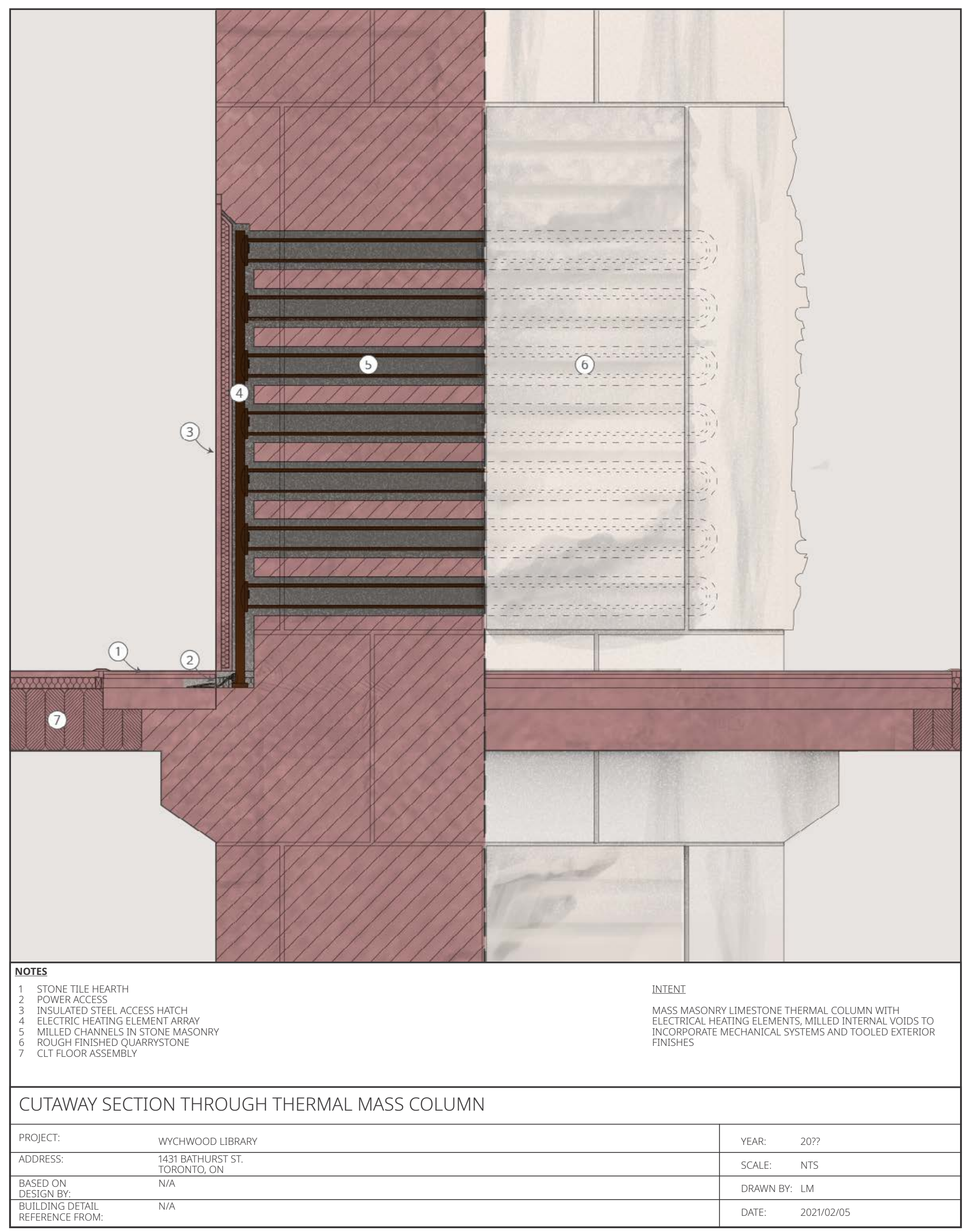




\section{Works Cited}

ACO Heritage Awards, "Philip Carter: Recipient of the 2020 Eric Arthur Lifetime Achievement Award" 2020. < https://acoheritageawards.ca/phillip-carter/>

Architectural Graphics Standards 2nd ed. (New York: John Wiley \& sons, 1936.)

Architectural Graphics Standards, 6th ed., (New York: John Wiley \& sons, 1970.)

Architectural Graphics Standards, (New York: John Wiley \& sons, 12th ed. 2016.)

Brown, W. Douglas. Eden Smith: Toronto's Arts and Crafts Architect. (Toronto: W. Douglas Brown, 2003.)

Canada's Standards and Guidelines for the Conservation of Historic Places, 2nd ed. Standard 11, (34) 2020.

Carney, Mark. "Value(s)," (Toronto: McClelland \& Stewart, 2021).

Carter, Philip H. "Wychwood Library. 1978." philipcarter.ca <http://www.philliphcarter. ca/index_files/WychwoodHome.htm>

City of Toronto By-Law 1367-2017, Schedule A, "Statement of Significance Reasons for Designation 1433 Bathurst Street"

City of Toronto. Toronto Official Plan. Toronto, ON: 2019. https://www.toronto.ca/ wp-content/uploads/2019/06/8f06-OfficialPlanAODA_Compiled-3.0.pdf (accessed: 2020-12-07).

Deamer, Peggy. "Craft and Design 'Detail: The subject of the object."' Architecture and Labor. (New York: Routledge, 2020) 9.

The Fratry Building Renovation at Carlisle Cathedral / Feilden Fowles, Archdaily [retrieved 2021/03/29]

Greenberg, Ken. Toronto Reborn, (Toronto: Dundurn Press, 2019.)

Goldsmith, Philip. Heritage Impact Assessment: Wychwood Library, 1433 Bathurst St, Toronto. 16 March 2016.

Notes on Building Construction, (London: Longmans Green \& Co.,1891.)

Reconnecting the City: The Historic Urban Landscape Approach and the Future of Built Heritage, ed. Francesco Bandarin et al. Wiley: 2014.

Richards, Adam. "Nithurst Farm: Architects' Statement," adamrichards.co.uk [retrieved 2021/03/29]

Taha Amin, and Groupwork. "Clerkenwell Close: Architect's Statement," Groupwork. co.uk [retrieved 2021/03/29]

Steelcore Construction Ltd. "Historical Projects," steelcore.ca <https://www.steelcore. ca/historical> [retrieved 2021/04/10]

Toronto Public Library. "Carnegie Library: Wychwood," torontopubliclibrary.ca $<$ https://www.torontopubliclibrary.ca/about-the-library/library-history/carnegiewychwood.jsp> 